San Jose State University

SJSU ScholarWorks

Master's Theses

Master's Theses and Graduate Research

Spring 2012

\title{
Kinetic Modeling Of Methanol Synthesis From Carbon Monoxide, Carbon Dioxide, And Hydrogen Over A Cu/ZnO/Cr203 Catalyst
}

Daaniya Rahman

San Jose State University

Follow this and additional works at: https://scholarworks.sjsu.edu/etd_theses

Part of the Chemical Engineering Commons

\section{Recommended Citation}

Rahman, Daaniya, "Kinetic Modeling Of Methanol Synthesis From Carbon Monoxide, Carbon Dioxide, And Hydrogen Over A Cu/ZnO/Cr2O3 Catalyst" (2012). Master's Theses. 4162.

DOI: https://doi.org/10.31979/etd.tpdm-4bgg

https://scholarworks.sjsu.edu/etd_theses/4162

This Thesis is brought to you for free and open access by the Master's Theses and Graduate Research at SJSU ScholarWorks. It has been accepted for inclusion in Master's Theses by an authorized administrator of SJSU ScholarWorks. For more information, please contact scholarworks@sjsu.edu. 
KINETIC MODELING OF METHANOL SYNTHESIS FROM CARBON MONOXIDE, CARBON DIOXIDE, AND HYDROGEN OVER A Cu/ZnO/Cr $\mathrm{O}_{3}$ CATALYST

\author{
A Thesis \\ Presented to \\ The Faculty of the Department of Chemical and Materials Engineering \\ San José State University \\ In Partial Fulfillment \\ Of the Requirements for the Degree \\ Master of Chemical and Materials Engineering \\ by \\ Daaniya Rahman
}

May 2012 
(C) 2012

Daaniya Rahman

ALL RIGHTS RESERVED 
The Designated Thesis Committee Approves the Thesis Titled KINETIC MODELING OF METHANOL SYNTHESIS FROM CARBON MONOXIDE, CARBON DIOXIDE, AND HYDROGEN OVER A Cu/ZnO/Cr $\mathrm{O}_{3}$ CATALYST

by

Daaniya Rahman

\section{APPROVED FOR THE DEPARTMENT OF CHEMICAL AND MATERIALS ENGINEERING \\ SAN JOSE STATE UNIVERSITY}

May 2012

Dr. Melanie McNeil

Dr. Gregory Young

Dr. Arthur Diaz
Department of Chemical and Materials Engineering

Department of Chemical and Materials Engineering

Department of Chemical and Materials Engineering 


\section{ABSTRACT \\ KINETIC MODELING OF METHANOL SYNTHESIS FROM CARBON MONOXIDE, CARBON DIOXIDE AND HYDROGEN OVER A Cu/ZnO/Cr $\mathrm{O}_{3}$ CATALYST}

by Daaniya Rahman

The main purpose of this study was to investigate kinetic models proposed in the literature for methanol synthesis and select the best fit model using regression techniques in POLYMATH. Another aim was to use the results from the best fit model to explain some aspects and resolve some questions related to methanol synthesis kinetics. Two statistically sound kinetic models were chosen from literature based on their goodness of fit to the respective kinetic data. POLYMATH, the non-linear regression software, was used to fit published experimental data to different kinetic models and evaluate kinetic parameters. The statistical results from POLYMATH were used for comparison of the models and selection of the best fit model. The results obtained from the best fit kinetic model were then used to analyze the trends and kinetic features related to methanol synthesis. The study was primarily concentrated on the effect of reaction conditions on the relative contribution of $\mathrm{CO}$ and $\mathrm{CO}_{2}$ in producing methanol.

The combined model that included both $\mathrm{CO}$ and $\mathrm{CO}_{2}$ hydrogenation rate terms was the best fit kinetic rate expression that described methanol synthesis kinetics most appropriately. A number of reaction conditions such as conversion, pressure, $\mathrm{CO} / \mathrm{CO}_{2}$, and hydrogen content in the feed can have marked effects on the relative contribution of $\mathrm{CO}$ and $\mathrm{CO}_{2}$ in synthesizing methanol. Therefore, no generalizations can be made regarding the main carbon source in methanol. 


\section{ACKNOWLEDGEMENTS}

I owe my deepest gratitude to my advisor, Dr. Melanie McNeil for her unending guidance, support, and encouragement throughout my endeavor to write this thesis. I would like to thank my committee members, Dr. Gregory Young and Dr. Arthur Diaz for their invaluable suggestions and feedback. I extend my heartfelt thanks to my parents for their love and blessings. Last but not the least, I am immensely grateful to my husband, Tarique and my son, Ibrahim for their patience, love, and support. 


\section{Table of Contents}

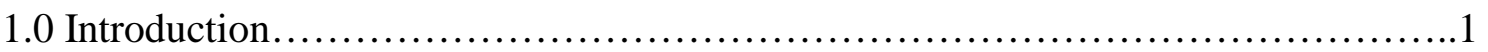

1.1 Significance................................................... 3

1.2 Focus of Study................................................ 4

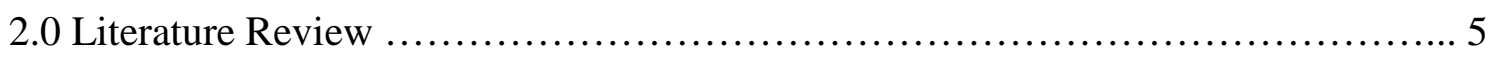

2.1 Overview...................................................... 5

2.2 Reaction Mechanism................................................5

2.3 Kinetic Models..................................................9

2.4 Reaction Conditions................................................ 14

2.4.1 Temperature..........................................14

2.4.2 Pressure ........................................................

2.4.3 Space Velocity.......................................... 16

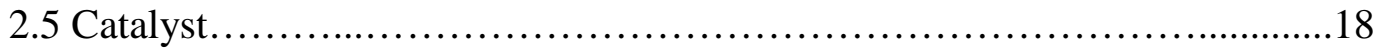

2.6 Summary........................................................

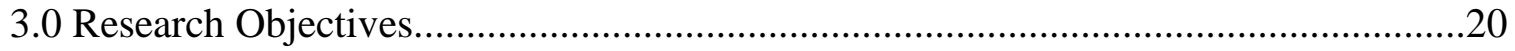

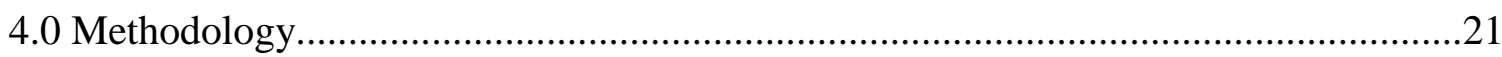

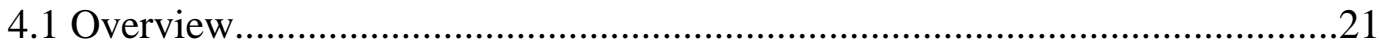

4.2 Selection of Statistically Sound Kinetic Models........................................21

4.3 Data Evaluation.................................................................................2

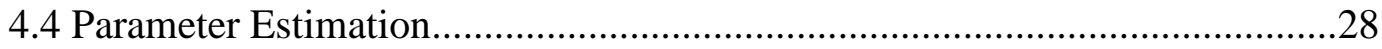

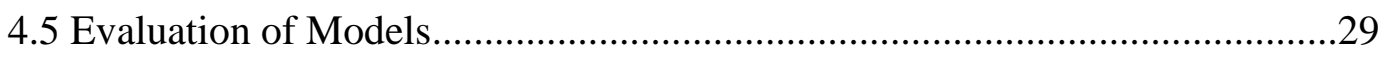

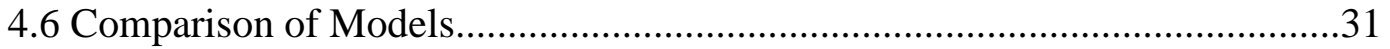




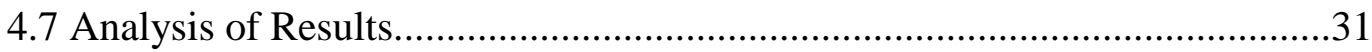

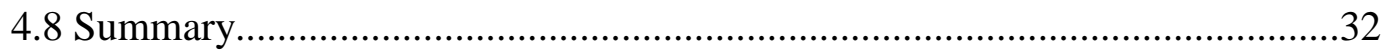

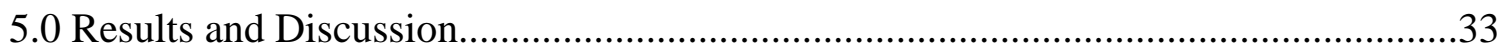

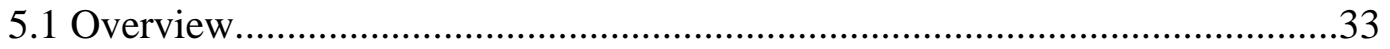

5.2 Regression Results and Parameter Evaluation...........................................33

5.3 Role of $\mathrm{CO} / \mathrm{CO}_{2}$ in Producing Methanol..................................................43

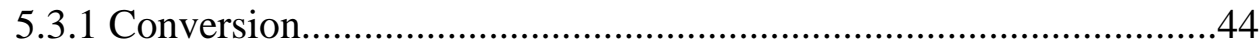

5.3.2 Hydrogen Content in Feed.....................................................45

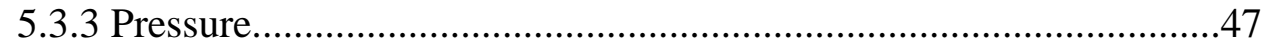

5.3.4 $\mathrm{CO} / \mathrm{CO}_{2}$ Content in the Feed.................................................49

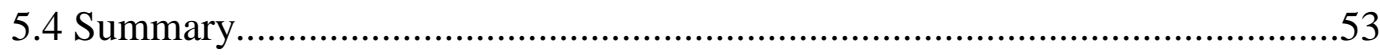

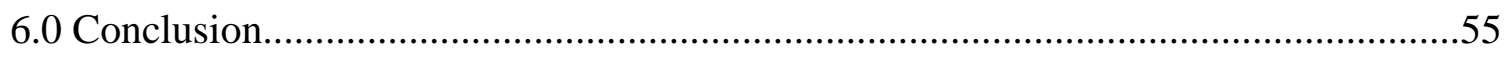

References..........................................................57

Appendix A: Additional Experimental Data ......................................................61

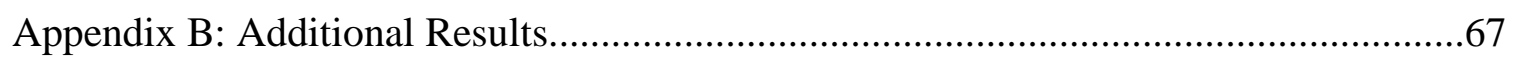




\section{List of Figures}

Figure 1 Relationship between reaction temperature and $\mathrm{CO}_{2}$ conversion and methanol yield from experimental results and thermodynamic predictions

Figure 2 Relationship between reaction pressure and $\mathrm{CO}_{2}$ conversion and methanol yield from experimental results and thermodynamic predictions

Figure 3 Relationship between space velocity and $\mathrm{CO}_{2}$ conversion and methanol yield

Figure 4 Rates of methanol formation as a function of space velocity for methanol synthesis over $\mathrm{Cu} / \mathrm{ZnO} / \mathrm{Al}_{2} \mathrm{O}_{3}$ with synthesis gas containing 10 vol\% $\mathrm{CO}_{2}$. Reaction conditions: $\mathrm{T}=523 \mathrm{~K}, \mathrm{P}=3.0 \mathrm{MPa}, \mathrm{H}_{2} / \mathrm{COx}=4$

Figure 5 Reaction rates for methanol and water

Figure 6 Comparison of experimental and predicted (by Graaf's model) methanol production rate

Figure 7 Comparison of experimental and predicted (by Rozovskii's model) methanol production rate

Figure 8 Comparison of experimental methanol production rate and those predicted by Graaf's and Rozovskii's models at low $\mathrm{CO}_{2}$ inlet partial pressures

Figure 9 Comparison of experimental methanol production rate and those predicted by Graaf's and Rozovskii's models at high $\mathrm{CO}_{2}$ inlet partial pressures

Figure 10 Comparison of experimental values of methanol production rate and rates estimated form the combined model

Figure 11 Comparison of experimental methanol production rate values and those estimated from the combined kinetic rate expression and Graaf's and Rozovskii's models

Figure 12 Gibb's free energy change, $\Delta \mathrm{G}$, for $\mathrm{CO}$ and $\mathrm{CO}_{2}$ hydrogenation to $\mathrm{CH}_{3} \mathrm{OH}$ and the WGS reaction at $\mathrm{P}=75 \mathrm{~atm}$ and three different conversion levels as a function of temperature 
Figure 13 Plot of methanol synthesis rate and $\% \mathrm{CO}_{2}$ in the feed under lean $\mathrm{H}_{2}$ conditions

Figure 14 Plot of overall rate as function of $\% \mathrm{CO}_{2}$ at a pressure of $50 \mathrm{~atm}$

Figure 15 Plot of the relative contribution of $\mathrm{CO}$ and $\mathrm{CO}_{2}$ at a pressure of 50 atm 48

Figure 16 Plot of rates calculated from combined model and $\mathrm{CO}$ hydrogenation $\quad 49$ model when $\% \mathrm{CO}_{2}$ in feed $=0$

Figure 17 Plot of overall methanol synthesis rate as a function of $\% \mathrm{CO}$ in feed $\quad 50$ when $\% \mathrm{CO}_{2}$ in feed $=0$

Figure 18 Predicted (-) compared to experimental (a) methanol production rate versus mole percent carbon monoxide in the feed at $513 \mathrm{~K}$ and $4.38 \mathrm{MPa}$

Figure 19 Plot of relative contribution of $\mathrm{CO}$ hydrogenation vs. $\% \mathrm{CO}_{2}$ in the feed

Figure 20 Comparison of $\mathrm{CO}$ and $\mathrm{CO}_{2}$ hydrogenation rate

Figure A.1 Conversion plotted as a function of $\mathrm{W} / \mathrm{F}_{\mathrm{A} 0}$

Figure B.1 Residual plot generated by fitting Graaf's model to low $\mathrm{CO}_{2}$ inlet partial pressure data.

Figure B.2 Residual plot generated by fitting Graaf's model to low $\mathrm{CO}_{2}$ inlet partial pressure data

Figure B.3 Residual plot generated by fitting combined model to entire range of kinetic data. 


\section{List of Tables}

Table 1 Summary of Kinetic Models proposed in literature for

Methanol Synthesis

Table 2 Experimental results reported by Calverley 25

Table 3 Variables, constants and parameters in the study 29

Table 4 Statistical tests for model evaluation 31

Table 5 POLYMATH results of fitting Graaf's and Rozovskii's model 34

Table 6 Values of kinetic parameters for Graaf's and Rozovskii's model 35

Table 7 POLYMATH results for the comparative study 40

Table 8 Values of kinetic parameters obtained from fitting the combined 42 rate equation

Table A.1 Experimental results published by Calverley 59

Table B.1 Polymath report generated by fitting Graaf's model to low $\mathrm{CO}_{2} \quad 69$ inlet partial pressure data

Table B.2 Polymath report generated by fitting Rozovskii's model to high $\mathrm{CO}_{2} \quad 70$ inlet partial pressure data

Table B.3 Polymath report generated by fitting combined model to entire range of kinetic data 


\section{List of Symbols}

$r$

$\mathrm{p}$

$\mathrm{k}$

f

$\alpha$

$\theta$

$\Delta \mathrm{H} \quad$ enthalpy change of reaction

$\Delta \mathrm{G} \quad$ Gibb's free energy change

$\mathrm{K}_{\mathrm{eq}} \quad$ equilibrium constant for methanol synthesis reaction

$\mathrm{K}_{\mathrm{i}} \quad$ constants relative to adsorption equilibrium terms in the model

$\mathrm{R}^{2} \quad$ correlation coefficient 


\section{CHAPTER 1}

\section{INTRODUCTION}

Kinetic modeling is an important tool in the design and optimization of chemical synthesis processes. Kinetic studies aid in reactor design and are important means to gain a better insight of the overall process so that it can be modified for optimum operating conditions and better yields. A detailed knowledge of the reaction scheme can often lead to betterment of the production process resulting in appreciable profits [1]. One such industrially important process is the synthesis of methanol.

Methanol is a widely used industrial feedstock and a promising alternative energy resource. It is mainly produced from a mixture of carbon monoxide, carbon dioxide, and hydrogen under high pressure and temperature using $\mathrm{Cu} / \mathrm{ZnO}$ - based catalysts. Synthesis of methanol takes place via three main reactions [2]:

- hydrogenation of carbon monoxide

$$
\mathrm{CO}+2 \mathrm{H}_{2} \rightleftarrows \mathrm{CH}_{3} \mathrm{OH}
$$

Reaction (1)

$$
(\Delta \mathrm{H}=-91 \mathrm{~kJ} / \mathrm{mol} ; \Delta \mathrm{G}=-25.34 \mathrm{~kJ} / \mathrm{mol})
$$

- hydrogenation of carbon dioxide

$$
\begin{gathered}
\mathrm{CO}_{2}+3 \mathrm{H}_{2} \rightleftarrows \mathrm{CH}_{3} \mathrm{OH}+\mathrm{H}_{2} \mathrm{O} \quad \text { Reaction (2) } \\
(\Delta \mathrm{H}=-49.5 \mathrm{~kJ} / \mathrm{mol} ; \Delta \mathrm{G}=3.30 \mathrm{~kJ} / \mathrm{mol})
\end{gathered}
$$

- water-gas shift reaction

$$
\begin{gathered}
\mathrm{CO}+\mathrm{H}_{2} \mathrm{O} \rightleftarrows \mathrm{CO}_{2}+\mathrm{H}_{2} \quad \text { Reaction (3) } \\
(\Delta \mathrm{H}=-41.2 \mathrm{~kJ} / \mathrm{mol} ; \Delta \mathrm{G}=-28.60 \mathrm{~kJ} / \mathrm{mol})
\end{gathered}
$$


$\mathrm{Cu} / \mathrm{ZnO}$-based catalysts have been reported to be the most beneficial for this process due to their high activity, selectivity, and stability which is further enhanced by using supports and promoters [2,3]. Major kinetic studies for methanol synthesis were done as early as 1977 , and, even recently, authors are trying to model the process kinetics [2]. Although reaction mechanisms for this process have been studied for decades now, there has been no agreement on one exact scheme. There are concerns regarding the role of carbon dioxide in the methanol synthesis process, the identity of the active sites on the catalyst, and the role of $\mathrm{ZnO}[3,4$ and 5].

There have been several efforts to improve the methanol synthesis process since its inception by BASF (Baden Aniline and Soda Factory) in the 1920's by developing new, more efficient, and stable catalysts, new reactor configurations, and optimizing the reaction conditions like temperature, pressure, and space velocity. Catalyst innovation involves using effective supports like $\mathrm{ZnO}$ and $\mathrm{ZrO}_{2}$, promoters like alumina, zirconia, and other elements like boron, cobalt, gallium, and magnesium to enhance the catalyst performance at varied reaction temperatures $[3,6]$. Since methanol synthesis is an exothermic reaction, high temperatures enhance methanol yield but only up to an optimum temperature due to thermodynamic limitations. These limitations result in decreasing the equilibrium yield with very high temperatures. Therefore, new methods of synthesis at low temperatures have been developed [7]. The pressure range has also been lowered over the years considering the economics of the process [6]. However, the reaction mechanism remains a topic of debate and is still being investigated. 


\subsection{Significance}

Methanol synthesis is of large industrial significance. Its global production was around 45 million metric tons in 2010 and is expected to increase to 85 million metric tons per year by 2012 [8]. Chemical Market Associates Inc., in their 2010 World Methanol Cost Study Report stated "The global methanol industry is in the midst of the greatest capacity buildup in its history" [9]. The 2011 report stated "Global methanol demand growth was robust in 2010 and is expected to continue at about the same pace" [37]. This high methanol production caters to a wide variety of applications. Methanol is used as a feedstock for many important chemicals like formaldehyde, acetic acid, methyl tert-butyl ether, and chloromethane which in turn are used in various applications like paints, plastics, and plywood to explosives [6]. Methanol, either in pure form or blended with gasoline is also used as a transportation fuel. It holds excellent promise as an alternative source of energy since it offers several advantages clean burning properties, low emissions, high octane rating, high volatility, high energy density, easy transport, and ability to be incorporated in the existing engines without major modifications in the infrastructure [2,10, and 11]. Methanol is also being used as an energy carrier in fuel cell research applications [11]. The world methanol industry has a significant impact on the global economy, generating over $\$ 12$ billion in annual economic activity while creating over 100,000 direct and indirect jobs [8].

Another aspect of importance is the production of methanol from hydrogenation of carbon dioxide which may help utilize the excess $\mathrm{CO}_{2}$ from the atmosphere, thereby 
reducing one of the major greenhouse gases and mitigating the main cause of global warming $[2,6]$.

Since methanol offers so many benefits as an alternative energy source and is of use in a multitude of applications, optimizing and enhancing its production by modeling its reaction kinetics could be of considerable importance. Due to the disagreement on the methanol synthesis reaction scheme, there is always a scope to develop new and effective kinetic models which can prove to be useful in the improvement of the process resulting in high methanol yields and greater profits.

\subsection{Focus of Study}

The focus of my study is to investigate and compare the validity of kinetic models proposed in literature for methanol synthesis from $\mathrm{CO} / \mathrm{CO}_{2} / \mathrm{H}_{2}$ over a Cu-based $\mathrm{ZnO} / \mathrm{Cr}_{2} \mathrm{O}_{3}$ catalyst by fitting them to published experimental data over a range of inlet $\mathrm{CO}_{2}$ partial pressures and analyze the kinetic aspects of methanol production using the results predicted by the best fit kinetic model. 


\section{CHAPTER 2}

\section{LITERATURE REVIEW}

\subsection{Overview}

Methanol production was first carried out in the 1920's by BASF. It holds immense industrial significance due to the wide variety of applications it caters to. It has been reported that global methanol consumption reached 40.4 million metric tons in 2007 and is expected to increase to 58.6 million metric tons by 2012 [12]. Due to its industrial importance and high consumption, numerous investigations have been carried out in order to improve the methanol production process. Among various means, kinetic modeling is one of the most important tools in optimizing and enhancing the overall process. A large number of experimental results have been reported in literature regarding the reaction kinetics of methanol synthesis but some questions and doubts still remain unanswered. The main controversies revolve around the reaction mechanism (role of $\mathrm{CO}$ and $\mathrm{CO}_{2}$ ) and identity of active sites. The literature review analyzes the following aspects of methanol synthesis kinetics:

- Reaction Mechanism

- Kinetic Models

- Reaction Conditions

- Catalyst

\subsection{Reaction Mechanism}

Methanol synthesis occurs via three reactions namely: hydrogenation of carbon monoxide, hydrogenation of carbon dioxide, and water gas shift reactions as shown in 
Chapter 1. There have been a number of studies on methanol synthesis kinetics involving $\mathrm{Cu}$-based catalysts for decades now but controversies still remain regarding the reaction mechanism. One of the major concerns has been the role of $\mathrm{CO}_{2}$ in methanol production. Initial kinetic studies on methanol synthesis by Natta et al. and Leonov et al. considered only $\mathrm{CO}$ and $\mathrm{H}_{2}$ as the main reactants and neglected any contribution from $\mathrm{CO}_{2}$ [13]. Later, Klier et al. in 1982 showed that methanol was mainly formed from CO and $\mathrm{H}_{2}$ that adsorbed on the catalyst and $\mathrm{CO}_{2}$ acted only as a promoter and not as a main reactant. They also suggested that methanol production rate was maximum at a $\mathrm{CO}_{2} / \mathrm{CO}$ ratio of 2:28 which was governed by a balance between the promoting effect of $\mathrm{CO}_{2}$ and retarding effect due to strong adsorption of $\mathrm{CO}_{2}$ [14]. In another study, Liu et al. conducted initial rate experiments in a batch reactor to determine the effect of feed composition on methanol production rate and obtained conflicting results. They showed that methanol formation rate increased with increasing $\mathrm{CO}_{2}$ pressure. A year later, they presented a more detailed study and proposed that hydrogenation of $\mathrm{CO}_{2}$ was the primary reaction in producing methanol at low temperature, low conversion, and in the absence of water but at high temperature, high conversion, and in the presence of water, methanol was primarily produced via $\mathrm{CO}$ hydrogenation [15].

Chinchen et al. reported in their study that $\mathrm{CO}_{2}$ was the primary reactant in methanol production using ${ }^{14} \mathrm{C}$-labeled reactants [16]. Takagawa and Ohsugi, in 1987, determined the empirical rate equations for all the three methanol synthesis reactions and showed that methanol production rate increased with increase in $\mathrm{CO}_{2} / \mathrm{CO}$ ratio in the beginning of the reaction but decreased as the ratio increased and water started to form. 
They claimed their results to be in accordance with both Klier et al. and Liu et al. [17]. McNeil et al. in their experimental study found that 2 mole $\% \mathrm{CO}_{2}$ in the feed yielded optimum methanol production rate. They also found the contribution of $\mathrm{CO}_{2}$ to methanol formation to be more at lower temperatures. Unlike other studies, they developed a rate expression based on mechanistic information which included the effects of $\mathrm{CO}_{2}$, both as a methanol producer as well as a rate inhibitor [18].

Another group of researchers led by Rozovskii et al. showed that there was no direct path for hydrogenation of CO to methanol. They reported in their earlier study, using C-14 labeling techniques and in a more recent study using Temperature Programmed Desorption technique that methanol formation takes place through $\mathrm{CO}_{2}$ hydrogenation [19]. In a methanol synthesis study conducted by Fujita et al. at atmospheric pressure in a flow reactor, it was found that $\mathrm{CO}_{2}$ produced methanol via hydrogenation of formate species formed on $\mathrm{Cu}$ and $\mathrm{CO}$ produced methanol via hydrogenation of formate species formed on $\mathrm{ZnO} \cdot \mathrm{CO}_{2}$ hydrogenation rates were found to be more rapid than $\mathrm{CO}$ hydrogenation rates. They reported that the presence or absence of water and the difference in the reactivity of the former and latter formate species mainly caused a difference in the methanol production rates from $\mathrm{CO}$ and $\mathrm{CO}_{2}$ [20].

In 1998, Sun and co workers studied methanol synthesis and water gas shift reaction using IR technique and found that $\mathrm{CO}_{2}$ hydrogenation was the principle pathway in methanol production for both $\mathrm{CO}_{2}$ and $\mathrm{CO}_{2} / \mathrm{CO}$ hydrogenation reactions. The rate determining step was found to be the hydrogenation of formate species. They suggested 
that $\mathrm{CO}$ addition lowers the activation energy of the production process, in addition to affecting the reaction path [4]. In another study, Sahibzada et al. showed that the intrinsic rate of $\mathrm{CO}_{2}$ hydrogenation was twenty times faster than $\mathrm{CO}$ hydrogenation and at $\mathrm{CO}_{2}>1 \%$, it was the main source of methanol production. They reported that methanol formation rate increased linearly with increase in $\mathrm{CO}_{2}$ concentration in the absence of products [21]. Further establishing the role of $\mathrm{CO}_{2}$ in methanol production, Ostrovskii, studied methanol synthesis mechanism on $\mathrm{Cu} / \mathrm{Zn}$ containing catalyst under a wide range of experimental conditions and showed that $\mathrm{CO}_{2}$ was the principal source of methanol production [22].

Recently, Lim et al. conducted a comprehensive study assuming $\mathrm{CO}$ and $\mathrm{CO}_{2}$ to adsorb on different $\mathrm{Cu}$ sites and water to adsorb on a $\mathrm{ZnO}$ site. They found that $\mathrm{CO}_{2}$ hydrogenation rate was slower than $\mathrm{CO}$ hydrogenation rate which decreased methanol formation rate but since $\mathrm{CO}_{2}$ decreases WGS reaction rate, it, therefore decreases the production of DME, a byproduct from methanol. It was therefore, concluded that methanol production rate can be indirectly enhanced by finding an optimum $\mathrm{CO}_{2}$ concentration. They claim to be the first study among the various ones reporting the role of $\mathrm{CO}_{2}$ in methanol synthesis, suggesting a kinetic mechanism relating $\mathrm{CO}$ and $\mathrm{CO}_{2}$ hydrogenation reactions [2]. In a more recent study by the same authors, they have used the developed kinetic model to evaluate the effect of carbon dioxide fraction on the methanol yield, and have also devised an optimization strategy to maximize methanol production rate taking $\mathrm{CO}_{2}$ fraction and temperature profile into account [30]. 


\subsection{Kinetic Models}

A number of kinetic models have been proposed in the literature and kinetic parameters have been evaluated, each based on a different set of assumptions regarding the reaction pathway and reaction conditions. Leonov et al. were the first to present a kinetic model for methanol synthesis over a $\mathrm{Cu} / \mathrm{ZnO} / \mathrm{Al}_{2} \mathrm{O}_{3}$ catalyst. However, they did not consider the effect of $\mathrm{CO}_{2}$ in the feed [13]. Later Klier et al. and Villa et al. proposed models which included the $\mathrm{p}_{\mathrm{CO} 2}$ terms but did not treat $\mathrm{CO}_{2}$ as the main reactant $[13,14]$. The model proposed by Villa et al. was developed based on the scheme that methanol was produced from only $\mathrm{CO}$ and a $\mathrm{CO}_{2}$ adsorption term was included since $\mathrm{CO}_{2}$ adsorbs strongly at high concentrations. Takagawa and Ohsugi derived empirical rate expressions for the three methanol synthesis reactions under a wide range of experimental conditions [17]. Graaf et al. derived a kinetic model taking into account both $\mathrm{CO}$ and $\mathrm{CO}_{2}$ hydrogenation and the water gas shift reaction. They derived 48 reaction schemes by assuming different elementary steps to be rate limiting and then selected the best possible kinetic model using statistical discrimination [31]. The kinetic model derived by Graaf et al. is shown in Table 1. McNeil et al. developed a carbon dioxide hydrogenation rate expression based on mechanistic information reported in literature in contrast to the earlier models based on empirical expressions [18]. Skrzypek et al. derived their kinetic model based on Reactions (2) and (3) since they have shown through their experiments that methanol synthesis prefers $\mathrm{CO}_{2}$ in spite of $\mathrm{CO}$ as a carbon source [32].

A kinetic model for methanol synthesis was presented by Askgaard et al. and the kinetic parameters were evaluated using gas phase thermodynamics and surface science 
studies. They found that the calculated rates when extrapolated to actual working conditions compared well with the measured rates [23]. Froment and Buschhe conducted experiments and developed a steady state kinetic model based on a detailed reaction scheme assuming $\mathrm{CO}_{2}$ to be the main source of carbon in methanol. Their model described the effects of temperature, pressure, and gas phase composition on methanol production rates even beyond their own experimental conditions [13]. In another kinetic study by Kubota et al., kinetic equations for methanol synthesis were developed assuming $\mathrm{CO}_{2}$ hydrogenation to be the predominant reaction. The authors found their equations to be reasonably accurate since the yield values obtained from their equations and those from experiments conducted in a test plant compared well [24].

Šetinc and Levec proposed a kinetic model for liquid phase methanol synthesis in 2001 and showed that methanol production is proportional to the $\mathrm{CO}_{2}$ concentration and not to the CO concentration [33].

Rozovskii and Lin proposed two reaction schemes to build the theoretical kinetic models which could fit the experimental data well. They used two different gas phase compositions, one enriched with $\mathrm{CO}_{2}$ and the other with $\mathrm{CO}$ to test the applicability of their models. They found that both the schemes proved to be effective when dealing with a $\mathrm{CO}_{2}$ enriched mixture, but, the kinetic model based on scheme 1 did not match with the experimental data well when using a CO enriched mixture [19]. Lim et al. developed a comprehensive kinetic model consisting of 48 reaction rates based on different possible rate determining steps. They showed through parameter estimation that, among the 48 rates, surface reaction of a methoxy species was the rate determining step for $\mathrm{CO}$ 
hydrogenation, hydrogenation of a formate intermediate was the rate determining step for $\mathrm{CO}_{2}$ hydrogenation and formation of a formate intermediate was the rate determining step for the water-gas shift reaction. However they used a $\mathrm{Cu} / \mathrm{ZnO} / \mathrm{Al}_{2} \mathrm{O}_{3} / \mathrm{Zr}_{2} \mathrm{O}_{3}$ catalyst [2]. Grabow and Mavrikakis have developed a comprehensive microkinetic model using density functional theory calculations to deal with the uncertainties regarding the reaction mechanism and nature of active sites [34].

Table 1 summarizes the various kinetic models, proposed in literature along with the experimental reaction conditions.

Table 1. Summary of Kinetic Models proposed in literature for methanol synthesis.

\begin{tabular}{|c|c|c|c|}
\hline $\begin{array}{l}\text { Operating } \\
\text { Conditions }\end{array}$ & Kinetic Model & $\begin{array}{l}\text { Author, } \\
\text { Year }\end{array}$ & Ref. \\
\hline $\begin{array}{l}493-533 \mathrm{~K} \\
40-55 \mathrm{~atm}\end{array}$ & $r_{\mathrm{CH}_{3} \mathrm{OH}}=k\left(\frac{p_{\mathrm{CO}}^{0.5} p_{\mathrm{H}_{2}}}{p_{\mathrm{CH}}^{0.66} \mathrm{OH}}-\frac{p_{\mathrm{CH}_{3} \mathrm{OH}}^{0.34}}{p_{\mathrm{CO}}^{0.5} p_{\mathrm{H}_{2}} K_{2}^{*}}\right)$ & $\begin{array}{l}\text { Leonov } \\
\text { et al., } \\
1973\end{array}$ & 13 \\
\hline $\begin{array}{l}498-523 \mathrm{~K} ; \\
75 \mathrm{~atm}\end{array}$ & 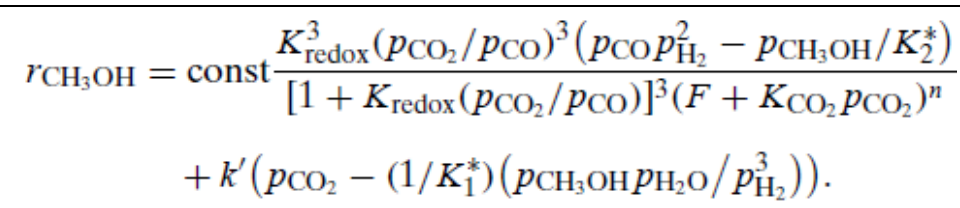 & $\begin{array}{l}\text { Klier } e t \\
\text { al., } \\
1982\end{array}$ & 14 \\
\hline $\mathrm{N} / \mathrm{A}$ & $\begin{aligned} r_{\mathrm{CH}_{3} \mathrm{OH}} & =\frac{f_{\mathrm{CO}} f_{\mathrm{H}_{2}^{2}}-f_{\mathrm{CH}_{3} \mathrm{OH}} / K_{2}^{*}}{\left(A+B f_{\mathrm{CO}}+C f_{\mathrm{H}_{2}}+G f_{\mathrm{CO}_{2}}\right)^{3}} \\
r_{\mathrm{RWGS}} & =\frac{f_{\mathrm{CO}_{2}} f_{\mathrm{H}_{2}}-f_{\mathrm{CO}} f_{\mathrm{H}_{2} \mathrm{O}} K_{3}^{*}}{M^{2}}\end{aligned}$ & $\begin{array}{l}\text { Villa } e t \\
\text { al., } \\
1985\end{array}$ & 13 \\
\hline
\end{tabular}




\begin{tabular}{|c|c|c|c|}
\hline $\begin{array}{l}\text { Operating } \\
\text { Conditions }\end{array}$ & Kinetic Model & $\begin{array}{l}\text { Author, } \\
\text { Year }\end{array}$ & Ref. \\
\hline $\begin{array}{l}483-518 \mathrm{~K} \\
15-50 \mathrm{bar}\end{array}$ & 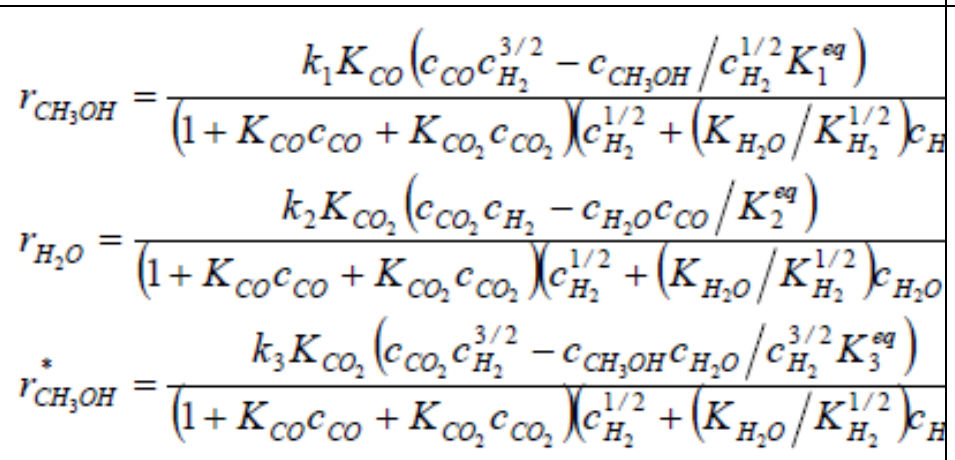 & $\begin{array}{l}\text { Graaf et } \\
\text { al., } 1988\end{array}$ & 31 \\
\hline $\begin{array}{l}483-513 \mathrm{~K} ; \\
2.89-4.38 \\
\mathrm{MPa}\end{array}$ & $\begin{aligned} r= & \frac{k_{\mathrm{f}}^{\prime} K_{\mathrm{CH}} K_{\mathrm{H}_{2}}^{2} K_{\mathrm{H}}^{2} K_{\mathrm{CO}}\left(p_{\mathrm{CO}} p_{\mathrm{H}_{2}}^{2}-p_{\mathrm{CH}_{3} \mathrm{OH}} / K_{\mathrm{eq}_{2}}\right)}{K_{\mathrm{CH}} K_{\mathrm{H}_{2}}^{3 / 2} K_{\mathrm{H}}^{3 / 2} K_{\mathrm{CO}} p_{\mathrm{CO}} p_{\mathrm{H}_{2}}^{3 / 2}+K_{\mathrm{CO}_{2}} p_{\mathrm{CO}_{2}}+K_{\mathrm{H}_{2}}^{\prime} p_{\mathrm{H}_{2}}} \\
& +\frac{k_{\mathrm{f}}^{\prime \prime} K_{\mathrm{H}_{2}} K_{\mathrm{H}} K_{\mathrm{CO}_{2}} K_{\mathrm{CHO}_{2}}\left[p_{\mathrm{CO}_{2}} p_{\mathrm{H}_{2}}-p_{\mathrm{CH}_{3} \mathrm{OH}} p_{\mathrm{H}_{2} \mathrm{O}} /\left(K_{\mathrm{eq}_{2}}^{\prime \prime} p_{\mathrm{H}_{2}}^{2}\right)\right]}{K_{\mathrm{H}_{2}}^{1 / 2} K_{\mathrm{H}}^{1 / 2} K_{\mathrm{CO}_{2}} K_{\mathrm{CHO}_{2}} p_{\mathrm{CO}_{2}} p_{\mathrm{H}_{2}}^{1 / 2}+K_{\mathrm{CO}_{2}}^{\prime \prime} p_{\mathrm{CO}_{2}}^{2}+K_{\mathrm{H}_{2} \mathrm{O}} p_{\mathrm{H}_{2} \mathrm{O}}^{3}}\end{aligned}$ & $\begin{array}{l}\text { McNeil } \\
\text { et al., } \\
1989\end{array}$ & 18 \\
\hline $\begin{array}{l}483-563 \mathrm{~K} \\
1-4 \text { bar }\end{array}$ & $\begin{array}{l}r_{+}=k_{-11} K_{5}^{-3 / 2} K_{8}^{-1} K_{9} K_{10} K_{11}\left(\frac{p_{\mathrm{H}_{2}}}{p_{\mathrm{o}}}\right)^{3 / 2}\left(\frac{p_{\mathrm{CO}_{2}}}{p_{\mathrm{o}}}\right) \theta_{\star}^{2} \\
r_{-}=k_{-11} K_{5}^{-3 / 2} K_{8}^{-1} K_{9} K_{10} K_{11} \frac{1}{K_{\mathrm{G}}} \frac{p_{\mathrm{CH}_{3} \mathrm{OH}} p_{\mathrm{H}_{2} \mathrm{O}}}{p_{\mathrm{H}_{2}}^{3 / 2} p_{\mathrm{o}}^{1 / 2}} \theta_{*}^{2}\end{array}$ & $\begin{array}{l}\text { Askgaar } \\
\text { d et al., } \\
1995\end{array}$ & 23 \\
\hline $\begin{array}{l}453-553 \mathrm{~K} \\
15-51 \mathrm{bar}\end{array}$ & $\begin{array}{l}r_{\mathrm{MeOH}}= \\
\frac{k_{5 \mathrm{a}}^{\prime} K_{2}^{\prime} K_{3} K_{4} K_{\mathrm{H}_{2}} p_{\mathrm{CO}_{2}} p_{\mathrm{H}_{2}}\left[1-\left(1 / K^{*}\right)\left(p_{\mathrm{H}_{2} \mathrm{O}} p_{\mathrm{CH}_{3} \mathrm{OH}} / p_{\mathrm{H}_{2}}^{3} p_{\mathrm{CO}_{2}}\right)\right]}{\left(1+\left(K_{\mathrm{H}_{2} \mathrm{O}} / K_{8} K_{9} K_{\mathrm{H}_{2}}\right)\left(p_{\mathrm{H}_{2} \mathrm{O}} / p_{\mathrm{H}_{2}}\right)+\sqrt{K_{\mathrm{H}_{2}} p_{\mathrm{H}_{2}}}+K_{\mathrm{H}_{2} \mathrm{O}} p_{\mathrm{H}_{2} \mathrm{O}}\right)^{3}} \\
r_{\mathrm{RWGS}}= \\
\frac{k_{1}^{\prime} p_{\mathrm{CO}_{2}}\left[1-K_{3}^{*}\left(p_{\mathrm{H}_{2} \mathrm{O}} p_{\mathrm{CO}} / p_{\mathrm{CO}_{2} p_{\mathrm{H}_{2}}}\right)\right]}{\left(1+\left(K_{\mathrm{H}_{2} \mathrm{O}} / K_{8} K_{9} K_{\mathrm{H}_{2}}\right)\left(p_{\mathrm{H}_{2} \mathrm{O}} / p_{\mathrm{H}_{2}}\right)+\sqrt{K_{\mathrm{H}_{2}} p_{\mathrm{H}_{2}}}+K_{\mathrm{H}_{2} \mathrm{O}} p_{\mathrm{H}_{2} \mathrm{O}}\right)}\end{array}$ & $\begin{array}{l}\text { Froment } \\
\text { and } \\
\text { Bussche } \\
1996\end{array}$ & 13 \\
\hline
\end{tabular}




\begin{tabular}{|c|c|c|c|}
\hline $\begin{array}{l}\text { Operating } \\
\text { Conditions }\end{array}$ & Kinetic Model & $\begin{array}{l}\text { Author, } \\
\text { Year }\end{array}$ & Ref. \\
\hline $\begin{array}{l}473-548 \mathrm{~K} \\
4.9 \mathrm{MPa}\end{array}$ & $\begin{array}{r}k_{\mathrm{M}}=\frac{\left.P\left(\mathrm{CH}_{3} \mathrm{OH}\right) P\left(\mathrm{H}_{2} \mathrm{O}\right) /\left[K_{\mathrm{M}} P^{2}\left(\mathrm{H}_{2}\right)\right]\right\}}{\left[1+K_{\mathrm{CO}_{2}} \times P\left(\mathrm{CO}_{2}\right)\right.} \\
\left.\quad+K_{\mathrm{H}_{2} \mathrm{O}} \times P\left(\mathrm{H}_{2} \mathrm{O}\right)\right]^{2} \\
k_{\mathrm{R}}\left\{P\left(\mathrm{CO}_{2}\right)-\right. \\
R_{\mathrm{R}}=\frac{P\left(\mathrm{CO}^{2} P\left(\mathrm{H}_{2} \mathrm{O}\right) /\left[K_{\mathrm{R}} \cdot \mathrm{P}\left(\mathrm{H}_{2}\right)\right]\right\}}{1+K_{\mathrm{CO}_{2} P\left(\mathrm{CO}_{2}\right)+K_{\mathrm{H}_{2} \mathrm{O}} P\left(\mathrm{H}_{2} \mathrm{O}\right)}}\end{array}$ & $\begin{array}{l}\text { Kubota } \\
\text { et al., } \\
2001\end{array}$ & 24 \\
\hline $\begin{array}{l}473-513 \mathrm{~K} \\
34-41 \mathrm{bar}\end{array}$ & $\begin{array}{l}r_{M e}=A_{M e} e^{\left(-\frac{E_{M e}}{R T}\right)} \frac{c_{\mathrm{CO}_{2}}\left(c_{\mathrm{H}_{2}}-c_{\mathrm{H}_{2, \alpha q}}\right)}{\left(1+A_{W} e^{\left(\frac{E_{W}}{R T}\right)} c_{\mathrm{H}_{2} \mathrm{O}}\right)^{2}} \\
r_{\mathrm{H}_{2} \mathrm{O}}=A_{\mathrm{H}_{2} \mathrm{O}} e^{\left(-\frac{E_{\mathrm{H}_{2} \mathrm{O}}}{R T}\right)} \frac{c_{\mathrm{CO}_{2}}-c_{\mathrm{CO}_{2, \mathrm{q}}}}{\left(1+A_{W} e^{\left(\frac{E_{W}}{R T}\right)} c_{\mathrm{H}_{2} \mathrm{O}}\right)}\end{array}$ & $\begin{array}{l}\text { Šetinc } \\
\text { and } \\
\text { Levec, } \\
2001\end{array}$ & 33 \\
\hline $\begin{array}{l}513 \mathrm{~K} ; 5.2 \\
\mathrm{MPa}\end{array}$ & $r=\frac{k_{3} p_{\mathrm{H}_{2}}\left(1-\frac{p_{\mathrm{mm}^{\prime} \mathrm{H}_{2} \mathrm{O}}}{K_{\left.\mathrm{Pm}_{\mathrm{m}}\right) \rho_{\mathrm{H}_{2}}^{3} p_{\mathrm{CO}}}}\right)}{1+K_{-2} p_{\mathrm{H}_{2} \mathrm{O}}+K_{-2} p_{\mathrm{H}_{2} \mathrm{O}} /\left(K_{1} p_{\mathrm{CO}_{2}}\right)}$ & $\begin{array}{l}\text { Rozovs- } \\
\text {-kii and } \\
\text { Lin, } \\
2003\end{array}$ & 19 \\
\hline $\begin{array}{l}523-553 \mathrm{~K} ; 5 \\
\mathrm{MPa}\end{array}$ & 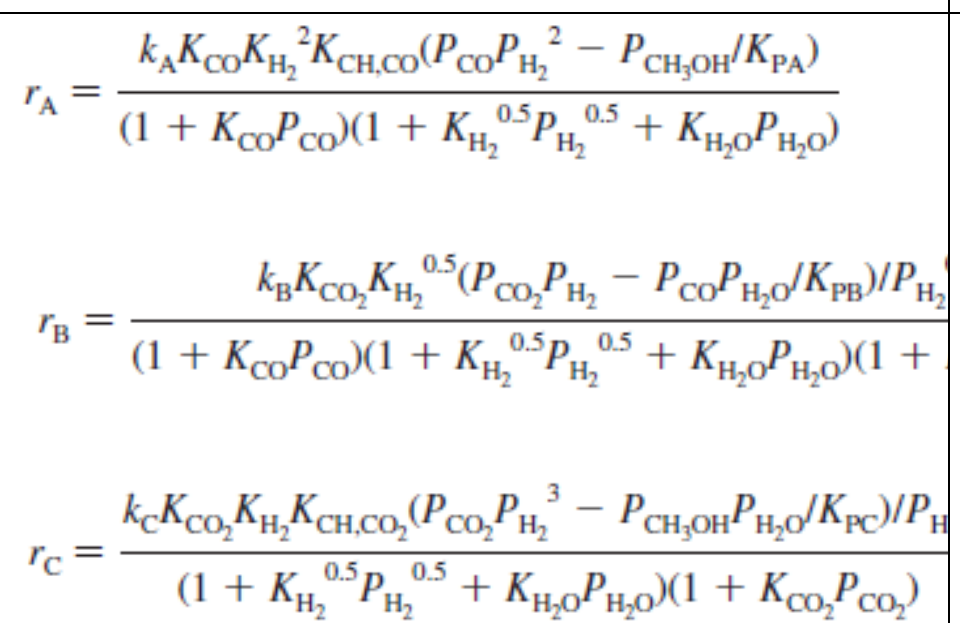 & $\begin{array}{l}\text { Lim } e t \\
\text { al., } 2009\end{array}$ & 2 \\
\hline
\end{tabular}




\subsection{Reaction Conditions}

The main reaction conditions to be considered in methanol synthesis are temperature, pressure, and space velocity.

\subsubsection{Temperature}

Methanol synthesis is usually carried out at 493-573 K [1, 23]. Since, hydrogenation reactions of $\mathrm{CO}$ and $\mathrm{CO}_{2}$ are exothermic; their rates increase with temperature but only up to a certain temperature. At higher temperatures, the rates begin to decrease as the thermodynamic equilibrium constant decreases as temperature increases. Therefore, very high temperatures are not suitable. It was reported by Bill et al. that methanol yield increased with temperature but only up to 493 K [6]. Similarly it was found by Xin et al. that maximum $\mathrm{CO}_{2}$ conversion and yield were possible at around $523 \mathrm{~K}$. They also reported that methanol synthesis was more sensitive to reaction temperature than the water gas shift reaction. Figure 1 shows the dependence of $\mathrm{CO}_{2}$ conversion and methanol yield on reaction temperature [25].

Extreme temperatures limit the efficiency of methanol production due to thermodynamic limitations. Therefore, a low temperature route of methanol synthesis has been proposed by Tsubaki and co workers. They conducted the experiments at $443 \mathrm{~K}$ on a copper based catalyst using ethanol as a catalytic solvent. They showed that the reaction mechanism at low temperature followed: formate to methyl formate to methanol pathway instead of formate to methoxy to methanol route. They proposed that low temperature methanol production enabled high conversions up to 50-80\% and reduction of production cost without any thermodynamic equilibrium [7]. 


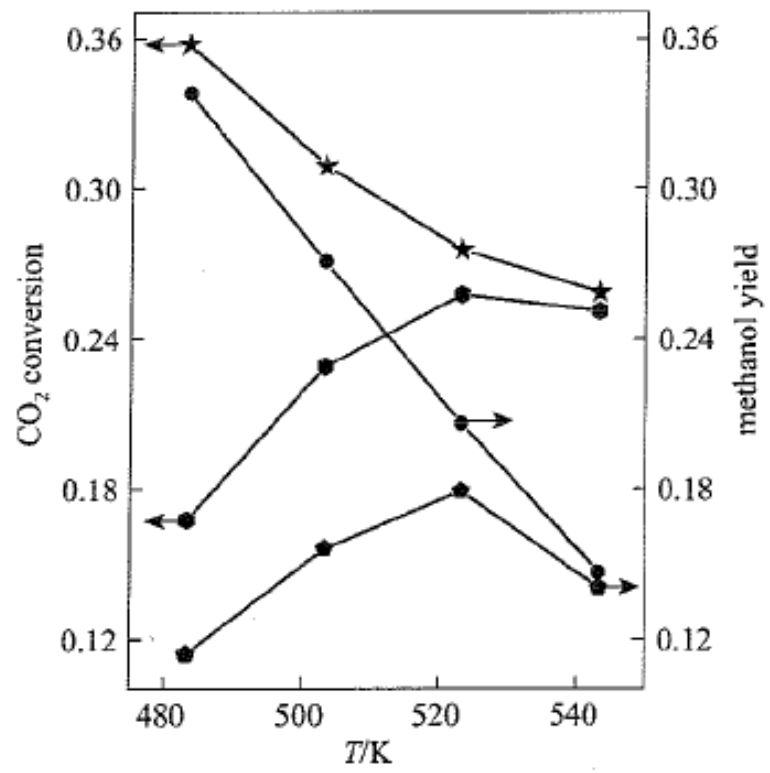

Figure 1. Relationship between reaction temperature and $\mathrm{CO}_{2}$ conversion and methanol yield from experimental results and thermodynamic predictions (Reprinted with permission from [25]).

\subsubsection{Pressure}

Methanol production was initially carried out at very high pressures when it was first started in 1920's by BASF. Later, ICI lowered pressures to 50-100 atm using a $\mathrm{Cu} / \mathrm{ZnO} / \mathrm{Al}_{2} \mathrm{O}_{3}$ catalyst [6]. In 1988 , Graaf et al. studied the kinetics of methanol synthesis form $\mathrm{CO}, \mathrm{CO}_{2}$ and $\mathrm{H}_{2}$ over the same catalyst and developed a kinetic model operative at pressures of 15-50 atm. They claimed their low pressure methanol synthesis kinetic model to be more precise in illustrating the experimental values compared to the previously proposed models [26]. It was reported by Deng et al. that methanol production could be carried at 20 atm using $\mathrm{Cu} / \mathrm{ZnO} / \mathrm{Al}_{2} \mathrm{O}_{3}$ catalyst [6]. 
Xin et al. reported that high pressure was advantageous for $\mathrm{CO}_{2}$ hydrogenation as shown in Figure 2 [25].

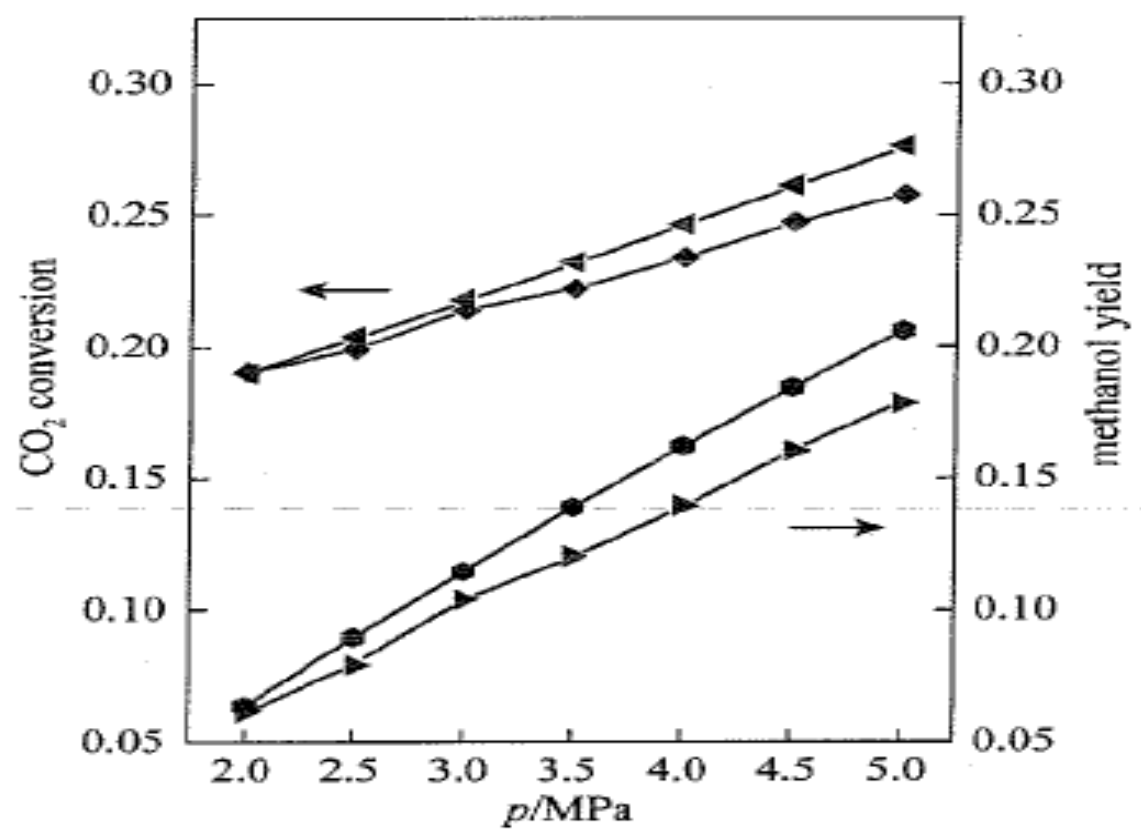

Figure 2. Relationship between reaction pressure and $\mathrm{CO}_{2}$ conversion and methanol yield from experimental results and thermodynamic predictions (Reprinted with permission from [25]).

However, very high pressures tend to increase the production cost and are unsafe.

Therefore, present efforts are to decrease the operating pressure without affecting the yield by developing novel catalysts.

\subsubsection{Space Velocity}

Space velocity can have complicated effects on methanol yield. Xin et al.

reported that both $\mathrm{CO}_{2}$ conversion and methanol yield decreased as space velocity was increased for a given value of $\mathrm{CO}_{2}$ concentration.

Their results are shown in Figure 3 [25]. 


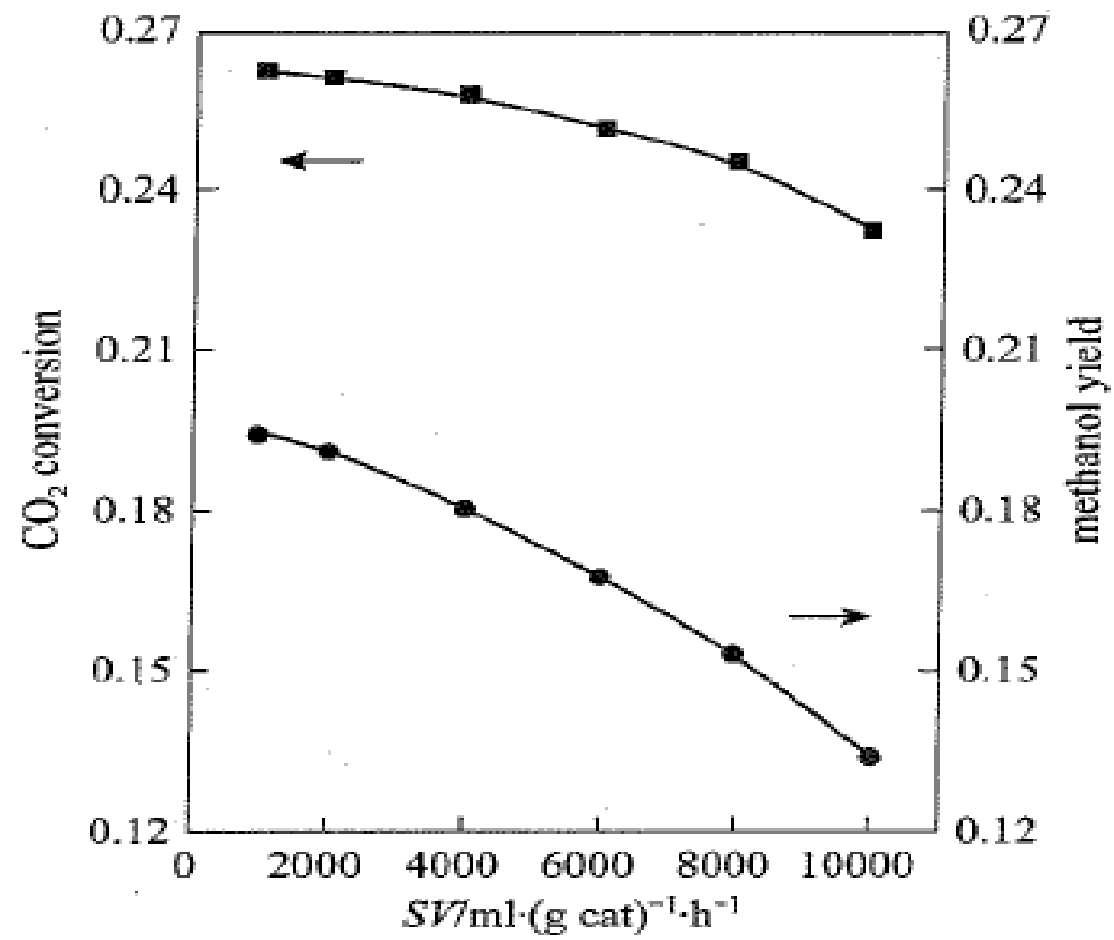

Figure 3. Relationship between space velocity and $\mathrm{CO}_{2}$ conversion and methanol yield (Reprinted with permission from [25]).

However, in another study, Lee and co workers found that methanol yields increased at low space velocities but only up to a particular value of $\mathrm{CO}_{2}$ concentration after which it began to decrease. They reported that maximum rate of methanol production could be achieved with an optimum value of space velocity, as shown in Figure 4 [27]. 


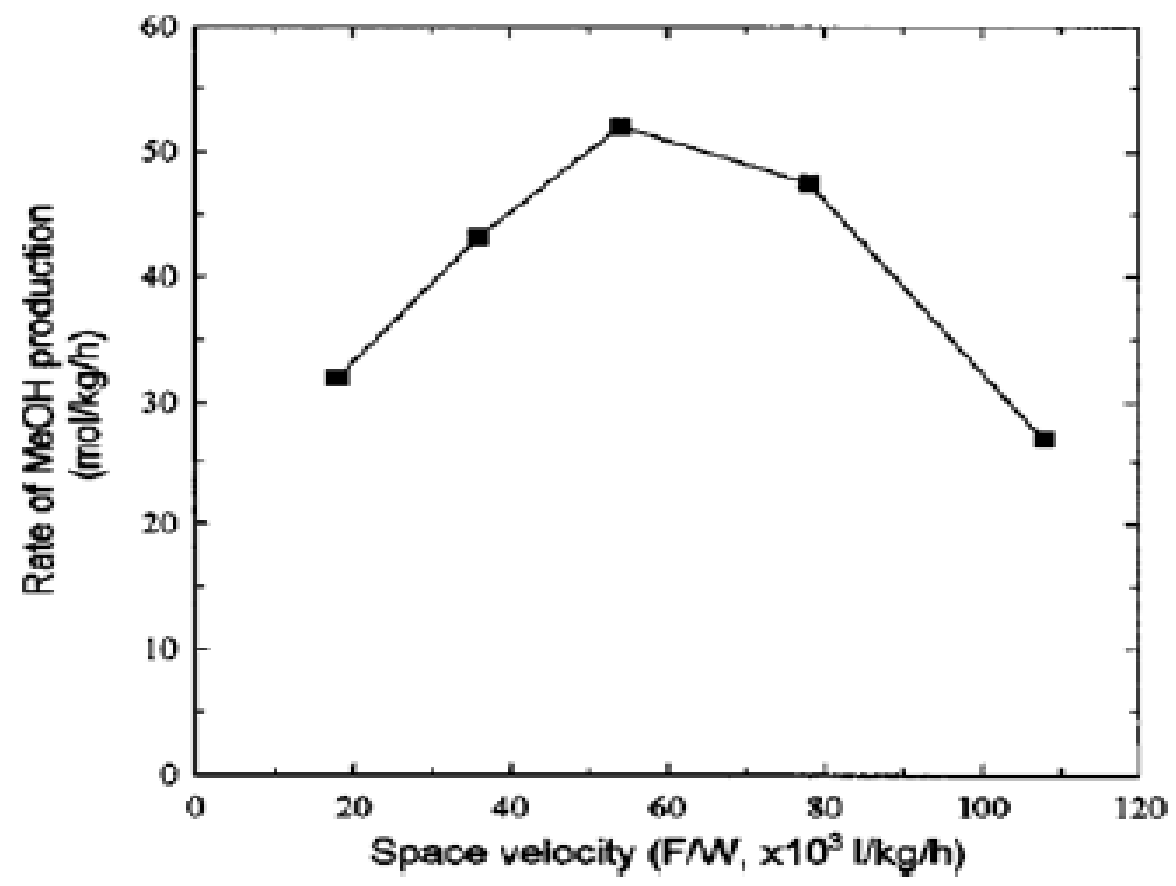

Figure 4. Rates of methanol formation as a function of space velocity for methanol synthesis over $\mathrm{Cu} / \mathrm{ZnO} / \mathrm{Al}_{2} \mathrm{O}_{3}$ catalyst with synthesis gas containing $10 \mathrm{vol} \% \mathrm{CO}_{2}$. Reaction conditions: $\mathrm{T}=523 \mathrm{~K}, \mathrm{P}=3.0 \mathrm{MPa}, \mathrm{H}_{2} / \mathrm{COx}=4$ (Reprinted with permission from [27]).

\subsection{Catalyst}

$\mathrm{Cu} / \mathrm{ZnO} / \mathrm{Al}_{2} \mathrm{O}_{3}$ is the catalyst mostly chosen for methanol synthesis due to its high selectivity, stability, and activity. Copper acts as the main active component, $\mathrm{ZnO}$ acts as a supporter and $\mathrm{Al}_{2} \mathrm{O}_{3}$ acts as a promoter. Another promoter used in the catalyst system is chromia $[2,6]$. However, there are many controversies and questions regarding the individual catalyst components, the role of $\mathrm{ZnO}$, and the identity of active sites. Most of the authors are of the view that metallic copper is the active component of the catalyst and the role of $\mathrm{ZnO}$ is to enhance dispersion of copper particles. Ovesen et al. concluded from their results that $\mathrm{Cu}$ was the active catalytic component in methanol synthesis [23]. 
Froment and Bussche also assumed $\mathrm{Cu}$ to be the active catalytic site and $\mathrm{ZnO}$ to provide structural promotion in the development of their detailed kinetic model for methanol formation [13]. Another group of researchers led by Fujitani et al., however, have demonstrated conflicting results. They showed using surface science techniques that the role of $\mathrm{ZnO}$ was to form active sites in addition to dispersing $\mathrm{Cu}$ particles [5]. Ostrovskii also reported that methanol synthesis occurs on the $\mathrm{ZnO}$ component of the catalyst [22].

Since, $\mathrm{CO}$ and $\mathrm{CO}_{2}$ hydrogenation is believed to occur on two different sites, it is proposed that doubts regarding the identity of active sites could be resolved $[2,18]$. There are also efforts to develop novel catalysts that can effectively operate at lower temperatures, lower pressures, and exhibit water tolerance since water acts as an inhibitor for the catalyst [12].

\subsection{Summary}

A large volume of literature is contributed to studying methanol synthesis reaction kinetics owing to its importance in the industry. However, a number of controversies still remain unresolved regarding the reaction mechanism, in particular. Although $\mathrm{CO}_{2}$ has been accepted to be the primary source of carbon in methanol, its role and its effect on methanol production rates has not yet been described clearly. Modeling of reaction kinetics can, therefore, prove to be beneficial in understanding the overall process. A number of kinetic models have been proposed in literature and there is still scope to develop newer and more effective models which could help improve the process and enhance methanol yield. 


\section{CHAPTER 3}

\section{RESEARCH OBJECTIVES}

The primary objective of this study was to investigate different kinetic models that have been proposed in literature for methanol synthesis over a copper- based zinc/chromia catalyst. Another aspect of this work was to compare the goodness of fit of different models and select the best fit model by fitting experimental kinetic data over a range of inlet carbon dioxide partial pressures.

Models based on a mechanism considering $\mathrm{CO}$ hydrogenation to be the principal pathway in forming methanol were compared to those derived from the scheme considering $\mathrm{CO}_{2}$ to be the primary reactant in methanol synthesis over different ranges of $\mathrm{CO}_{2}$ partial pressures in the feed. Each of these models was also compared to a combined kinetic rate expression. The aim was to select the kinetic model and rate expression that fits the data best and can describe methanol synthesis kinetics most appropriately.

It was hypothesized that the model based on the $\mathrm{CO}$ hydrogenation pathway should fit the rate data better in case of low $\mathrm{CO}_{2}$ feed partial pressures, while the model based on the $\mathrm{CO}_{2}$ hydrogenation pathway should fit the data with high $\mathrm{CO}_{2}$ content more effectively. It was also presumed that the combined rate expression including both $\mathrm{CO}$ and $\mathrm{CO}_{2}$ hydrogenation rate terms will prove to be the best fit kinetic model. The study also used the results from the best fit model to explain some aspects and resolve some arguments related to methanol synthesis kinetics. 


\section{CHAPTER 4}

\section{METHODOLOGY}

\subsection{Overview}

This study comprises of analyzing and comparing different kinetic models and selecting the best fit kinetic rate expression for methanol synthesis from $\mathrm{CO}, \mathrm{CO}_{2}$, and $\mathrm{H}_{2} \mathrm{O}$ over a $\mathrm{Cu} / \mathrm{ZnO} / \mathrm{Cr}_{2} \mathrm{O}_{3}$ catalyst. Non linear regression techniques in POLYMATH were used to determine the rate parameters and goodness of fit of the models. The methodology included the following steps:

- Selection of statistically sound kinetic models

- Data evaluation

- Parameter estimation

- Evaluation of models

- Comparison of models

- Analysis of Results

\subsection{Selection of statistically sound kinetic models}

A kinetic rate expression is derived from the reaction mechanism by assuming a particular rate limiting step. Rate laws are written in the following form:

$$
\text { rate }=\frac{(\text { Kinetic term }) \cdot(\text { Potential term })}{(\text { Adsorption term })^{n}}
$$

Equation (1)

A rate equation should fit a set of data better than other alternative rate expressions to prove its effectiveness. However, any one kinetic model cannot be considered the most accurate since rate laws often exhibit the same form and more than 
one model can fit a set of data with equal efficacy. Another aspect of importance is developing a kinetic model that can be applied at temperatures and pressures pertinent to the industry.

As mentioned in Sections 2.2, methanol synthesis kinetics has been a point of controversy despite of the fact that a large volume of literature and experimental results have been reported regarding the mechanism and kinetic modeling. One of the main unresolved issues is the source of carbon in methanol and the role of $\mathrm{CO}_{2}$ in methanol synthesis. Some researchers believe that $\mathrm{CO}_{2}$ is the primary reactant in forming methanol while many others are of the view that carbon in methanol comes from $\mathrm{CO}$. As a result, different mechanistic schemes have been written based on which various kinetic models have been proposed in literature, as shown in Table 1 in Section 2.3.

Among the kinetic models proposed in literature, two models have been selected for this study based on their goodness of fit to the respective kinetic data. The validity and effectiveness of the developed rate models was tested by determining how well they fit the experimental data compared to other proposed models. The model based on the reaction scheme which considers $\mathrm{CO}$ to be the primary reactant in methanol synthesis is:

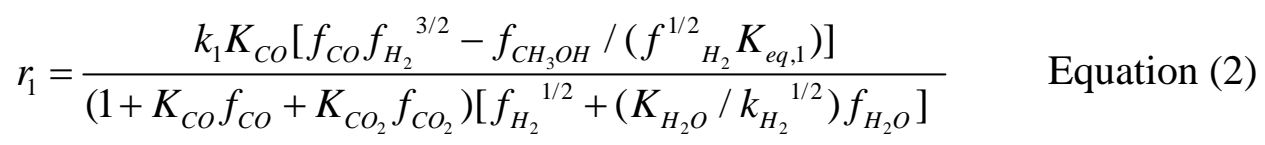

where,

$\mathrm{r}_{1}=$ reaction rate

$\mathrm{f}_{\mathrm{i}}=$ fugacity of component $\mathrm{i}$

$\mathrm{k}_{\mathrm{i}}=$ reaction rate constant 
$\mathrm{K}_{\mathrm{eq}}=$ equilibrium constant for methanol synthesis reaction

$\mathrm{K}_{\mathrm{i}}=$ constants relative to adsorption equilibrium terms in the model

It was proposed by Graaf et al. in 1988. Graaf and co authors developed three independent kinetic equations for $\mathrm{CO}$ hydrogenation, $\mathrm{CO}_{2}$ hydrogenation and water gas shift reaction. Among them, the kinetic model based on $\mathrm{CO}$ hydrogenation treating $\mathrm{CO}$ as the main reactant was chosen for this study. The fugacities in Equation (2) have been replaced by partial pressures since the fugacity coefficients calculated for the species at the used temperature and pressure are close to unity. The coefficients were calculated using the Fugacity Coefficient Solver of Thermosolver software.

The authors have shown that the experimental and estimated values of reaction rates for methanol and water agree to a satisfactory extent as shown in Figure 5. Also, they found the model statistically appropriate based on the standard $\chi_{2}$ test [26].

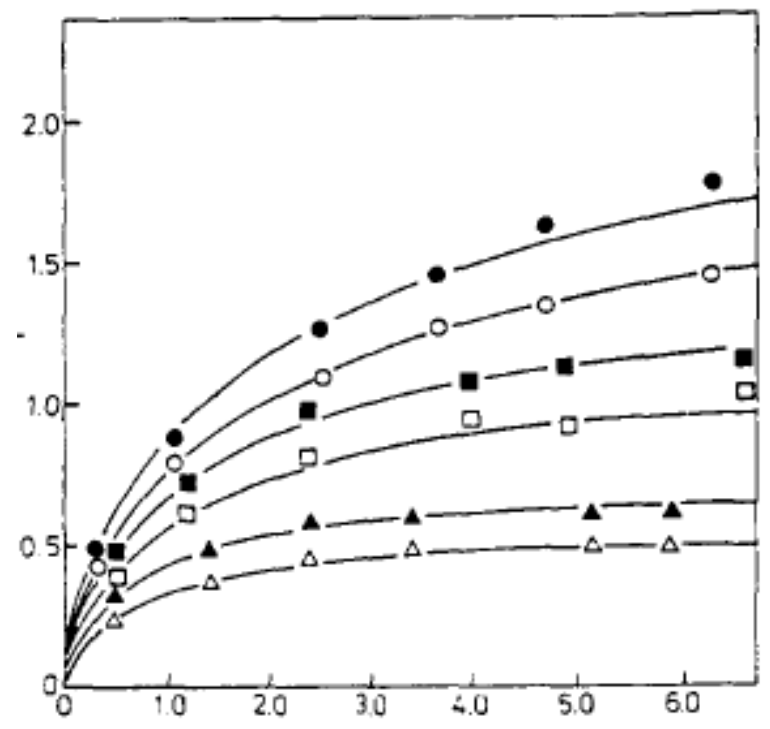

Figure 5. Reaction rates for methanol and water: $(\circ)$ and $(\bullet), p=50$ bar, ( $\square$ ) and ( $\bullet), p=30$ bar, $(\Delta)$ and $(\mathbf{\Lambda}), \mathrm{p}=15$ bar. Open symbols= reaction rates for methanol. Closed symbols $=$ reaction rates for water. Lines $=$ calculated with model $($ Reprinted with permission from [26]). 
The other model selected for this study was put forth by Rozovskii and co workers. It was based on the fact that methanol was formed from only carbon dioxide and not carbon monoxide. The authors believed that $\mathrm{CO}$ hydrogenation to methanol did not take place directly. Instead, $\mathrm{CO}$ was converted to $\mathrm{CO}_{2}$ via the water gas shift reaction which underwent hydrogenation to form methanol. The kinetic model is of the form:

$$
r=\frac{k_{3} p_{\mathrm{H}_{2}}\left(1-\frac{p_{m} p_{\mathrm{H}_{2} \mathrm{O}}}{K_{p(m)} p_{\mathrm{H}_{2}}{ }^{3} p_{\mathrm{CO}_{2}}}\right)}{1+K_{-2} p_{\mathrm{H}_{2} \mathrm{O}}+K_{-2} p_{\mathrm{H}_{2} \mathrm{O}} /\left(K_{1} p_{\mathrm{CO}_{2}}\right)}
$$

where,

$r=$ reaction rate

$\mathrm{k}_{\mathrm{i}}=$ reaction rate constant

$\mathrm{K}_{\mathrm{i}}=$ equilibrium constant of step $\mathrm{i}$

$\mathrm{K}_{\mathrm{p}(\mathrm{m})}=$ methanol synthesis equilibrium constant

$p_{i}=$ partial pressure of component $i$

The authors reported that the relative error in the experimental and calculated partial pressure values for methanol and water was not more than $15 \%$ and $10 \%$ respectively [19].

\subsection{Data Evaluation}

An extensive set of rate vs. partial pressure data for a reaction carried out using $\mathrm{Cu} / \mathrm{ZnO} / \mathrm{Cr}_{2} \mathrm{O}_{3}$ catalyst at relevant temperature and pressure is needed for testing the goodness of fit of the proposed rate equation. It has to be ensured that the selected data is good enough for the fitting procedure. Data was selected based on the number of 
independent experimental data points (minimum three data points for one parameter), repeatability and reproducibility of runs, standard deviation, and errors in measurement.

In this study, experimental data reported by Calverley was used in kinetic modeling. Calverley conducted methanol synthesis experiments at $100 \mathrm{~atm}$ and $285^{\circ} \mathrm{C}$. Rate vs. partial pressure data derived from Calverley's experimental results is listed in Table 2. The complete kinetic data set reported by Calverley is shown in Table A.1 in Appendix A.

Calverley used a fixed bed tubular reactor in his experiments. Since the reactor was operated in integral mode, the rates were calculated by fitting a polynomial function to conversion and turnover frequency data. The resulting polynomial was differentiated to obtain the rates. The complete method and graphs are shown in Appendix A.

Table 2. Rate vs. partial pressure data (modified from [35]).

\begin{tabular}{|c|c|c|c|c|c|c|}
\hline Expt. no. & Partial pre & ure in reac & g mixture & & & rate (mole \\
\hline & $\mathrm{P}_{\mathrm{H} 2}$ & $\mathrm{P}_{\mathrm{CO}}$ & $\mathrm{P}_{\mathrm{CO} 2}$ & $\mathrm{P}_{\mathrm{CH} 3 \mathrm{OH}}$ & $\mathrm{P}_{\mathrm{H} 2 \mathrm{O}}$ & \\
\hline 1 & 23.6611 & 47.47184 & 10.2643 & 7.22825 & 0.100708 & 0.036951 \\
\hline 2 & 22.39149 & 48.44998 & 10.74025 & 6.54032 & 0.09771 & 0.036873 \\
\hline 3 & 22.92911 & 48.47728 & 10.64591 & 6.16146 & 0.099122 & 0.036873 \\
\hline 4 & 26.75057 & 58.83309 & 0.261214 & 4.90524 & 0.002338 & 0.057407 \\
\hline 5 & 25.59639 & 60.18043 & 0.352938 & 4.12758 & 0.002955 & 0.057324 \\
\hline 6 & 26.25064 & 57.83377 & 0.21978 & 2.97 & 0.001964 & 0.098346 \\
\hline 7 & 26.52385 & 57.85767 & 0.15642 & 2.8215 & 0.001412 & 0.098346 \\
\hline
\end{tabular}




\begin{tabular}{|c|c|c|c|c|c|c|}
\hline \multirow[t]{2}{*}{ Expt. no. } & \multicolumn{5}{|c|}{ Partial pressure in reacting mixture (atm) } & \multirow{2}{*}{$\begin{array}{l}\text { rate(mole } \\
\left.\mathrm{g}^{-1} \mathrm{~h}^{-1}\right)\end{array}$} \\
\hline & $\mathrm{P}_{\mathrm{H} 2}$ & $\mathrm{P}_{\mathrm{CO}}$ & $\mathrm{P}_{\mathrm{CO} 2}$ & $\mathrm{P}_{\mathrm{CH} 3 \mathrm{OH}}$ & $\mathrm{P}_{\mathrm{H} 2 \mathrm{O}}$ & \\
\hline 8 & 27.25414 & 56.1685 & 0.11682 & 4.5045 & 0.001116 & 0.098537 \\
\hline 9 & 27.57242 & 56.16534 & 0.08712 & 4.2867 & 0.000842 & 0.098537 \\
\hline 10 & 27.43637 & 54.68739 & 0.073778 & 6.62008 & 0.000729 & 0.098413 \\
\hline 11 & 27.53455 & 54.65099 & 0.105682 & 6.52038 & 0.001048 & 0.098413 \\
\hline 12 & 25.80793 & 58.23389 & 0.307076 & 4.00794 & 0.002679 & 0.052876 \\
\hline 13 & 23.61426 & 53.98524 & 0.382848 & 6.05179 & 0.003297 & 0.046801 \\
\hline 14 & 24.75748 & 52.78336 & 0.374872 & 6.70981 & 0.003461 & 0.046745 \\
\hline 15 & 25.63614 & 55.97083 & 4.871298 & 4.0504 & 0.043921 & 0.052479 \\
\hline 16 & 43.12371 & 39.80287 & 4.729087 & 5.71936 & 0.100859 & 0.021616 \\
\hline 17 & 21.5991 & 60.16416 & 0.28304 & 3.24032 & 0.002 & 0.059686 \\
\hline 18 & 26.15155 & 57.8314 & 0.23562 & 3.0294 & 0.002097 & 0.097692 \\
\hline 19 & 26.32651 & 57.57811 & 0.218226 & 3.23407 & 0.001964 & 0.098233 \\
\hline 20 & 27.1295 & 56.16234 & 0.13662 & 4.5837 & 0.001299 & 0.097884 \\
\hline 21 & 18.07447 & 65.23821 & 0.231988 & 2.47716 & 0.001265 & 0.067878 \\
\hline 22 & 23.37286 & 47.2388 & 0.176176 & 2.60876 & 0.001716 & 0.048809 \\
\hline 23 & 39.07473 & 33.71077 & 0.071148 & 3.60822 & 0.001623 & 0.020618 \\
\hline 24 & 16.3641 & 53.59279 & 0.1596 & 1.6128 & 0.000959 & 0.065731 \\
\hline 25 & 14.85073 & 46.44027 & 0.109824 & 1.01376 & 0.000691 & 0.098233 \\
\hline 26 & 15.17839 & 45.98898 & 0.102784 & 1.28832 & 0.000668 & 0.098253 \\
\hline
\end{tabular}




\begin{tabular}{|c|c|c|c|c|c|c|}
\hline \multirow[t]{2}{*}{ Expt. no. } & \multicolumn{5}{|c|}{ Partial pressure in reacting mixture (atm) } & \multirow{2}{*}{$\begin{array}{l}\text { rate(mole } \\
\left.\mathrm{g}^{-1} \mathrm{~h}^{-1}\right)\end{array}$} \\
\hline & $\mathrm{P}_{\mathrm{H} 2}$ & $\mathrm{P}_{\mathrm{CO}}$ & $\mathrm{P}_{\mathrm{CO} 2}$ & $\mathrm{P}_{\mathrm{CH} 3 \mathrm{OH}}$ & $\mathrm{P}_{\mathrm{H} 2 \mathrm{O}}$ & \\
\hline 27 & 26.70627 & 54.65583 & 0.259512 & 3.84353 & 0.002496 & 0.052513 \\
\hline 28 & 24.19182 & 47.08725 & 0.128066 & 2.50712 & 0.001295 & 0.052513 \\
\hline 29 & 26.04254 & 18.17773 & 0.0295 & 1.49 & 0.000832 & 0.010788 \\
\hline 30 & 25.9988 & 18.17061 & 0.0254 & 1.54 & 0.000715 & 0.010788 \\
\hline 31 & 26.2044 & 11.15081 & 7.925114 & 1.915 & 0.366614 & 0.025611 \\
\hline 32 & 37.11324 & 15.35355 & 12.96311 & 5.9812 & 0.61683 & 0.025611 \\
\hline 33 & 26.34675 & 11.23801 & 7.87404 & 1.755 & 0.363389 & 0.025611 \\
\hline 34 & 26.51445 & 8.606552 & 11.45455 & 1.27 & 0.694653 & \\
\hline 35 & 15.44279 & 13.87243 & 16.92149 & 0.635 & 0.370807 & 0.026659 \\
\hline 36 & 26.86179 & 12.69082 & 6.751975 & 1.965 & 0.281328 & 0.031318 \\
\hline 37 & 26.57701 & 13.91582 & 4.815106 & 2.23 & 0.181025 & 0.029586 \\
\hline 38 & 26.63701 & 13.94311 & 4.80367 & 2.16 & 0.180649 & 0.029688 \\
\hline 39 & 26.37333 & 15.58774 & 3.620792 & 2.525 & 0.120593 & 0.022224 \\
\hline 40 & 25.63808 & 16.4711 & 2.744082 & 2.48 & 0.084081 & 0.01628 \\
\hline 41 & 26.08267 & 17.27464 & 1.17477 & 2.66 & 0.034917 & 0.012843 \\
\hline 42 & 26.35364 & 18.75499 & 0.332431 & 2.285 & 0.009195 & 0.008732 \\
\hline 43 & 24.48028 & 53.31206 & 5.112754 & 6.17143 & 0.046215 & 0.045423 \\
\hline 44 & 27.12064 & 17.16944 & 1.469595 & 1.055 & 0.045696 & 0.065599 \\
\hline 45 & 28.72466 & 7.9083 & 11.37746 & 0.51 & 0.813492 & 0.001358 \\
\hline
\end{tabular}




\begin{tabular}{|l|l|l|l|l|l|l|}
\hline \multirow{2}{*}{ Expt.no. } & \multicolumn{5}{|l|}{ Partial pressure in reacting mixture (atm) } & \multicolumn{2}{l|}{\begin{tabular}{l} 
rate(mole \\
\cline { 3 - 6 } $\mathrm{g}^{-1} \mathrm{~h}^{-1}$
\end{tabular}} \\
\cline { 2 - 6 } & $\mathrm{P}_{\mathrm{H} 2}$ & $\mathrm{P}_{\mathrm{CO}}$ & $\mathrm{P}_{\mathrm{CO} 2}$ & $\mathrm{P}_{\mathrm{CH} 3 \mathrm{OH}}$ & $\mathrm{P}_{\mathrm{H} 2 \mathrm{O}}$ & \\
\hline 46 & 28.26576 & 10.49342 & 8.2016 & 0.63 & 0.434889 & 0.017594 \\
\hline 47 & 28.31764 & 12.25776 & 6.11422 & 0.69 & 0.27805 & 0.031063 \\
\hline 48 & 27.66529 & 16.81097 & 3.214026 & 0.91 & 0.104119 & 0.06436 \\
\hline 50 & 27.10585 & 18.34763 & 1.61544 & 0.955 & 0.04698 & 0.075925 \\
\hline 51 & 27.64567 & 18.08989 & 0.735522 & 0.93 & 0.022127 & 0.07193 \\
\hline
\end{tabular}

The data looks adequate since there are sufficient numbers of experimental runs. The results are reported up to 3 significant figures. A Varian 920 gas chromatograph was used to measure $\mathrm{H}_{2}, \mathrm{CO}$, and $\mathrm{CO}_{2}$. Known mixtures of $\mathrm{CO}$ and $\mathrm{H}_{2}$ were sampled with the GC over a range of compositions to verify the linearity of response. A Varian 1440 gas chromatograph was used to quantify hydrocarbons and methanol. The author has reported that the reproducibility of the experiments was acceptable. Exit methanol concentration remained within $2 \%$ for a given run when calculated over time.

Carbon balance calculated for each run was limited to $1 \%$. Also, constant catalytic activity was maintained throughout the experiment to ensure uniformity in the results. Calverley also showed that the experiments were essentially carried out in the kinetic regime and the external and internal mass transfer rates could be neglected at the given experimental conditions. The concentration gradient of $\mathrm{CO}$ near the catalyst surface was found to be negligibly small. Methanol yields were found to be independent 
of catalyst particle size showing that internal mass transfer rates were very small. The author also reported insignificant temperature gradients during the experiments [35].

\subsection{Parameter Estimation}

Estimation of kinetic parameters was done by fitting the rate equations shown in Section 4.1 to the experimental data shown in Section 4.2 using POLYMATH, a nonlinear regression software. The model proposed by Graaf was fit to only those data points which show low or zero $\mathrm{CO}_{2}$ inlet partial pressures while the model proposed by Rozovskii was fit to those data points where $\mathrm{CO}_{2}$ partial pressures are high in the feed. The combined rate expression was fit to the entire range of data.

A minimum of three and maximum of seven parameters were estimated including the reaction rate constants $(\mathrm{k})$ and the adsorption equilibrium constants $\left(\mathrm{K}_{\mathrm{i}}\right)$. The reaction equilibrium constants $\left(\mathrm{K}_{\mathrm{P}, \mathrm{I}}\right)$ were calculated from THERMOSOLVER software since increasing the number of parameters beyond a limit may make the model less realistic.

Table 3 shows the variables, constants and parameters estimated in this study.

Table 3. Variables, constants and parameters in this study.

\begin{tabular}{|l|l|l|}
\hline Constants & Variables & Parameters \\
\hline Temperature & $\begin{array}{l}\text { Partial pressure/product } \\
\text { composition }\end{array}$ & Reaction rate constant $(\mathrm{k})$ \\
\hline Space Velocity & Reaction rates & $\begin{array}{l}\text { Adsorption equilibrium } \\
\text { constant }\left(\mathrm{K}_{\mathrm{i}}\right)\end{array}$ \\
\hline Catalyst composition & $\begin{array}{l}\text { Reaction equilibrium } \\
\text { constant }\left(\mathrm{K}_{\mathrm{P}, \mathrm{I}}\right)\end{array}$ \\
\hline
\end{tabular}

4.5 Evaluation of Models

The goodness of fit of the kinetic models was evaluated by comparing the rates 
obtained from the model with those reported by Calverley. The statistical information and plots reported in the POLYMATH results were used to judge the quality of the developed model. The following points were used as guidelines in determining the goodness of fit of the developed kinetic model [29]:

- $\mathrm{R}^{2}$ and $\mathrm{R}_{\text {adj }}^{2}: \mathrm{R}^{2}$ and $\mathrm{R}^{2}$ adj are the correlation coefficients which determine if the model represents the experimental data precisely or not. A correlation coefficient close to one indicates an adequate regression model. They can also be used for comparing various models representing the same dependent variable.

- Variance and Rmsd: A small variance $(<0.01)$ and Rmsd usually indicate a good model. These parameters can be used for comparing various models representing the same dependent variable.

- Graph: If a plot of the calculated and measured values of the dependent variable shows different trends, it signifies an inadequate model.

- Residual plot: The residual plot showing the difference between the calculated and experimental values of the dependent variable as function of the experimental values will be used a measure of goodness of fit of the model. A randomly distributed residual plot is an indication of goodness of fit of a model. If the residuals show a clear trend, it is indicative of an inappropriate model.

- Confidence intervals: The $95 \%$ confidence intervals should be smaller and should have the same sign as the respective parameter values for a statistically good model. The guidelines are also summarized in Table 4. 
Table 4. Statistical tests for model evaluation.

\begin{tabular}{|l|l|}
\hline Statistical Parameters & Expected Behaviour \\
\hline $\mathrm{R}^{2}$ & $>0.80$ \\
\hline Confidence interval & Smaller and of same sign \\
\hline Variance & $<0.01$ \\
\hline Graph & Similar trends \\
\hline Residual Plot & Random distribution \\
\hline
\end{tabular}

\subsection{Comparison of Models}

The statistical results from POLYMATH form the basis for comparison of the kinetic models. Four main comparisons were done in this study. They are:

- Graaf's model vs. Rozovskii's model for low $\mathrm{CO}_{2}$ partial pressure data

- Graaf's model vs. Rozovskii's model for high $\mathrm{CO}_{2}$ partial pressure data

- Combined model vs. Graaf's model for entire range of data

- Combined model vs. Rozovskii's model for entire range of data

This comparative study was used to select the model that fit the experimental data best and described methanol synthesis kinetics most appropriately.

\subsection{Analysis of Results}

The results obtained from the best fit kinetic model were used to analyze the trends and aspects related to methanol synthesis. The analysis was mainly concentrated on the effect of different reaction conditions on the relative contribution of $\mathrm{CO}$ and $\mathrm{CO}_{2}$ to producing methanol. 


\subsection{Summary}

Kinetic models proposed by researchers were selected based on their efficacy in describing methanol synthesis kinetics. Experimental data reported by Calverley after evaluation was selected for the purpose of modeling. Multiple non linear regression techniques in POLYMATH were used to fit the models to the experimental data in order to determine the kinetic parameters and the goodness of fit of the models. Statistical tests in POLYMATH were used to compare the effectiveness of various models in depicting kinetics of methanol synthesis and select the best fit kinetic model. The results predicted by the most appropriate model were used in studying some kinetic features of methanol synthesis. 


\section{CHAPTER 5}

\section{RESULTS AND DISCUSSION}

\subsection{Overview}

The models were fit to the experimental kinetic data to study their effectiveness in describing methanol synthesis kinetics. Three different models were compared to select the best fit model using regression techniques. The results and data generated from the best fit model were then used to study some trends and kinetic aspects of methanol synthesis. This chapter includes the following content:

- Regression results and parameter evaluation

- Role of $\mathrm{CO} / \mathrm{CO}_{2}$ in producing methanol

\subsection{Regression Results and Parameter Evaluation}

A wide range of data including both low and high $\mathrm{CO}_{2}$ inlet partial pressures was chosen for regression so that the applicability of the kinetic models could be validated properly. The equilibrium constants for $\mathrm{CO}$ and $\mathrm{CO}_{2}$ hydrogenation reactions at the reaction temperature were calculated using the THERMOSOLVER software. They were found to be $3.88^{*} 10^{-4}$ for $\mathrm{CO}$ hydrogenation and $7.7 * 10^{-5}$ for $\mathrm{CO}_{2}$ hydrogenation reaction. The equilibrium constants were also calculated using the equations presented by Graaf et al [36]. The values were found to be very close using the two methods.

The statistical features obtained by fitting Graaf's model to low inlet $\mathrm{CO}_{2}$ partial pressure data and Rozovskii's model to high inlet $\mathrm{CO}_{2}$ partial pressure data are summarized in Table 5. 
Table 5. POLYMATH results of fitting Graaf's and Rozovskii's model.

\begin{tabular}{|c|c|c|c|c|c|c|}
\hline \multirow[t]{2}{*}{ Model } & \multicolumn{6}{|c|}{ Parameters } \\
\hline & $\mathrm{R}^{2}$ & $\mathrm{R}^{2} \mathrm{adj}$ & Variance & Rmsd & Residuals & $\begin{array}{l}95 \% \\
\text { confidence } \\
\text { intervals }\end{array}$ \\
\hline Graaf & 0.81 & 0.75 & $1.9 * 10^{-4}$ & 0.00323 & scattered & $\begin{array}{l}\text { positive, } \\
\text { smaller }\end{array}$ \\
\hline Rozovskii & 0.91 & 0.89 & $4.13 * 10^{-5}$ & 0.0016 & scattered & $\begin{array}{l}\text { positive, } \\
\text { smaller }\end{array}$ \\
\hline
\end{tabular}

The statistical features listed in Table 4 are used as indicators of the quality of the regression models. They are explained below:

- $\mathrm{R}^{2}$ and $\mathrm{R}^{2}$ adj were close to one suggesting the models satisfactorily represent the kinetic data

- Variance and Rmsd was sufficiently small to indicate that both the models represent the data accurately

- Residuals as shown in Figures B.1 and B.2 in Appendix B were randomly distributed and did not follow a particular trend signifying the models are statistically appropriate

- Confidence intervals are listed in polymath reports for both the models shown in Tables B.1 and B.2 in Appendix B. The models were statistically stable since the confidence intervals were much smaller than the respective absolute values of the parameters

The parameter values obtained from the fitting procedure are shown in Table 6. 
Table 6. Values of kinetic parameters for Graaf's and Rozovskii's model.

\begin{tabular}{|c|c|}
\hline \multicolumn{2}{|c|}{ Model } \\
\hline \multicolumn{2}{|c|}{ Graaf } \\
\hline Parameter & Value \\
\hline $\mathrm{k}_{1}\left((\mathrm{~atm} \cdot \mathrm{h})^{-1}\right)$ & 0.0535 \\
\hline $\mathrm{K}_{\mathrm{CO}}\left(\mathrm{atm}^{-1}\right)$ & 0.0022 \\
\hline $\mathrm{K}_{\mathrm{CO} 2}\left(\mathrm{~atm}^{-1}\right)$ & 0.0185 \\
\hline $\mathrm{K}_{\mathrm{wh}}\left(\mathrm{atm}^{-1}\right)$ & 1011 \\
\hline \multicolumn{2}{|c|}{ Rozovskii } \\
\hline $\mathrm{k}_{3}\left((\mathrm{~atm} \cdot \mathrm{h})^{-1}\right)$ & 0.0031 \\
\hline $\mathrm{K}_{-2}\left(\mathrm{~atm}^{-1}\right)$ & 5.104 \\
\hline $\mathrm{K}_{1}\left(\mathrm{~atm}^{-1}\right)$ & 9.978 \\
\hline
\end{tabular}

The graphical representation of the results is shown in Figures 6 and 7.

Figure 6 shows a comparison of experimental values of rate and those calculated from Graaf's model when the inlet $\mathrm{CO}_{2}$ partial pressures were negligibly small.

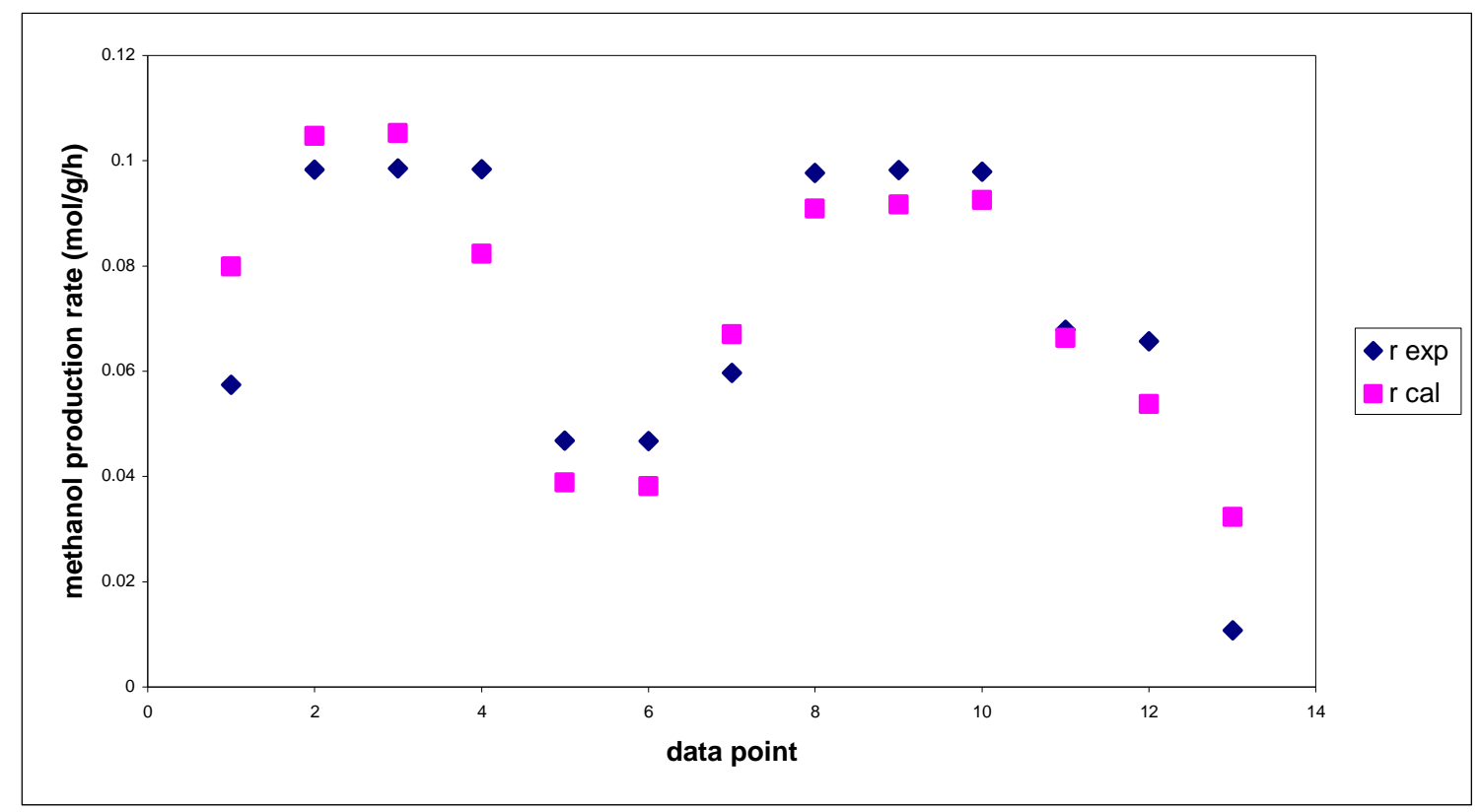

Figure 6. Comparison of experimental and predicted (by Graaf's model) methanol production rate. 
Figure 6 shows that the model proposed by Graaf which was based on $\mathrm{CO}$ being the primary reactant, fit to the data well where $\mathrm{CO}_{2}$ feed partial pressures were very low. The experimental and estimated rates matched each other quite closely, thereby confirming the hypothesis. Figure 7 shows a comparison of experimental and calculated values of rate for Rozovskii's model for high $\mathrm{CO}_{2}$ partial pressure data. The residual plots for both the regression models are shown in Figures B.1 and B.2 in Appendix B. Also, the polymath reports summarizing the statistical features of the regression are shown in Tables B.1 and B.2 in Appendix B.

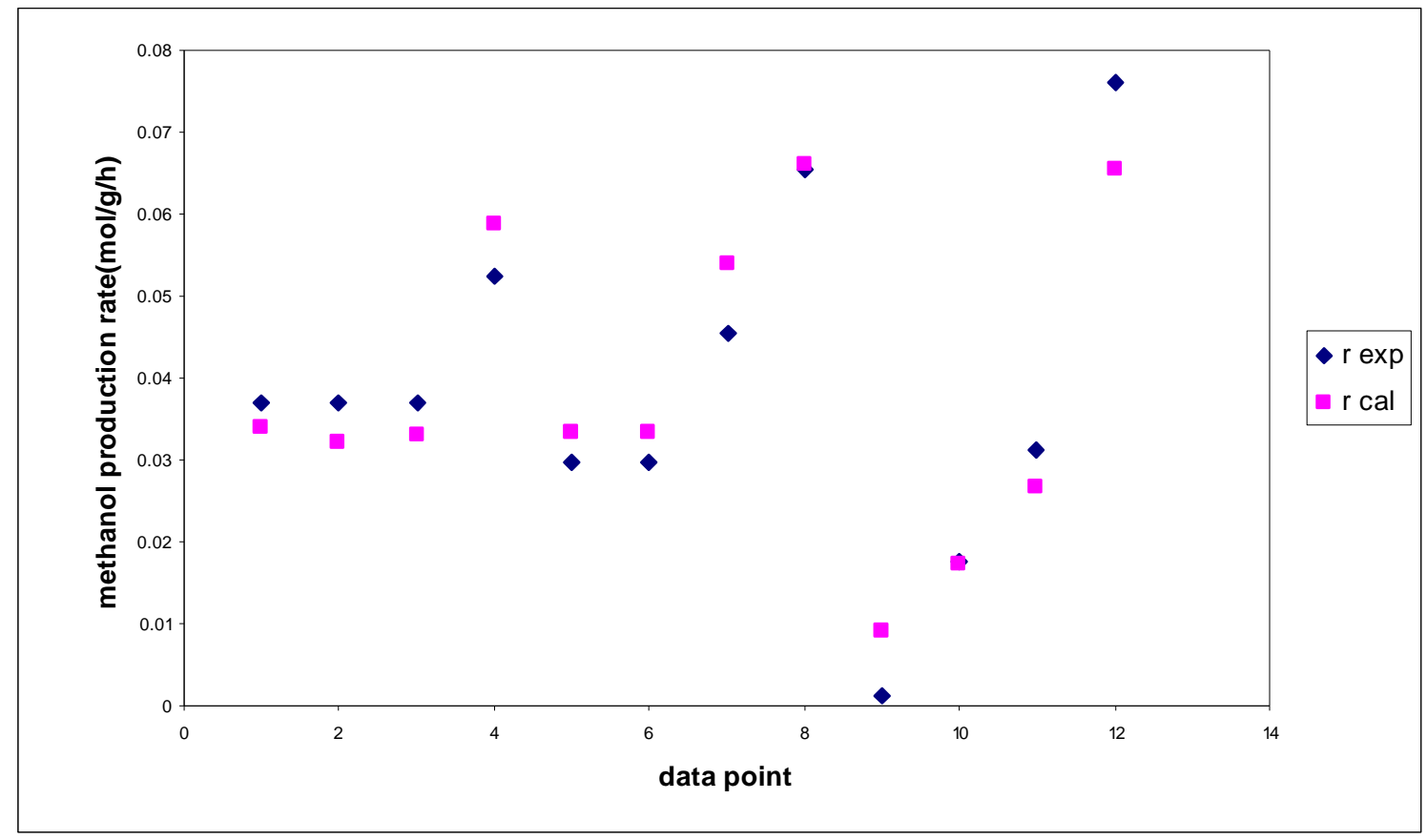

Figure 7. Comparison of experimental and predicted (by Rozovskii's model) methanol production rate.

For $\mathrm{CO}_{2}$ enriched feed, Rozovskii's model that was derived assuming $\mathrm{CO}_{2}$ to be the main reactant, provided an effective kinetic description of the methanol synthesis 
process. As shown in Figure 7, the rates estimated from Rozovskii's model are in good agreement with the experimental rate values.

Both the models were fit to low and high inlet $\mathrm{CO}_{2}$ partial pressure data in order to compare the effectiveness of each for the given range of data. Figure 8 shows a comparison of experimental values of rate and those calculated by Graaf's model and Rozovskii's model when $\mathrm{CO}_{2}$ partial pressures were negligibly small in the feed.

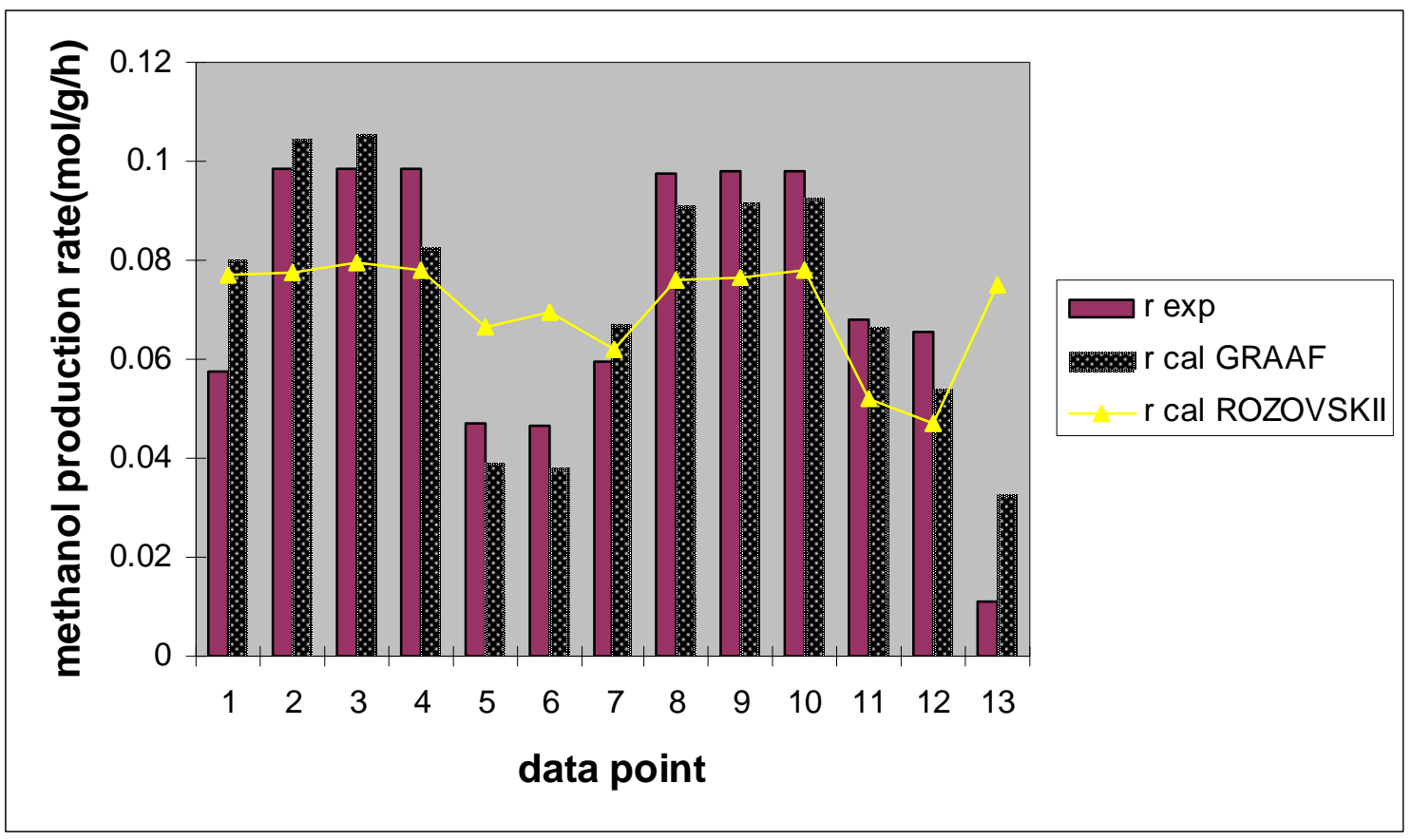

Figure 8. Comparison of experimental methanol production rate and those predicted by Graaf's and Rozovskii's models at low $\mathrm{CO}_{2}$ inlet partial pressures.

Line column charts have been used to represent the data since it is easier to read the data with these plots. The trend in Figure 8 on the next page shows that Graaf's model fit better to the experimental data than Rozovskii's model when $\mathrm{CO}_{2}$ was in negligible amounts in the feed. Figure 9 shows a comparison of experimental rate values 
and rate values estimated from Graaf's and Rozovskii's models when the $\mathrm{CO}_{2}$ partial pressures were high in the feed.

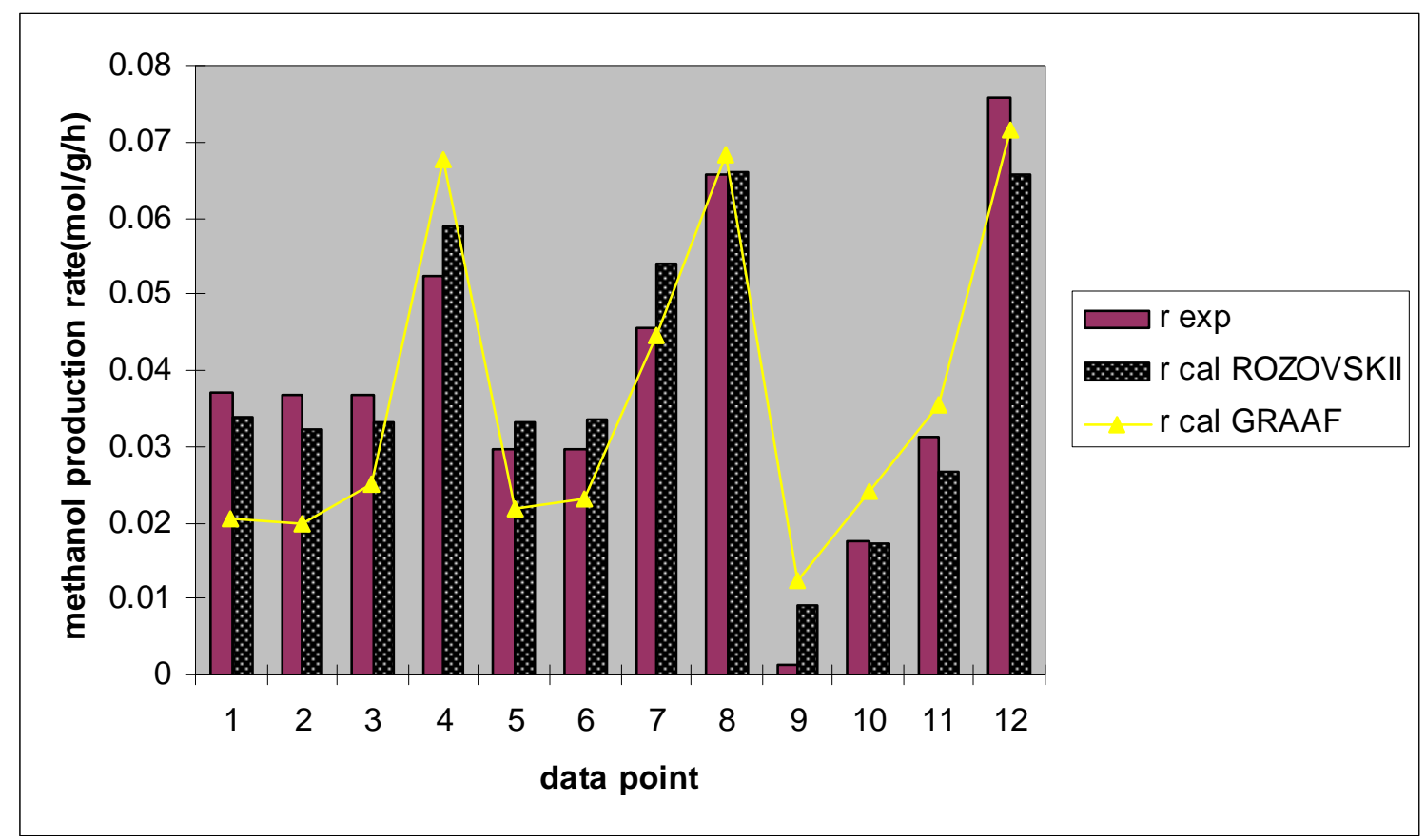

Figure 9. Comparison of experimental methanol production rate and those predicted by Graaf's and Rozovskii's models at high $\mathrm{CO}_{2}$ inlet partial pressures.

It can be observed that in this case, Rozovskii's model provided a better kinetic description of the process. Rozovskii's model that was based on treating $\mathrm{CO}_{2}$ as the primary reactant does not match the low $\mathrm{CO}_{2}$ content data at all. However, when $\mathrm{CO}_{2}$ content in the feed was high, both Graaf's and Rozovskii's model fit to the experimental data satisfactorily. The rates calculated by Graaf also followed the experimental data points closely, though not as close as the rates estimated by Rozovskii's model. This 
feature was also observed by Rozovskii in his study. The models proposed by him fit to the experimental results better when $\mathrm{CO}_{2}$ amounts were higher in the feed [19].

The combined rate expression by summing equations 1 and 2 can be written

as,

$$
r_{1}=\frac{k_{1} K_{C O}\left[f_{C O} f_{H_{2}}{ }^{3 / 2}-f_{C_{3} O H} /\left(f^{1 / 2}{ }_{H_{2}} K_{e q, 1}\right)\right]}{\left(1+K_{C O} f_{C O}+K_{\mathrm{CO}_{2}} f_{\mathrm{CO}_{2}}\right)\left[f_{\mathrm{H}_{2}}{ }^{1 / 2}+\left(K_{\mathrm{H}_{2} \mathrm{O}} / k_{\mathrm{H}_{2}}{ }^{1 / 2}\right) f_{\mathrm{H}_{2} \mathrm{O}}\right]}+\frac{k_{3} p_{\mathrm{H}_{2}}\left(1-\frac{p_{m} p_{\mathrm{H}_{2} \mathrm{O}}}{K_{p(m)} p_{\mathrm{H}_{2}} p_{\mathrm{CO}_{2}}}\right)}{1+K_{-2} p_{\mathrm{H}_{2} \mathrm{O}}+K_{-2} p_{\mathrm{H}_{2} \mathrm{O}} /\left(K_{1} p_{C O_{2}}\right)}
$$

Equation (4)

The parameters in this expression were fit to the entire range of experimental data including low as well as high $\mathrm{CO}_{2}$ inlet partial pressures. Figure 10 shows a comparison of experimental values of rate and rates estimated form the combined model.

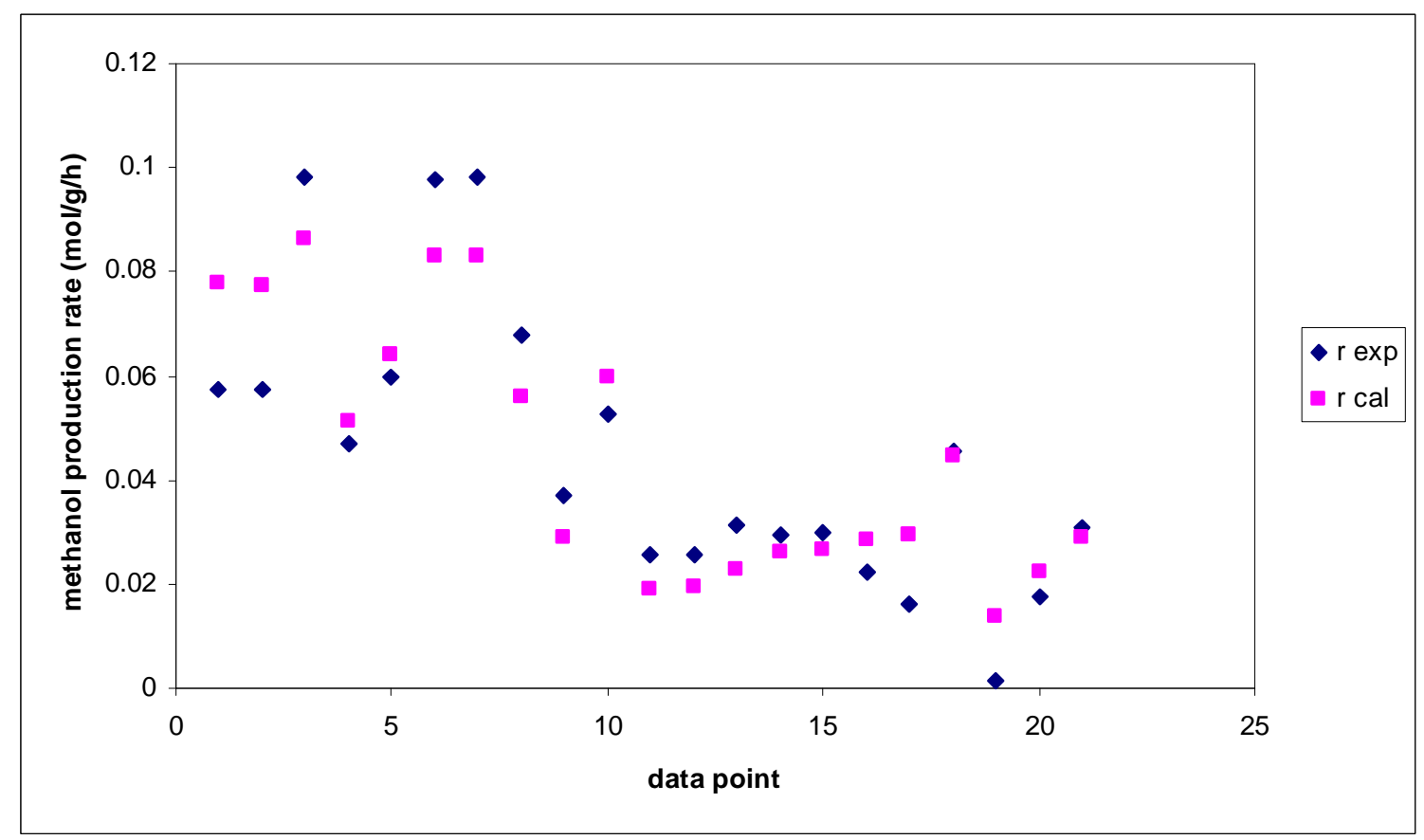

Figure 10. Comparison of experimental values of methanol production rate and rates estimated form the combined model. 
The graph shows a good agreement between the experimental and simulated data. The kinetic parameters obtained from fitting this expression are listed in Table 7. The residual plot is shown in Figure B.3 in Appendix B. A polymath report showing the statistical features of the regression in detail is listed in Table B.3 in Appendix B.

Table 7. Values of kinetic parameters obtained from fitting the combined rate equation.

\begin{tabular}{|l|l|}
\hline Parameter & Value \\
\hline $\mathrm{k}_{1}\left((\mathrm{~atm} \cdot \mathrm{h})^{-1}\right)$ & 0.0232 \\
\hline $\mathrm{K}_{\mathrm{CO}}$ & 0.0024 \\
\hline $\mathrm{K}_{\mathrm{CO} 2}$ & 0.0625 \\
\hline $\mathrm{K}_{\mathrm{wh}}$ & 11.099 \\
\hline $\mathrm{k}_{3}\left((\mathrm{~atm} \cdot \mathrm{h})^{-1}\right)$ & 0.0009 \\
\hline $\mathrm{K}_{-2}$ & 0.0032 \\
\hline $\mathrm{K}_{1}$ & 0.0226 \\
\hline
\end{tabular}

As mentioned in Section 4.5, four main comparisons are done in this study. The data set used for fitting to the combined model was also fit to Graaf's and Rozovskii's model separately. The comparison of the experimental rate values and those estimated from the combined kinetic rate expression as well as from Graaf's and Rozovskii's models is shown in Figure 11. The degree of fit obtained with a model was very sensitive to the initial parameter value guesses, so attempts were made with a variety of initial guess combinations. 


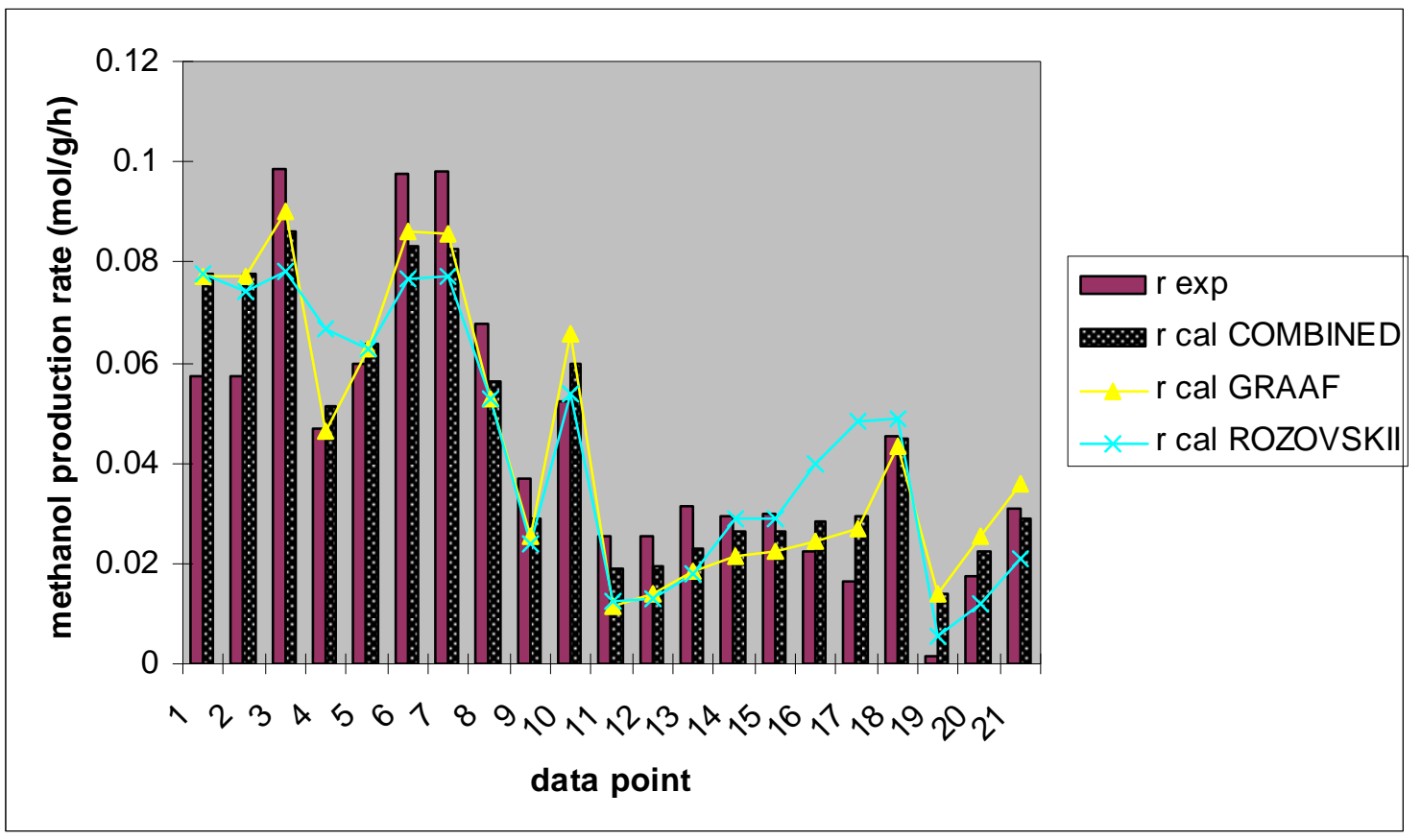

Figure 11. Comparison of experimental methanol production rate values and those estimated from the combined kinetic rate expression and Graaf's and Rozovskii's models.

The trend in Figure 11 suggests that the combined rate expression fits to the experimental data better than the individual models. Although, the rates calculated from Graaf's model are also in good agreement with the experimental rate values, it is the combined rate expression which gives the best results. The results of fitting for the four comparisons are tabulated in Table 8. 
Table 8. POLYMATH results of fitting for the comparative study of models.

\begin{tabular}{|c|c|c|c|c|c|c|}
\hline \multicolumn{7}{|c|}{ low $\mathrm{CO}_{2}$ partial pressure } \\
\hline Parameter & \multirow[t]{2}{*}{$\mathrm{R}^{2}$} & \multirow[t]{2}{*}{$\mathrm{R}^{2} \mathrm{adj}$} & \multirow[t]{2}{*}{ Variance } & \multirow[t]{2}{*}{ Rmsd } & \multirow[t]{2}{*}{ Residuals } & \multirow{2}{*}{$\begin{array}{l}95 \% \\
\text { confidence } \\
\text { intervals }\end{array}$} \\
\hline Model & & & & & & \\
\hline Graaf & 0.81 & 0.75 & $1.9 * 10^{-4}$ & 0.00323 & scattered & $\begin{array}{l}\text { positive, } \\
\text { smaller }\end{array}$ \\
\hline Rozovskii & 0.106 & -0.67 & $8.5^{*} 10^{-4}$ & 0.0071 & $\begin{array}{l}\text { follow a } \\
\text { trend }\end{array}$ & $\begin{array}{l}\text { positive, } \\
\text { smaller }\end{array}$ \\
\hline \multicolumn{7}{|c|}{ high $\mathrm{CO}_{2}$ partial pressure } \\
\hline & $\mathrm{R}^{2}$ & $\mathrm{R}^{2} \mathrm{adj}$ & Variance & Rmsd & Residuals & $\begin{array}{l}95 \% \\
\text { confidence } \\
\text { intervals }\end{array}$ \\
\hline Graaf & 0.71 & 0.60 & $1.5^{*} 10^{-4}$ & 0.0029 & scattered & $\begin{array}{l}\text { positive, } \\
\text { smaller }\end{array}$ \\
\hline Rozovskii & 0.91 & 0.89 & $4.13 * 10^{-5}$ & 0.0016 & scattered & $\begin{array}{l}\text { positive, } \\
\text { smaller }\end{array}$ \\
\hline \multicolumn{7}{|l|}{ entire range } \\
\hline & $\mathrm{R}^{2}$ & $\mathrm{R}^{2} \mathrm{adj}$ & Variance & Rmsd & Residuals & $\begin{array}{l}95 \% \\
\text { confidence } \\
\text { intervals }\end{array}$ \\
\hline Combined & 0.85 & 0.78 & $1.6^{*} 10^{-4}$ & 0.0022 & scattered & $\begin{array}{l}\text { positive, } \\
\text { smaller }\end{array}$ \\
\hline Graaf & 0.82 & 0.79 & $1.5^{*} 10^{-4}$ & 0.0024 & scattered & $\begin{array}{l}\text { positive, } \\
\text { smaller }\end{array}$ \\
\hline \multicolumn{7}{|c|}{ entire range } \\
\hline & $\mathrm{R}^{2}$ & $\mathrm{R}^{2} \mathrm{adj}$ & Variance & Rmsd & Residuals & $\begin{array}{l}95 \% \\
\text { confidence } \\
\text { intervals }\end{array}$ \\
\hline Combined & 0.85 & 0.78 & $1.6 * 10^{-4}$ & 0.0022 & scattered & $\begin{array}{l}\text { positive, } \\
\text { smaller }\end{array}$ \\
\hline Rozovskii & 0.68 & 0.64 & $2.6^{*} 10^{-4}$ & 0.0033 & scattered & $\begin{array}{l}\text { positive, } \\
\text { smaller }\end{array}$ \\
\hline
\end{tabular}

The statistical parameters listed in Table 8 as well as the trend in Figure 11 indicate that the combined model is the best fit model. Based on the above mentioned results, it can be concluded that the combined rate expression which includes both $\mathrm{CO}$ and $\mathrm{CO}_{2}$ hydrogenation rate terms describes methanol synthesis kinetics in the best 
possible manner. It was also attempted to fit the combined model separately to low and high inlet $\mathrm{CO} 2$ partial pressure data, however, there were not enough data points in the two ranges to achieve proper regression results.

\subsection{Role of $\mathrm{CO} / \mathrm{CO}_{2}$ in Producing Methanol}

A number of kinetic models have been proposed in the literature attempting to describe methanol synthesis kinetics. However, the controversies regarding the carbon source in methanol and the nature of active sites still remain unsolved. An effort, therefore, was made in this study to come up with a model that can adequately describe some features and resolve questions related to methanol synthesis kinetics. The model proposed in this study is based on the fact that $\mathrm{CO}$ and $\mathrm{CO}_{2}$ hydrogenation both contribute to overall methanol production.

However, the relative contribution of $\mathrm{CO}$ and $\mathrm{CO}_{2}$ hydrogenation in producing methanol cannot be generalized. Instead, the question regarding the main source of carbon in methanol depends on specific conditions like conversion, pressure, relative amount of $\mathrm{CO}$ and $\mathrm{CO}_{2}$, as well as hydrogen content in the feed. The results have been discussed under the following conditions:

- Conversion

- Hydrogen content in the feed

- Pressure

- $\mathrm{CO} / \mathrm{CO}_{2}$ content in the feed 


\subsubsection{Conversion}

Figure 12 shows the Gibb's free energy change of hydrogenation of $\mathrm{CO}$ and $\mathrm{CO}_{2}$ to methanol as a function of temperature. It can be observed that $\mathrm{CO}_{2}$ hydrogenation has more negative $\Delta \mathrm{G}$ and thus a higher driving force at very low conversions whereas $\mathrm{CO}$ hydrogenation is more likely to occur at higher conversions at a temperature of $558 \mathrm{~K}$.

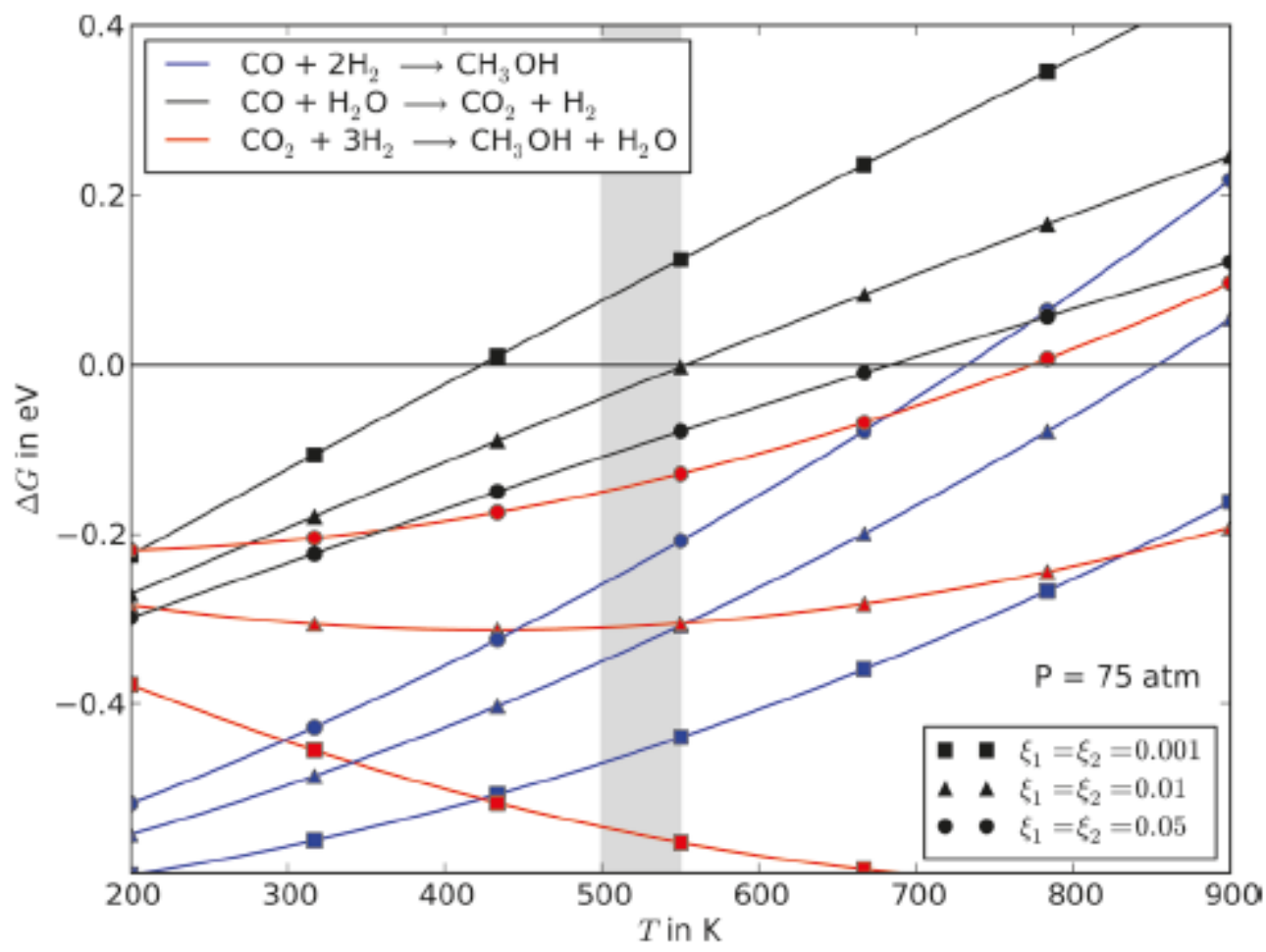

Figure 12. Gibb's free energy change, $\Delta \mathrm{G}$, for $\mathrm{CO}$ and $\mathrm{CO}_{2}$ hydrogenation to $\mathrm{CH}_{3} \mathrm{OH}$ and the WGS reaction at $\mathrm{P}=75 \mathrm{~atm}$ and three different conversion levels as a function of temperature (Reprinted with permission from [34]).

These results from thermodynamics prove that conversion levels can affect the extent to which $\mathrm{CO}$ and $\mathrm{CO}_{2}$ hydrogenation will contribute in producing methanol. We could not show the same behavior using our results since not enough data points were available at a constant feed composition and the conversions did not vary much in orders 
of magnitude. A similar result was reported by Liu et al. in their study in which they showed that hydrogenation of $\mathrm{CO}_{2}$ was the primary reaction in producing methanol at low conversion [15].

\subsubsection{Hydrogen Content in Feed}

Grabow and Mavrikakis have reported that hydrogen content in the feed can have a marked effect on methanol production rates for $\mathrm{CO}$ rich feeds [34]. Methanol production rate decreases almost linearly with increasing $\mathrm{CO}_{2}$ content in the feed when the feed is lean in $\mathrm{H}_{2}(<50 \%)$. A similar trend was predicted by our model. Figure 13 shows a plot of methanol synthesis rate and $\% \mathrm{CO}_{2}$ in the feed under lean $\mathrm{H}_{2}$ conditions.

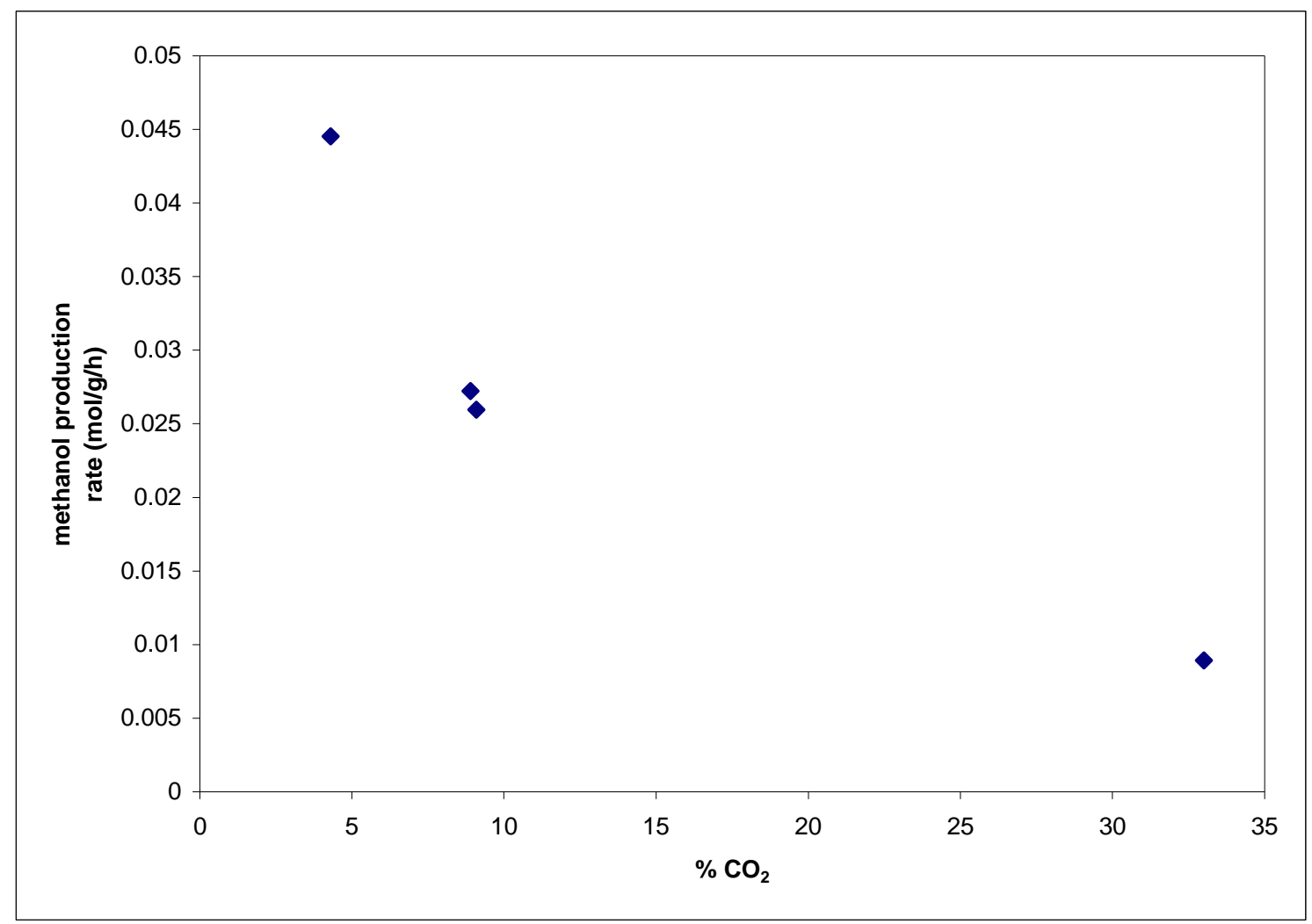

Figure 13. Plot of methanol synthesis rate and $\% \mathrm{CO}_{2}$ in the feed under lean $\mathrm{H}_{2}$ conditions. 
It was observed that the rate decreased linearly as $\mathrm{CO}_{2}$ content in the feed increased. This behavior can be attributed the fact that hydrogenation of one mole of $\mathrm{CO}$ to methanol needs two moles of $\mathrm{H}_{2}$ compared to $\mathrm{CO}_{2}$ which needs three moles of $\mathrm{H}_{2}$ to form methanol. Therefore, under lean hydrogen conditions, $\mathrm{CO}$ hydrogenation activity is increased. However, as $\mathrm{CO}_{2} \%$ in the feed increased, the overall rate decreased since $\mathrm{CO}$ hydrogenation was inhibited by increased amounts of $\mathrm{CO}_{2}$ in the feed. Also, since there was no water in the feed in the beginning, $\mathrm{CO}_{2}$ participated competitively in methanol synthesis as well as RWGS resulting in lower methanol production.

At a pressure of 50 atm, when hydrogen in the feed was increased slightly, the overall rate showed a maximum value at $\mathrm{CO}_{2} /\left(\mathrm{CO}+\mathrm{CO}_{2}\right)=0.036($ encircled in Figure 14) as predicted by the model developed in this study. Calverley and Smith reported similar results in their study. However, they observed the maxima when $0.05<\mathrm{CO}_{2} /\left(\mathrm{CO}+\mathrm{CO}_{2}\right)<$ 0.2 [35]. In our study, hydrogen content in the feed never increased beyond $60 \%$. But at lower pressures (50 atm in our case), less hydrogen may be needed in the feed for the rate to increase with increasing $\mathrm{CO}_{2}$ amounts. Figure 14 shows the overall rate plotted as function of $\mathrm{CO}_{2} \%$ at a pressure of 50 atm. 


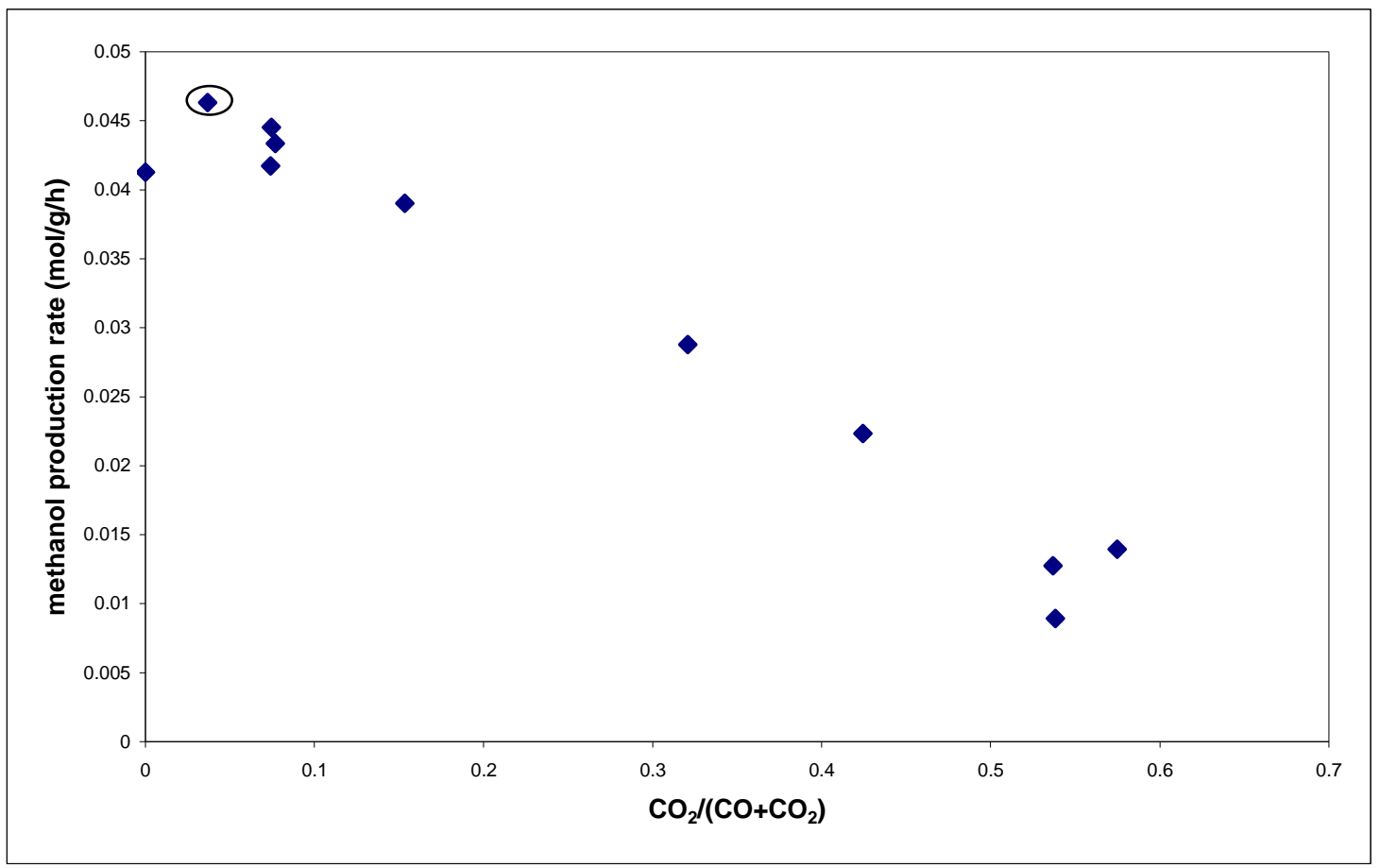

Figure 14. Plot of overall rate as function of $\% \mathrm{CO}_{2}$ at a pressure of $50 \mathrm{~atm}$.

Therefore, at 50 atm and $\mathrm{H}_{2}$ content of around $56 \%$ in the feed, overall methanol synthesis rate showed an increase in value as $\% \mathrm{CO}_{2}$ increased but it decreased again possibly due to adsorption of $\mathrm{CO}_{2}$ on active $\mathrm{Cu}$ sites necessary for $\mathrm{CO}$ activation. This behavior showing maximum rate a particular value of $\mathrm{CO}_{2} \%$ has been reported by other authors as well like Klier et al. McNeil et al., and Lim et al. [2, 14,and 18].

\subsubsection{Pressure}

Total pressure also affects the relative contribution from $\mathrm{CO}$ and $\mathrm{CO}_{2}$ in producing methanol. Figure 15 shows the relative contribution of $\mathrm{CO}$ and $\mathrm{CO}_{2}$ at a pressure of 50 atm calculated using the results from our model. 


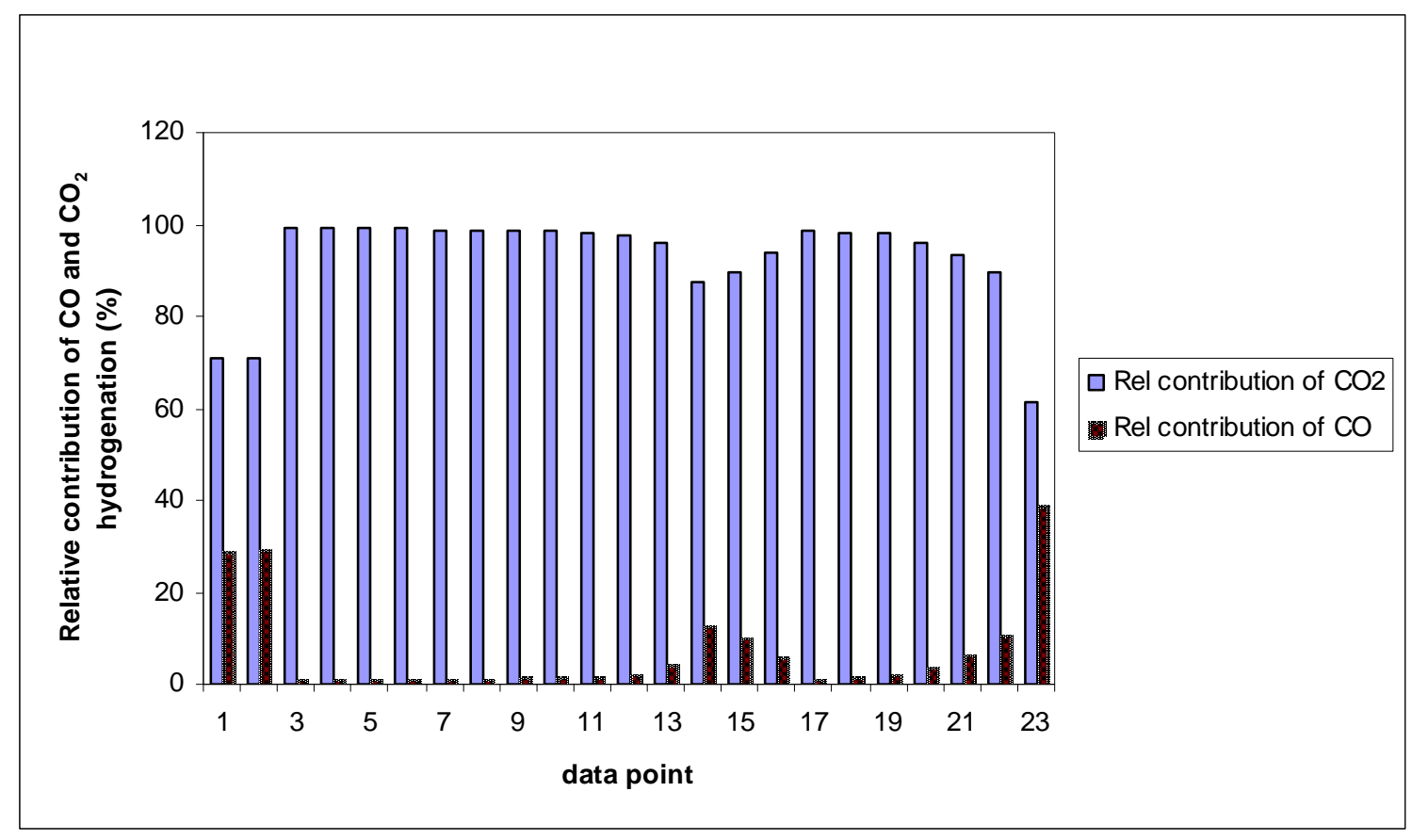

Figure 15. Plot of the relative contribution of $\mathrm{CO}$ and $\mathrm{CO}_{2}$ at a pressure of $50 \mathrm{~atm}$.

The plot clearly shows that $\mathrm{CO}_{2}$ contributes more than $\mathrm{CO}$ to methanol production at a low pressure of $50 \mathrm{~atm}$. A higher pressure of $99 \mathrm{~atm}$ was also reported in the experimental data. However, comparisons could not be made since there was insufficient number of data points where $\mathrm{CO}_{2}$ was present in the feed and the pressure was high. The effect of pressure on the relative contribution of $\mathrm{CO} / \mathrm{CO}_{2}$ hydrogenation to methanol synthesis can be explained using Le Chatelier's principle. Le Chatelier's principle states that "if a chemical system at equilibrium experiences a change in concentration, temperature, volume or pressure, then the equilibrium shifts to counteract the imposed change and a new equilibrium is established [38]." During CO hydrogenation, three moles of $\mathrm{CO}$ react to form one mole of product, whereas, during $\mathrm{CO}_{2}$ hydrogenation, four 
moles of $\mathrm{CO}_{2}$ react to form two moles of product. When the pressure was high, $\mathrm{CO}$ hydrogenation was favored since it is the pathway which results in lower compression.

\subsection{4 $\mathrm{CO} / \mathrm{CO}_{2}$ Content in the Feed}

Figure 16 shows a comparison between rates calculated from the combined model and those calculated from the $\mathrm{CO}$ hydrogenation model described in the previous sections when $\% \mathrm{CO}_{2}$ in the feed was zero.

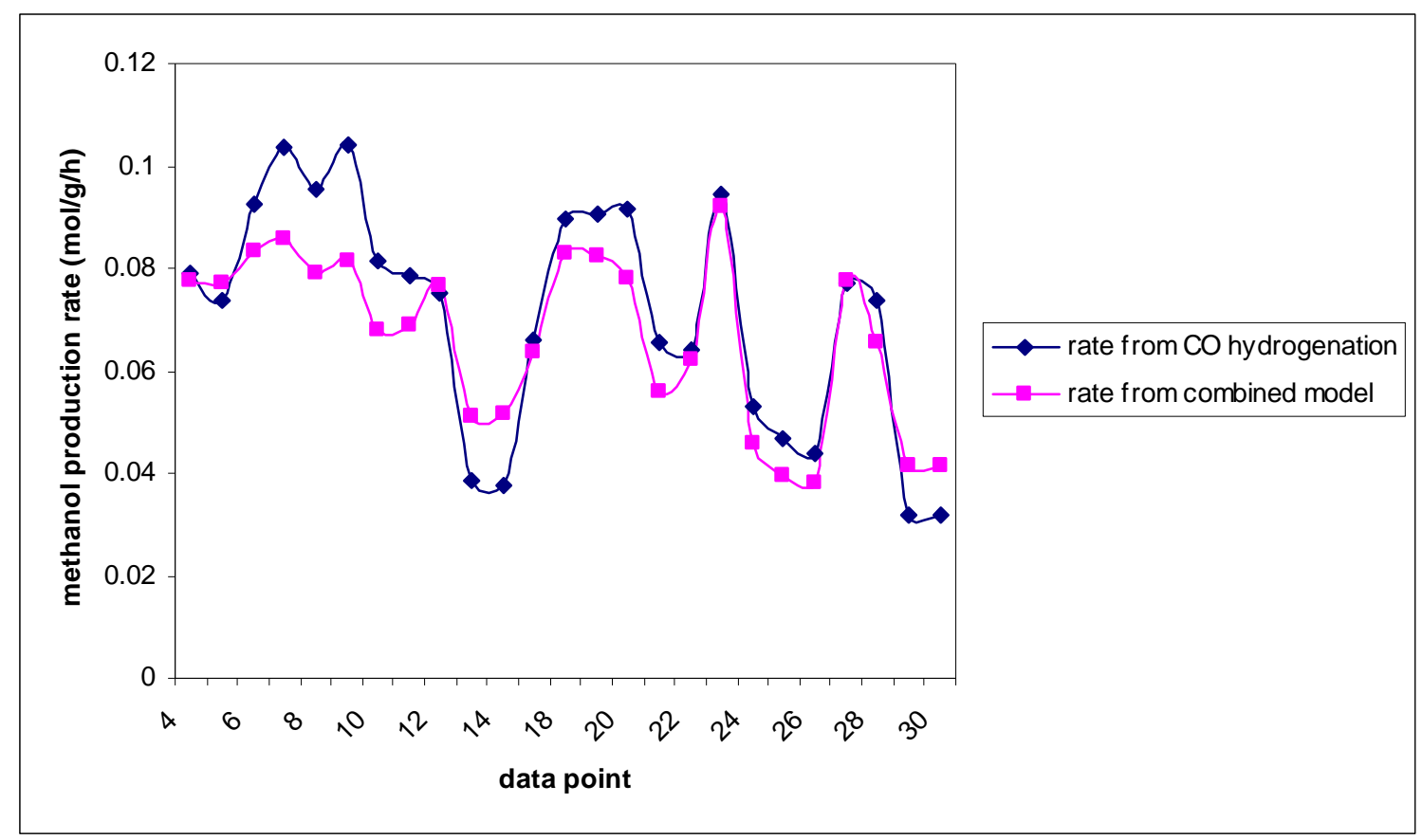

Figure 16. Plot of rates calculated from combined model and $\mathrm{CO}$ hydrogenation model when $\% \mathrm{CO}_{2}$ in feed $=0$.

The values of rates were quite close to each other suggesting the fact that in the absence of $\mathrm{CO}_{2}$, the entire methanol was produced entirely from $\mathrm{CO}$. The deviations could be a result of inadequate fitting of the models.

Results obtained from the combined model form the basis of studying a few trends related to methanol synthesis kinetics. Figure 17 shows overall rate plotted as a function of $\% \mathrm{CO}$ in the feed in the absence of $\mathrm{CO}_{2}$. 


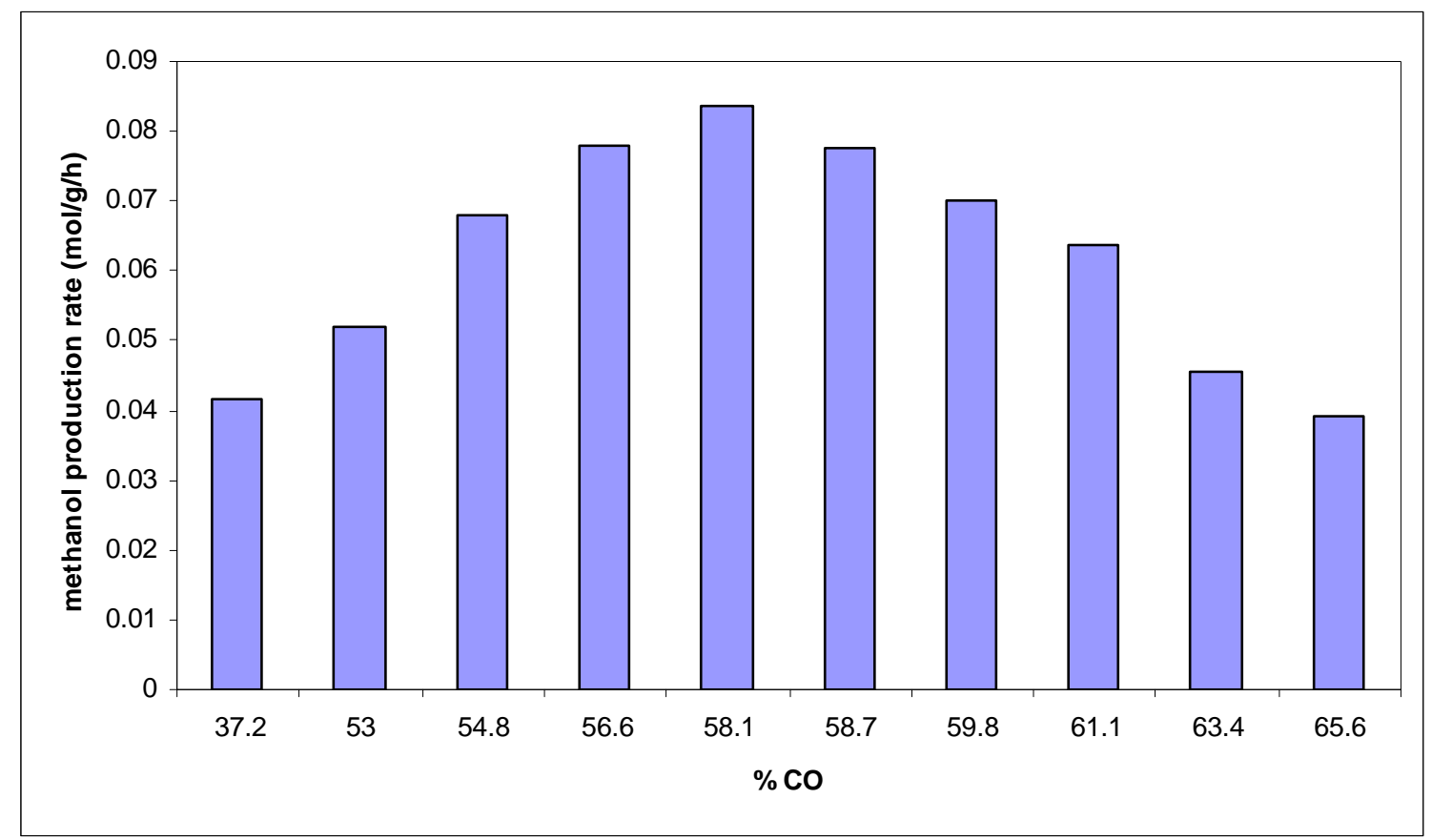

Figure 17. Plot of overall methanol synthesis rate as a function of $\% \mathrm{CO}$ in feed when $\%$ $\mathrm{CO}_{2}$ in feed $=0$.

The rate increased as $\mathrm{CO}$ amount in the feed increased, while it decreased when $\% \mathrm{CO}$ increased beyond $58 \%$. The increasing trend has also been shown by other authors, e.g., McNeil et al. [18], as shown in Figure 18. 


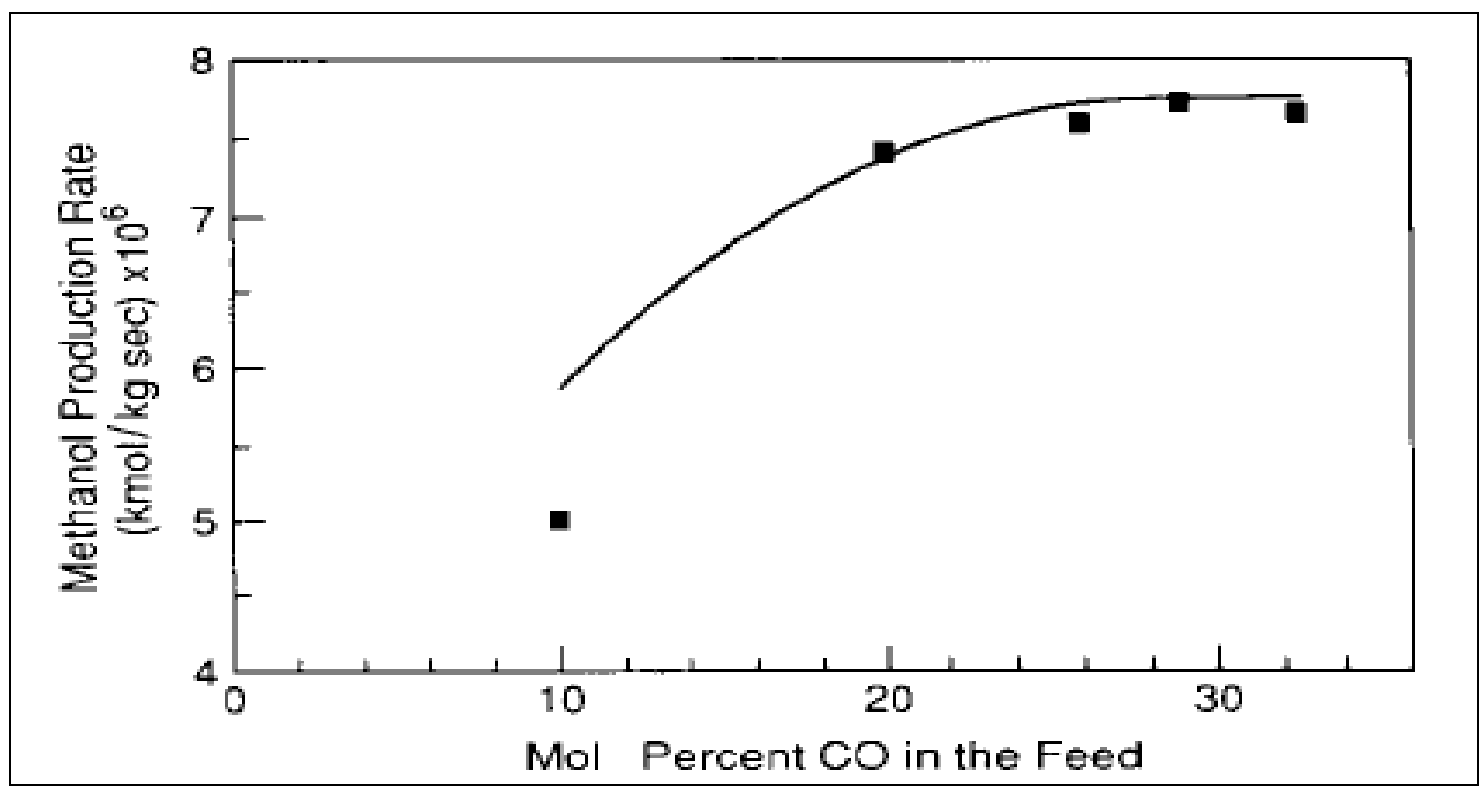

Figure 18. Predicted (-) compared to experimental (-) methanol production rate versus mole percent carbon monoxide in the feed at $513 \mathrm{~K}$ and 2.89/4.38 MPa (Reprinted with permission from [18]).

The decreasing trend can be explained by using the fact that in the absence of $\mathrm{CO}_{2}$, catalyst deactivation occurs via the Boudouard reaction resulting in carbon deposition and, therefore, decreasing methanol synthesis rate. The Boudouard reaction can be written as [39]:

$$
2 \mathrm{CO}(\mathrm{g}) \longleftrightarrow \mathrm{CO}_{2}(\mathrm{~g})+\mathrm{C}(\mathrm{s}) \quad \text { Reaction (4) }
$$

As amount of $\mathrm{CO}$ increased, the reaction proceeded in the forward direction at a faster rate leading to more carbon deposition and fouling of the catalyst, and therefore, reducing methanol production rates. The volcanic shape of the plot shown in Figure 17 has also been reported by Grabow and Mavrikakis [34]. They observed a volcano-shaped curve when methanol production was plotted as a function of $\mathrm{CO}_{2} /\left(\mathrm{CO}+\mathrm{CO}_{2}\right)$ feed ratio for CO- rich feeds [34]. 
Another trend predicted by our model is that the contribution from $\mathrm{CO}$ hydrogenation to forming methanol decreased as $\% \mathrm{CO}_{2}$ increased. The relative contribution from $\mathrm{CO}$ hydrogenation in synthesizing methanol plotted as a function of $\%$ $\mathrm{CO}_{2}$ is shown in Figure 19.

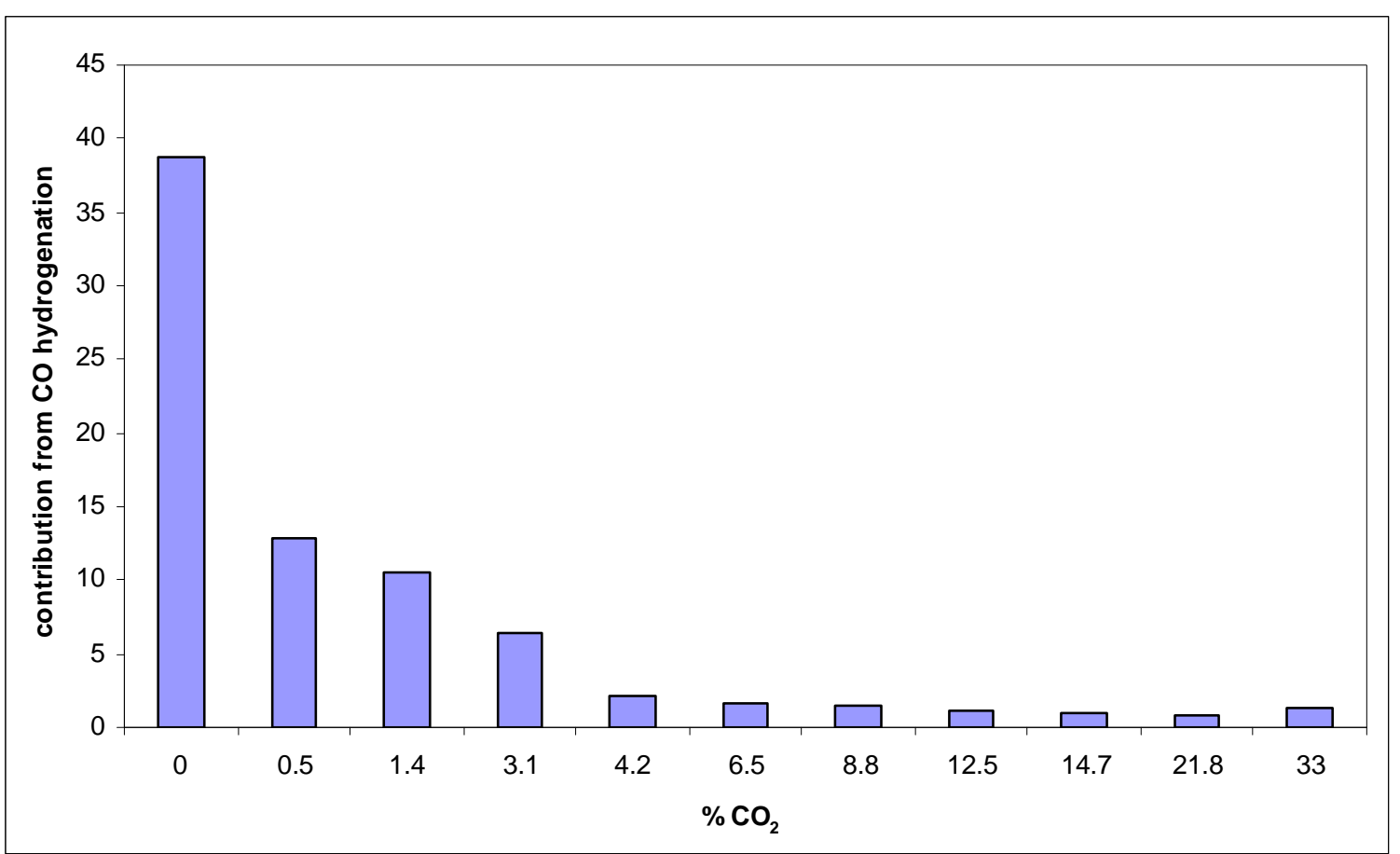

Figure 19. Plot of relative contribution of $\mathrm{CO}$ hydrogenation vs. $\% \mathrm{CO}_{2}$ in the feed.

The plot shows expected behavior since a high $\mathrm{CO}_{2}$ content can lead to inhibition of $\mathrm{CO}$ hydrogenation due to the strong adsorption of $\mathrm{CO}_{2}$ on active $\mathrm{Cu}$ sites necessary for $\mathrm{CO}$ activation.

It has been predicted by our model that the major fraction of methanol resulted from $\mathrm{CO}_{2}$ hydrogenation, as shown in Figure 20. 


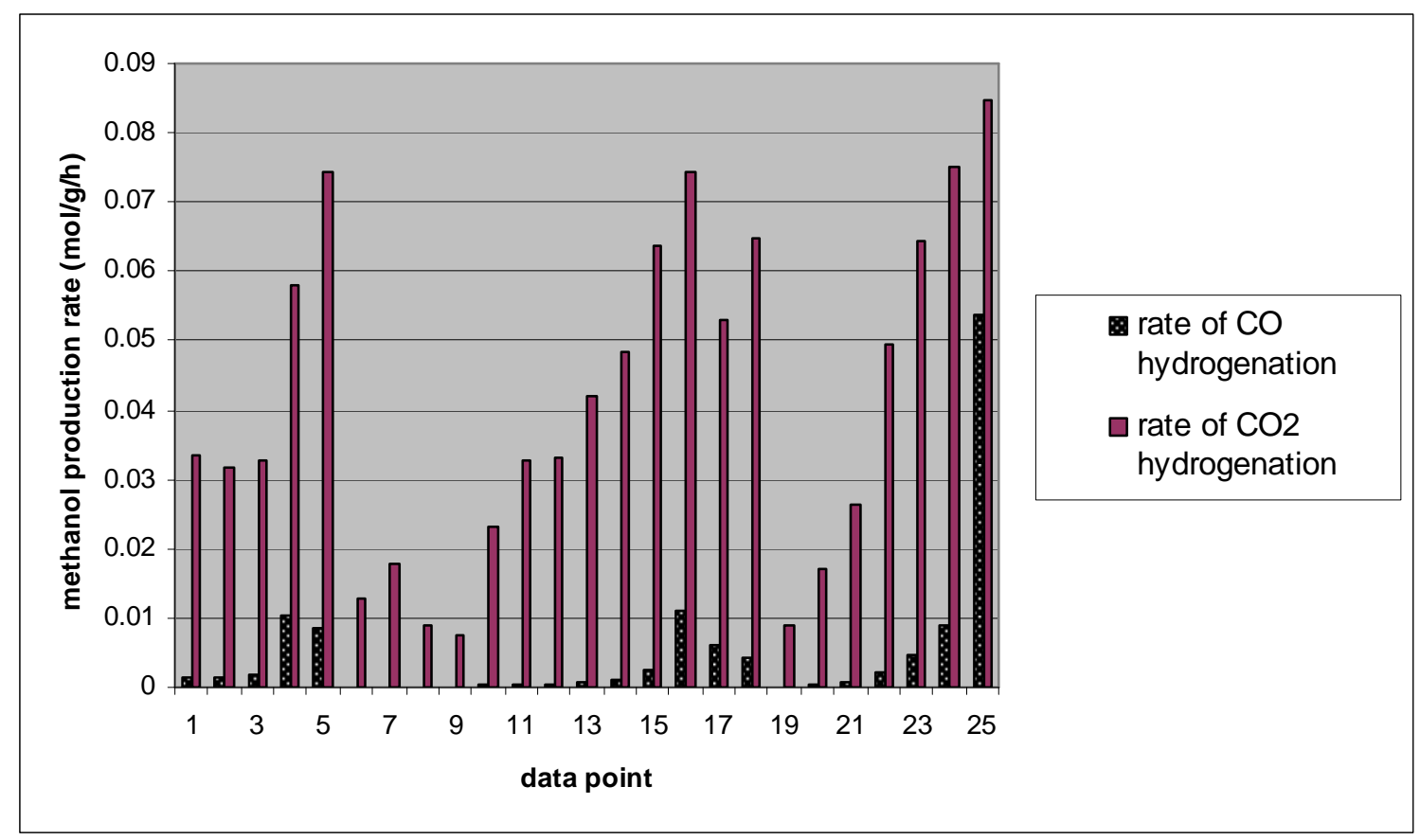

Figure 20. Comparison of $\mathrm{CO}$ and $\mathrm{CO}_{2}$ hydrogenation rate.

Sahibzada et al. also showed that the intrinsic rate of $\mathrm{CO}_{2}$ hydrogenation was twenty times faster than $\mathrm{CO}$ hydrogenation and at $\mathrm{CO}_{2}>1 \%$, it was the main source of methanol production [21]. This aspect was also studied by Grabow and Mavrikakis who showed that larger fraction of methanol was formed from $\mathrm{CO}_{2}$. However, they used a different feed composition [34].

\subsection{Summary}

Based on the regression results from POLYMATH, the combined model proposed in this study was selected to be the best fit kinetic model that describes methanol synthesis kinetics most appropriately. Predictions from this model have been successfully used to explain the trends related to methanol synthesis kinetics. It can be concluded that no generalization can be made regarding the carbon source in methanol. 
Instead, the relative contribution of $\mathrm{CO} / \mathrm{CO}_{2}$ hydrogenation in methanol production depends on various reaction conditions like conversion, pressure, $\mathrm{CO} / \mathrm{CO}_{2}$, and hydrogen content in the feed. Therefore, experimental data and results should be cautiously extrapolated and interpreted from low pressure/low conversion laboratory conditions to high pressure/high conversion industrial conditions. 


\section{CHAPTER 6}

\section{CONCLUSION}

This study comprised of investigating various kinetic models proposed in literature for methanol synthesis and selecting the most appropriate model using regression techniques. POLYMATH software was the non-linear regression tool used in fitting different models to published experimental data collected at a temperature of 558 $\mathrm{K}$ and pressures of 50 and 100 atm over a $\mathrm{Cu} / \mathrm{ZnO} / \mathrm{Cr}_{2} \mathrm{O}_{3}$ catalyst. The results of fitting revealed that the combined model including both $\mathrm{CO}$ and $\mathrm{CO}_{2}$ hydrogenation rate terms was the best fit model, thereby confirming the hypothesis made in this research. A kinetic model like this one that can describe methanol synthesis kinetics satisfactorily can prove to be very useful in kinetic studies of methanol leading to a better understanding of the process and improvements in yields and profits.

Kinetic aspects of methanol synthesis, primarily the relative contribution of $\mathrm{CO}$ and $\mathrm{CO}_{2}$ hydrogenation in producing methanol was also studied based on the results predicted by the best fit kinetic model developed in this work. The results suggest that no generalization can be made regarding the more dominant reaction pathway. Instead, the contribution from each hydrogenation pathway depends on reaction conditions like conversion, pressure, $\mathrm{CO} / \mathrm{CO}_{2}$, and hydrogen content in the feed. Methanol production can be maximized by optimizing these conditions. However, it is recommended to carefully interpret experimental data and extrapolate results from low pressure/low conversion laboratory conditions to high pressure/ high conversion industrial conditions when studying the relative importance of $\mathrm{CO}_{2}$ and $\mathrm{CO}$ hydrogenation reactions. Owing 
to the industrial importance of methanol, there will always be a scope to improve the productivity of the process. Therefore, further studies should be conducted in order to reveal more information regarding the kinetic aspects of methanol synthesis. 


\section{References}

1. C.J. Schack, M. A. McNeil and R.G. Rinker, "Methanol synthesis from hydrogen, carbon monoxide, and carbon dioxide over a CuO/ZnO/Al2O3 catalyst: I. Steady-state kinetics experiments," Appl. Catal., 50(1), 247-263 (1989).

2. H.W. Lim, M. Park, S. Kang, H. Chae, J.W. Bae and K. Jun,"Modeling of the kinetics for methanol synthesis using $\mathrm{Cu} / \mathrm{ZnO} / \mathrm{Al}_{2} \mathrm{O}_{3} / \mathrm{ZrO}_{2}$ catalyst: Influence of carbon dioxide during hydrogenation," Ind. Eng. Chem. Res., 48(23), 10448-10455 (2009).

3. J. Toyir, P. Piscina, J. Fierro and N. Homs, "Highly effective conversion of $\mathrm{CO}_{2}$ to methanol over supported and promoted copper-based catalysts: influence of support and promoter," Appl. Catal. B: Environmental, 29, 201-215 (2001).

4. Q. Sun, C. Liu, W. Pan, Q. Zhu and J. Deng, "In situ IR studies on the mechanism of methanol synthesis over an ultrafine $\mathrm{Cu} / \mathrm{ZnO} / \mathrm{Al}_{2} \mathrm{O}_{3}$ catalyst," Appl. Catal., 171(2), 301308 (1998).

5. T. Fujitani and J. Nakamura, "The chemical modification seen in the Cu/ZnO methanol synthesis catalysts," Appl. Catal. A: General, 191, 111-129 (2000).

6. X. Liu, G.Q. Lu, Z. Yan and J. Beltramini,"Recent advances in catalysts for methanol synthesis via hydrogenation of $\mathrm{CO}$ and $\mathrm{CO}_{2}$," Ind. Eng. Chem. Res., 42(25), 6518-6530 (2003).

7. R. Yang, X. Yu, Y. Zhang, W. Li and N. Tsubaki, "A new method of low-temperature methanol synthesis on $\mathrm{Cu} / \mathrm{ZnO} / \mathrm{Al}_{2} \mathrm{O}_{3}$ catalysts from $\mathrm{CO} / \mathrm{CO}_{2} / \mathrm{H}_{2}$," Fuel, 87, 443-450 (2008).

8. Methanol Institute (2009). Methanol production [Online]. Available at http://www.methanol.org/contentIndex.cfm?section=methanol\&topic=factSheets\&title= Methpr (accessed 1 February 2010).

9. PR Newswire Association (2010). CMIA completes 2010 world methanol cost study [Online]. Available at http://www.prnewswire.com/news-releases/cmai-completes-2010world-methanol-cost-study-83350592.html (accessed 3 February 2010).

10. M.R. Rahimpour and K. Alizadehhesari, "Enhancement of carbon dioxide removal in a hydrogen-permselective methanol synthesis reactor," Int J of Hydrogen Energ, 34, 1349-1362 (200 
11. MIT Technology Review (2006). Methanol: The new hydrogen [Online]. Available at http://www.technologyreview.com/energy/16629/page1/ (accessed 23 January 2010).

12. G. Centi and S. Perathoner, "Opportunities and prospects in the chemical recycling of carbon dioxide to fuels," Catal. Today, 148, 191-205 (2009).

13. K.M. V. Bussche and G.F. Froment, "A steady-state kinetic model for methanol synthesis and the water gas shift reaction on a commercial Cu/ZnO/Al ${ }_{2} \mathrm{O}_{3}$ catalyst," J. Catal., 161, 1-10 (1996).

14. K. Klier, V. Chatikavanij, R.G. Herman and G.W. Simmons, "Catalytic synthesis of methanol from CO/H $\mathrm{H}_{2}: 1 \mathrm{~V}$. Effects of carbon dioxide," J. Catal., 74, 343-360 (1982).

15. G. Liu, D. Willcox, M. Garland and H.H. Kung, "The role of $\mathrm{CO}_{2}$ in methanol synthesis on Cu-Zn Oxide: An isotope labeling study,” J. Catal., 96, 251-260 (1985).

16. G.C. Chinchen, P.J. Denny, D.G. Parker, M.S. Spencer and D.A. Whan, "Mechanism of methanol synthesis from $\mathrm{CO}_{2} / \mathrm{CO} / \mathrm{H}_{2}$ mixture over copper/zinc oxide/alumina catalysts: Use of ${ }^{14}$ C-labelled reactants," Appl. Catal., 30, 333-338 (1987).

17. M. Takagawa and M. Ohsugi, "Study on reaction rates for methanol synthesis from carbon monoxide, carbon dioxide and hydrogen," J. Catal., 107, 161-172 (1987).

18. M. A. McNeil, C.J. Schack and R.G. Rinker, "Methanol synthesis from hydrogen, carbon monoxide, and carbon dioxide over a $\mathrm{CuO} / \mathrm{ZnO} / \mathrm{Al}_{2} \mathrm{O}_{3}$ catalyst: II. Development of a phenomenological rate expression," Appl. Catal., 50(1), 265-285 (1989).

19. A.Y. Rozovskii and G.I. Lin, "Fundamentals of methanol synthesis and decomposition,” Top Catal., 22 (3-4), 137-150 (2003).

20. S. Fujita, M. Usui, H. Ito and N. Takezawa, "Mechanisms of methanol synthesis from carbon dioxide and from carbon monoxide at atmospheric pressure over $\mathrm{Cu} / \mathrm{ZnO}$," J. Catal., 157, 403-413 (1995).

21. M. Sahibzada, I.S. Metcalfe and D. Chadwick, "Methanol synthesis from $\mathrm{CO} / \mathrm{CO}_{2} / \mathrm{H}_{2}$ over $\mathrm{Cu} / \mathrm{ZnO} / \mathrm{Al}_{2} \mathrm{O}_{3}$ at differential and finite conversions," J. Catal., 174, 111-118 (1998).

22. V.E. Ostrovskii, "Mechanisms of methanol synthesis from hydrogen and carbon oxides at $\mathrm{Cu}$-Zn containing catalysts in the context of some fundamental problems of heterogeneous catalysis," Catal. Today, 77, 141-160 (2002).

23. T.S. Askgaard, J.K. Norskov, C.V. Ovesen and P. Stoltze, "A kinetic model of methanol synthesis," J. Catal., 156, 229-242 (1995). 
24. T. Kubota, I. Hayakawa, H. Mabuse, K. Mori, K. Ushikoshi, T. Watanabe and M. Saito, "Kinetic study of methanol synthesis from carbon dioxide and hydrogen," Appl. Organometal. Chem., 15, 121-126 (2001).

25. A.N. Xin, Z. Yizan, Z. Qiang and W. Jinfu, "Methanol synthesis from $\mathrm{CO}_{2}$ hydrogenation with a Cu/Zn/Al/Zr fibrous catalyst," Chinese J Chem Eng, 17(1), 88-94 (2009).

26. G.H Graaf, E.J. Stamhuis and A.A.C.M. Beenackers, "Kinetics of low pressure methanol synthesis,” Chem. Eng. Sci., 43(12), 3185-3195 (1988).

27. J.S. Lee, S.H. Han, H.G. Kim, K.H. Lee and Y.G. Kim, "Effects of space velocity on methanol synthesis from $\mathrm{CO}_{2} / \mathrm{CO} / \mathrm{H}_{2}$ over $\mathrm{Cu} / \mathrm{ZnO} / \mathrm{Al}_{2} \mathrm{O}_{3}$ catalyst," Korean J. Chem. Eng., 17 (3), 332-336 (2000).

28. V.D. Kuznetsov, F.S Shub and M.I. Temkin. "Kinetics of methanol synthesis and hydrolysis on a copper-containing catalyst," Kinet Catal +, 25(3), 510-517 (1984).

29. Polymath Software (Date not mentioned) Polymath Help Documentation [Online]. Available at http://www.polymath-softaware.com/PolymathHelp/ (accessed 12 April 2010).

30. H.W. Lim, H. Jun, M. Park, H. Kim, K. Ha, H. Chae, J.W. Bae and K. Jun, "Optimization of methanol synthesis reaction on $\mathrm{Cu} / \mathrm{ZnO} / \mathrm{Al}_{2} \mathrm{O}_{3} / \mathrm{ZrO}_{2}$ catalyst using genetic algorithm: Maximization of the synergetic effect by the optimal $\mathrm{CO}_{2}$ fraction," Korean J. Chem Eng., 27(6), 1760-1767 (2010).

31. G.H Graaf, H. Scholtens, E.J. Stamhuis and A.A.C.M. Beenackers, "Intra-particle diffusion limitations in low pressure methanol synthesis," Chem. Eng. Sci., 45(4), 773783 (1990).

32. J.Skryzpek, M. Lachowska and H. Moroz, "Kinetics of methanol synthesis over commercial copper/zinc oxide/alumina catalysts," Chem. Eng. Sci., 46(11), 2809-2813 (1991).

33. M. Setinc \& J. Levec, "Dynamics of a mixed slurry reactor for the three phase methanol synthesis,” Chem. Eng. Sci., 56, 6081-6087 (2001).

34. L.C. Grabow and M. Mavrikakis, "Mechanism of methanol synthesis on Cu through $\mathrm{CO}_{2}$ and $\mathrm{CO}$ hydrogenation," ACS Catal., 1, 365-384 (2011). 
35. E.M. Calverley, "A study of the mechanism and kinetics of the synthesis of methanol and higher alcohols over alkali promoted copper/zinc-oxide/chromia catalysts," Open Access Dissertations and Theses, Paper 1913 (1989).

36. G.H. Graaf and A.A.C.M Beenackers, "Comparison of two-phase and three-phase methanol synthesis processes," Chem Eng Process, 35, 413427 (1996).

37. PR Newswire Association (2011). CMIA Completes 2010 World Methanol Analysis [Online]. Available at http://www.prnewswire.com/news-releases/cmai-completes-2011world-methanol-analysis-105860938.html (accessed 3 November 2011).

38. Wikimedia Foundation Inc. (2011). Le Chatelier's principle [Online]. Available at en.wikipedia.org/wiki/Le_Chatelier's_principle (accessed 4 December 2011).

39. Wikimedia Foundation Inc. (2011). Boudouard reaction [Online]. Available at en.wikipedia.org/wiki/Boudouard_reaction (accessed 20 December 2011). 


\section{Appendix A}

\section{ADDITIONAL DATA}

The experimental results reported by Calverley are listed in Table A.1. The reported results included pressure, feed flow rate, catalyst weight, inlet mole fraction for $\mathrm{CO}, \mathrm{H}_{2}$, methanol and $\mathrm{CO}_{2}$ and the outlet mole fraction of methanol for a total of 51 runs.

Table A.1. Experimental results published by Calverley (Reprinted with permission from [35]).

\begin{tabular}{|c|c|c|c|c|c|c|c|c|}
\hline \multirow[t]{2}{*}{ Run \# } & \multirow{2}{*}{$\begin{array}{l}\text { Feed } \\
\text { flow } \\
\text { rate } \\
(\mathrm{mol} / \mathrm{h})\end{array}$} & \multirow[t]{2}{*}{ Pressure } & \multirow{2}{*}{$\begin{array}{l}\text { Catalyst } \\
\text { mass }\end{array}$} & \multicolumn{4}{|c|}{ Mole fraction in feed } & \multirow{2}{*}{$\begin{array}{l}\text { exit } \\
\text { mole } \\
\text { fraction } \\
\mathrm{CH}_{3} \mathrm{OH}\end{array}$} \\
\hline & & & & $\mathrm{CO}$ & $\mathrm{H}_{2}$ & $\mathrm{CH}_{3} \mathrm{OH}$ & $\mathrm{CO}_{2}$ & \\
\hline 1 & 1.834 & 99.7 & 1.56 & 0.482 & 0.312 & 0.019 & 0.089 & 0.0725 \\
\hline 2 & 1.799 & 99.7 & 1.56 & 0.491 & 0.318 & 0 & 0.091 & 0.0656 \\
\hline 3 & 1.799 & 99.7 & 1.56 & 0.491 & 0.318 & 0 & 0.091 & 0.0618 \\
\hline 4 & 1.828 & 99.7 & 1.56 & 0.587 & 0.311 & 0.019 & 0 & 0.0492 \\
\hline 5 & 1.793 & 99.7 & 1.56 & 0.598 & 0.317 & 0 & 0 & 0.0414 \\
\hline 6 & 2.709 & 99 & 1.56 & 0.581 & 0.309 & 0 & 0 & 0.03 \\
\hline 7 & 2.709 & 99 & 1.56 & 0.581 & 0.309 & 0 & 0 & 0.0285 \\
\hline 8 & 2.786 & 99 & 1.56 & 0.566 & 0.301 & 0.027 & 0 & 0.0455 \\
\hline 9 & 2.786 & 99 & 1.56 & 0.566 & 0.301 & 0.027 & 0 & 0.0433 \\
\hline 10 & 2.874 & 99.7 & 1.56 & 0.548 & 0.293 & 0.053 & 0 & 0.0664 \\
\hline 11 & 2.874 & 99.7 & 1.56 & 0.548 & 0.293 & 0.053 & 0 & 0.0654 \\
\hline 12 & 1.774 & 99.7 & 1.56 & 0.58 & 0.317 & 0 & 0 & 0.0402 \\
\hline
\end{tabular}




\begin{tabular}{|c|c|c|c|c|c|c|c|c|}
\hline \multirow[t]{2}{*}{ Run \# } & \multirow{2}{*}{$\begin{array}{l}\text { Feed } \\
\text { flow } \\
\text { rate } \\
(\mathrm{mol} / \mathrm{h})\end{array}$} & \multirow[t]{2}{*}{ Pressure } & \multirow{2}{*}{$\begin{array}{l}\text { Catalyst } \\
\text { mass }\end{array}$} & \multicolumn{4}{|c|}{ Mole fraction in feed } & \multirow{2}{*}{$\begin{array}{l}\text { exit } \\
\text { mole } \\
\text { fraction } \\
\mathrm{CH}_{3} \mathrm{OH}\end{array}$} \\
\hline & & & & $\mathrm{CO}$ & $\mathrm{H}_{2}$ & $\mathrm{CH}_{3} \mathrm{OH}$ & $\mathrm{CO}_{2}$ & \\
\hline 13 & 1.8 & 99.7 & 1.56 & 0.54 & 0.323 & 0 & 0 & 0.0607 \\
\hline 14 & 1.833 & 99.7 & 1.56 & 0.53 & 0.317 & 0.018 & 0 & 0.0673 \\
\hline 15 & 1.81 & 97.6 & 1.57 & 0.57 & 0.322 & 0 & 0.043 & 0.0415 \\
\hline 16 & 1.807 & 97.6 & 1.57 & 0.419 & 0.501 & 0 & 0.042 & 0.0586 \\
\hline 17 & 1.805 & 97.6 & 1.57 & 0.611 & 0.273 & 0 & 0 & 0.0332 \\
\hline 18 & 2.709 & 99 & 1.57 & 0.581 & 0.309 & 0 & 0 & 0.0306 \\
\hline 19 & 2.714 & 98.3 & 1.57 & 0.583 & 0.307 & 0.006 & 0 & 0.0329 \\
\hline 20 & 2.786 & 99 & 1.57 & 0.566 & 0.301 & 0.027 & 0 & 0.0463 \\
\hline 21 & 1.81 & 98.3 & 1.57 & 0.657 & 0.226 & 0 & 0 & 0.0252 \\
\hline 222 & 1.793 & 84.7 & 1.57 & 0.556 & 0.32 & 0 & 0 & 0.0308 \\
\hline 23 & 1.839 & 84.7 & 1.57 & 0.407 & 0.504 & 0 & 0 & 0.0426 \\
\hline 24 & 1.839 & 84 & 1.57 & 0.634 & 0.227 & 0 & 0 & 0.0192 \\
\hline 25 & 2.412 & 70.4 & 1.57 & 0.656 & 0.235 & 0 & 0 & 0.0144 \\
\hline 26 & 2.431 & 70.4 & 1.57 & 0.651 & 0.233 & 0.008 & 0 & 0.0183 \\
\hline 27 & 1.851 & 98.3 & 1.56 & 0.554 & 0.327 & 0 & 0 & 0.0391 \\
\hline 28 & 1.851 & 84.7 & 1.56 & 0.554 & 0.327 & 0 & 0 & 0.0296 \\
\hline 29 & 0.959 & 50 & 1.56 & 0.372 & 0.548 & 0 & 0 & 0.0298 \\
\hline 30 & 0.959 & 50 & 1.56 & 0.372 & 0.548 & 0 & 0 & 0.0308 \\
\hline
\end{tabular}




\begin{tabular}{|c|c|c|c|c|c|c|c|c|}
\hline \multirow[t]{2}{*}{ Run \# } & \multirow{2}{*}{$\begin{array}{l}\text { Feed } \\
\text { flow } \\
\text { rate } \\
(\mathrm{mol} / \mathrm{h})\end{array}$} & \multirow[t]{2}{*}{ Pressure } & \multirow{2}{*}{$\begin{array}{l}\text { Catalyst } \\
\text { mass }\end{array}$} & \multicolumn{4}{|c|}{ Mole fraction in feed } & \multirow{2}{*}{$\begin{array}{l}\text { exit } \\
\text { mole } \\
\text { fraction } \\
\mathrm{CH}_{3} \mathrm{OH}\end{array}$} \\
\hline & & & & $\mathrm{CO}$ & $\mathrm{H}_{2}$ & $\mathrm{CH}_{3} \mathrm{OH}$ & $\mathrm{CO}_{2}$ & \\
\hline 31 & 0.965 & 50 & 1.56 & 0.243 & 0.558 & 0 & 0.147 & 0.0383 \\
\hline 32 & 0.965 & 76 & 1.56 & 0.243 & 0.558 & 0 & 0.147 & 0.0787 \\
\hline 33 & 0.965 & 50 & 1.56 & 0.243 & 0.558 & 0 & 0.147 & 0.0351 \\
\hline 34 & 0.981 & 50 & 1.56 & 0.188 & 0.553 & 0 & 0.218 & 0.0254 \\
\hline 35 & 1.03 & 50 & 1.56 & 0.283 & 0.326 & 0 & 0.33 & 0.0127 \\
\hline 36 & 0.964 & 50 & 1.56 & 0.272 & 0.571 & 0 & 0.125 & 0.0393 \\
\hline 37 & 0.934 & 50 & 1.56 & 0.297 & 0.57 & 0 & 0.088 & 0.0446 \\
\hline 38 & 0.932 & 50 & 1.56 & 0.297 & 0.57 & 0 & 0.088 & 0.0432 \\
\hline 39 & 0.937 & 50 & 1.56 & 0.33 & 0.571 & 0 & 0.065 & 0.0505 \\
\hline 40 & 0.961 & 50 & 1.56 & 0.346 & 0.557 & 0 & 0.049 & 0.0496 \\
\hline 41 & 0.959 & 50 & 1.56 & 0.362 & 0.568 & 0 & 0.02 & 0.0532 \\
\hline 42 & 0.949 & 50 & 1.56 & 0.387 & 0.567 & 0 & 0.005 & 0.0457 \\
\hline 43 & 1.8 & 99.7 & 1.56 & 0.533 & 0.331 & 0 & 0.043 & 0.0619 \\
\hline 44 & 3.306 & 50 & 1.56 & 0.35 & 0.561 & 0 & 0.028 & 0.0211 \\
\hline 45 & 3.306 & 50 & 1.56 & 0.165 & 0.583 & 0 & 0.223 & 0.0102 \\
\hline 46 & 3.306 & 50 & 1.56 & 0.217 & 0.576 & 0 & 0.16 & 0.0126 \\
\hline 47 & 3.306 & 50 & 1.56 & 0.252 & 0.578 & 0 & 0.119 & 0.0138 \\
\hline 48 & 3.345 & 50 & 1.56 & 0.342 & 0.569 & 0 & 0.062 & 0.0182 \\
\hline
\end{tabular}




\begin{tabular}{|c|c|c|c|c|c|c|c|c|}
\hline \multirow[t]{2}{*}{ Run \# } & \multirow{2}{*}{$\begin{array}{l}\text { Feed } \\
\text { flow } \\
\text { rate } \\
(\mathrm{mol} / \mathrm{h})\end{array}$} & \multirow[t]{2}{*}{ Pressure } & \multirow{2}{*}{$\begin{array}{l}\text { Catalyst } \\
\text { mass }\end{array}$} & \multicolumn{4}{|c|}{ Mole fraction in feed } & \multirow{2}{*}{$\begin{array}{l}\text { exit } \\
\text { mole } \\
\text { fraction } \\
\mathrm{CH}_{3} \mathrm{OH}\end{array}$} \\
\hline & & & & $\mathrm{CO}$ & $\mathrm{H}_{2}$ & $\mathrm{CH}_{3} \mathrm{OH}$ & $\mathrm{CO}_{2}$ & \\
\hline 49 & 3.421 & 50 & 1.56 & 0.372 & 0.559 & 0 & 0.031 & 0.0191 \\
\hline 50 & 3.342 & 50 & 1.56 & 0.367 & 0.569 & 0 & 0.014 & 0.0186 \\
\hline 51 & 3.381 & 50 & 1.56 & 0.382 & 0.559 & 0 & 0 & 0.0089 \\
\hline
\end{tabular}

The information given in Table A.1 was used to predict the exit gas composition and the partial pressure of each species using material balance calculations.

The reactor was operated in integral mode during the experiments. Therefore, the following procedure was used to calculate the rates:

- At a given temperature and pressure, conversion for each run was calculated using the inlet and outlet composition of reactant, $\mathrm{CO}$. Conversion is calculated using the following expression:

$$
X_{A}=1-\frac{F_{A}}{F_{A_{0}}}
$$

where,

$\mathrm{X}_{\mathrm{A}}=$ conversion

$\mathrm{F}_{\mathrm{A} 0}=$ inlet molar flow rate of reactant

$\mathrm{F}_{\mathrm{A}}=$ outlet molar flow rate of reactant

- The ratio of catalyst weight to inlet molar flow rate of $\mathrm{CO}$ was also computed

- For a PFR, the rate equation can be written as, 


$$
-r_{A}=\frac{F_{A_{0}} d X_{A}}{d W}
$$

Equation A.1

or

$$
-r_{A}=\frac{d X_{A}}{d\left(\frac{W}{F_{A_{0}}}\right)}
$$

where,

$-\mathrm{r}_{\mathrm{A}}=$ rate of reaction

$\mathrm{F}_{\mathrm{A} 0}=$ inlet molar flow rate of reactant

$\mathrm{W}=$ catalyst weight

$\mathrm{X}_{\mathrm{A}}=$ conversion

- $\mathrm{X}_{\mathrm{A}}$ was plotted as a function of $\mathrm{W} / \mathrm{F}_{\mathrm{A} 0}$ and a curve was fit through the points, with the curve passing through the origin.

- The rates were then calculated by finding the slope of the curve at each data point. The polynomial function obtained was differentiated to give reaction rates at the corresponding value of conversion. The plot of $\mathrm{X}_{\mathrm{A}}$ vs. W/ $\mathrm{F}_{\mathrm{A} 0}$ is shown in Figure A.1. As shown in the graph, the curve fits to the data points satisfactorily with an $\mathrm{R}^{2}$ value of 0.81 . 


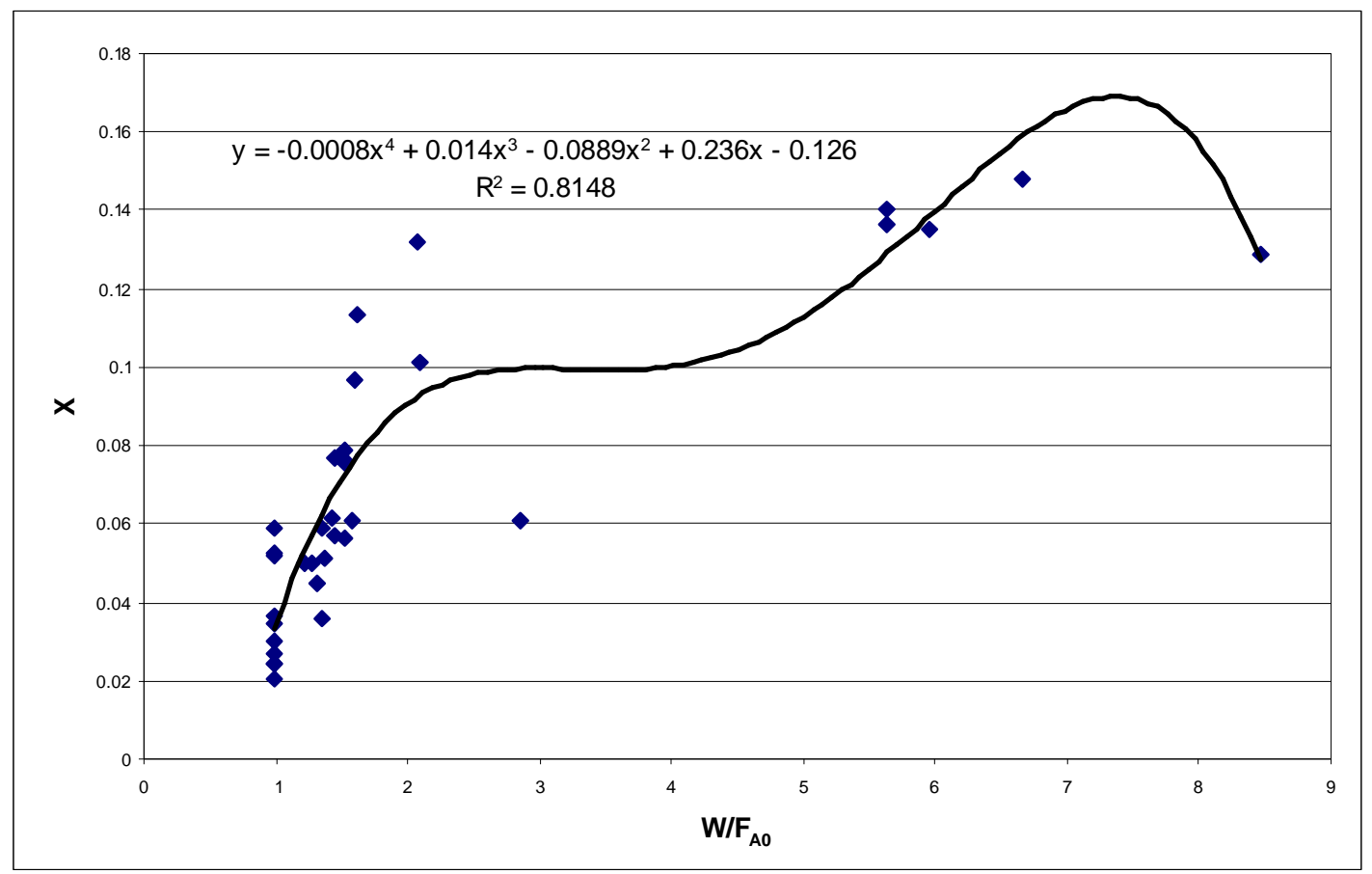

Figure A.1 Conversion plotted as a function of $\mathrm{W} / \mathrm{F}_{\mathrm{A} 0}$.

- A fourth order polynomial describes the curve and can be written as

$$
\mathrm{X}=-0.0008 \mathrm{TF}^{4}+0.014 \mathrm{TF}^{3}-0.0889 \mathrm{TF}^{2}+0.236 \mathrm{TF}-0.126 \quad \text { Equation A.3 }
$$

$\mathrm{TF}$ is the turnover frequency, used interchangeably for $\mathrm{W} / \mathrm{F}_{\mathrm{A} 0}$.

- Differentiating this polynomial, we get

$\frac{d X}{d T F}=0.236-(2 * 0.0889) * \mathrm{TF}+(3 * 0.014) * \mathrm{TF}^{2}-(4 * 0.0008) * \mathrm{TF}^{3}$ Equation A.4

Rates are obtained by finding the above mentioned differential at each value of conversion. The calculated values of rates are shown in Table 2 in Section 4.2. 


\section{Appendix B}

\section{ADDITIONAL RESULTS}

Experimental data including a range of low and high inlet $\mathrm{CO}_{2}$ partial pressures was used in the regression procedure. The model proposed by Graaf was fit to the low $\mathrm{CO}_{2}$ inlet partial pressure data and that proposed by Rozovskii was fit to the data with high $\mathrm{CO}_{2}$ content in the feed. As already explained in Section 4.4, residual plots show the deviation between the experimental values and the corresponding values calculated from the models. For a good fit, the residuals should be randomly distributed and not follow a clear trend around the line of err $=0$. The residual plots generated as a result of fitting Graaf's and Rozovskii's models to the kinetic data are shown in Figures B.1 and

\section{B.2.}

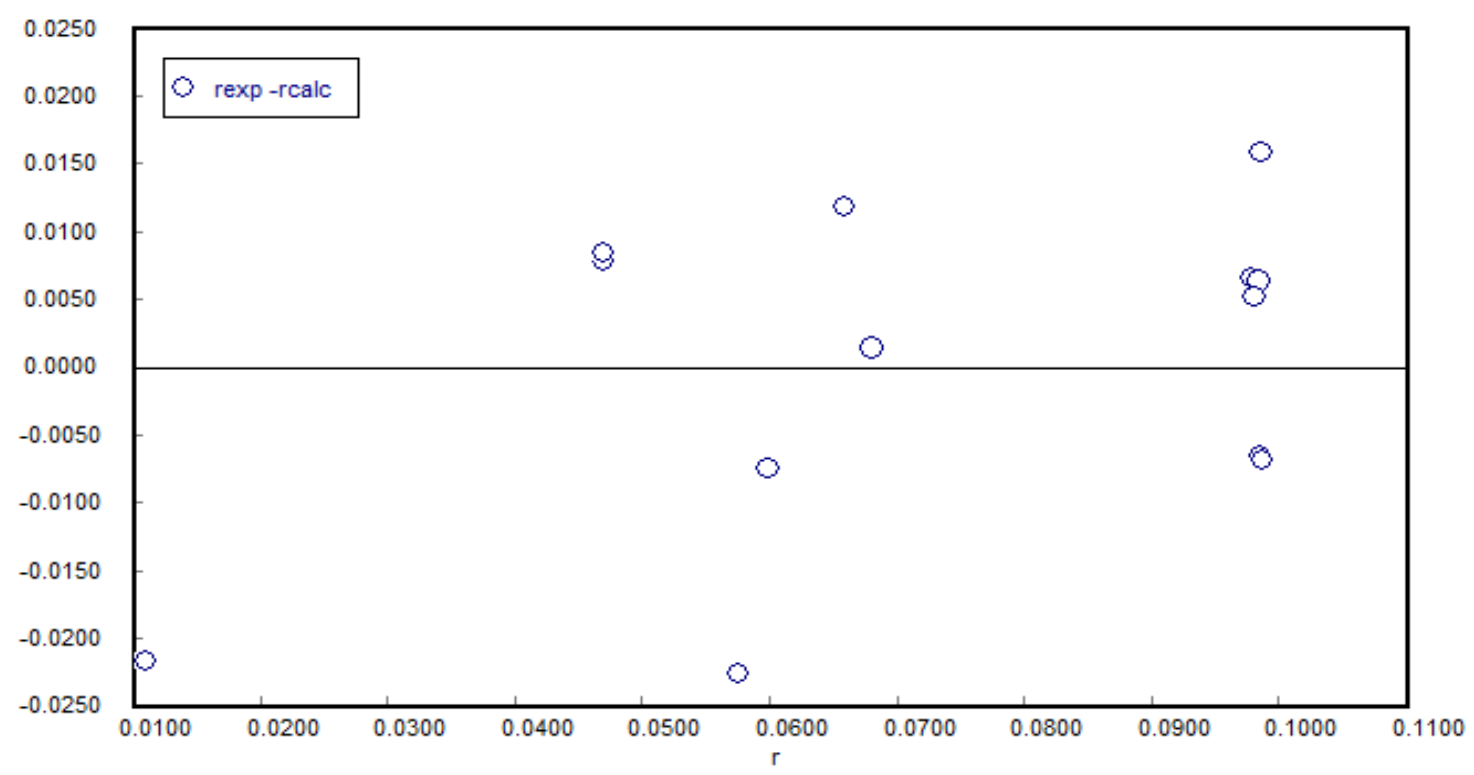

Figure B.1. Residual plot generated by fitting Graaf's model to low $\mathrm{CO}_{2}$ inlet partial pressure data. 


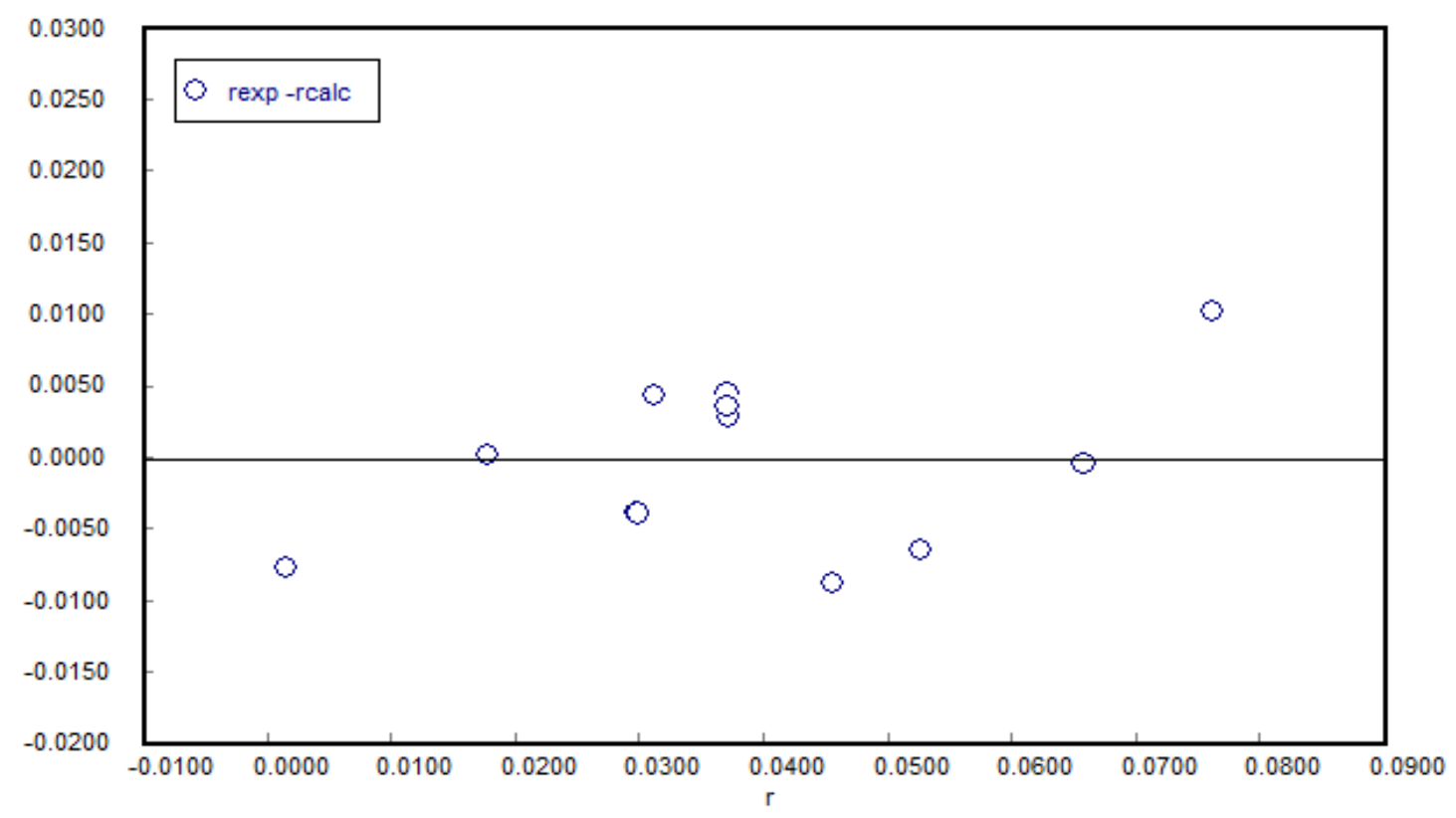

Figure B.2. Residual plot generated by fitting Graaf's model to low $\mathrm{CO}_{2}$ inlet partial pressure data.

As shown in the Figures B.1 and B.2, the residuals were distributed in a random manner around the line of err $=0$ and did not follow a clear trend indicating the goodness of fit of the two models. The polymath reports for the same regression models are shown in Tables B.1 and B.2 displaying the statistical features of the regression. 
Table B.1. Polymath report generated by fitting Graaf's model to low $\mathrm{CO}_{2}$ inlet partial pressure data.

POLYMATH Report

Nonlinear Regression (L-M)

Model: $\mathrm{r}=\left(\mathrm{k}^{*} \mathrm{Kco} *\left(\mathrm{pco} * \mathrm{ph} 2^{\wedge} 1.5-\right.\right.$

$\left.\left.\mathrm{pm} /\left(\mathrm{ph} 2^{\wedge} 0.5^{*} 0.000388\right)\right)\right) /\left((1+\mathrm{Kco} * \mathrm{pco}+\mathrm{KcO} 2 * \mathrm{pco} 2) *\left(\mathrm{ph} 2^{\wedge} 0.5+(\mathrm{Kwh}) * \mathrm{ph} 2 \mathrm{o}\right)\right)$

\begin{tabular}{|l|l|l|l|}
\hline Variable & Initial guess & Value & 95\% confidence \\
\hline$k$ & 0.1 & 0.0535024 & $6.141 \mathrm{E}-05$ \\
\hline Kco & 0.01 & 0.0022467 & $2.907 \mathrm{E}-06$ \\
\hline Kco2 & 0.001 & 0.0184968 & 0.0066304 \\
\hline Kwh & 10. & 1011. & 4.803157 \\
\hline
\end{tabular}

Nonlinear regression settings

Max \# iterations $=64$

Precision

\begin{tabular}{|l|l|}
\hline$R^{\wedge} 2$ & 0.8149573 \\
\hline$R^{\wedge}$ 2adj & 0.7532763 \\
\hline Rmsd & 0.0032336 \\
\hline Variance & 0.0001963 \\
\hline
\end{tabular}

General

\begin{tabular}{|l|l|}
\hline Sample size & 13 \\
\hline Model vars & 4 \\
\hline Indep vars & 5 \\
\hline Iterations & 29 \\
\hline
\end{tabular}


Table B.2. Polymath report generated by fitting Rozovskii's model to high $\mathrm{CO}_{2}$ inlet partial pressure data.

POLYMATH Report

Nonlinear Regression (L-M)

Model: $r=\left(k^{*} \mathrm{Kco} *\left(\mathrm{pco}{ }^{*} \mathrm{ph} 2^{\wedge} 1.5-\right.\right.$

$\left.\left.\mathrm{pm} /\left(\mathrm{ph} 2^{\wedge} 0.5^{*} 0.000388\right)\right)\right) /\left(\left(1+\mathrm{Kco} * \mathrm{pco}+\mathrm{Kco} 2^{*} \mathrm{pco} 2\right) *\left(\mathrm{ph} 2^{\wedge} 0.5+(\mathrm{Kwh}) * \mathrm{ph} 2 \mathrm{o}\right)\right)$

\begin{tabular}{|l|l|l|l|}
\hline Variable & Initial guess & Value & 95\% confidence \\
\hline k & 0.1 & 0.0535024 & $6.141 \mathrm{E}-05$ \\
\hline Kco & 0.01 & 0.0022467 & $2.907 \mathrm{E}-06$ \\
\hline Kco 2 & 0.001 & 0.0184968 & 0.0066304 \\
\hline Kwh & 10. & 1011. & 4.803157 \\
\hline
\end{tabular}

Nonlinear regression settings

Max \# iterations $=64$

Precision

\begin{tabular}{|l|l|}
\hline$R^{\wedge} 2$ & 0.8149573 \\
\hline$R^{\wedge}$ 2adj & 0.7532763 \\
\hline Rmsd & 0.0032336 \\
\hline Variance & 0.0001963 \\
\hline
\end{tabular}

General

Sample size 13

\begin{tabular}{l|l} 
Model vars & 4
\end{tabular}

\begin{tabular}{|l|l|}
\hline Indep vars & 5
\end{tabular}

\begin{tabular}{l|l} 
Iterations & 29
\end{tabular} 
The residual plot generated as a result of fitting the combined model to the entire range of data is shown in Figure B.3. The polymath report of the same regression is shown in Table B.3.

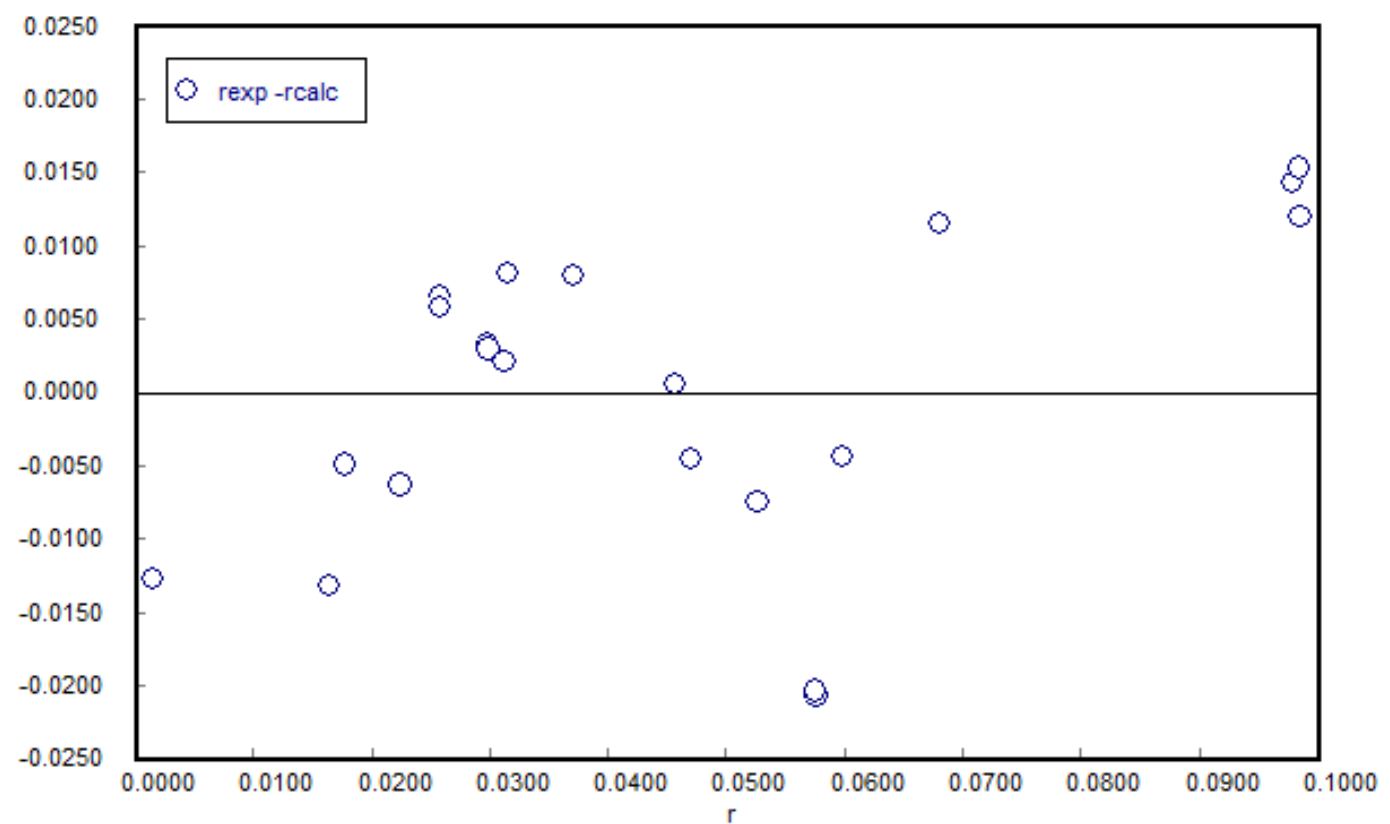

Figure B.3. Residual plot generated by fitting combined model to entire range of kinetic data.

The residuals as shown in Figure B.3 are randomly distributed and no clear trend was observed suggesting the combined model represents the kinetic data appropriately. 
Table B.3. Polymath report generated by fitting combined model to entire range of kinetic data.

Model: $r=\left(k^{*} p h 2 *(1-\right.$

$\left.\left.\left(\mathrm{pm} * \mathrm{ph} 2 \mathrm{o} /\left(0.000077 * \mathrm{ph} 2 \wedge{ }^{*} \mathrm{pco} 2\right)\right)\right)\right) /\left(1+\mathrm{Kh} 2 \mathrm{o}^{*} \mathrm{ph} 2 \mathrm{o}+\left(\mathrm{Kh} 2 \mathrm{o}^{*} \mathrm{ph} 2 \mathrm{o} / \mathrm{Kco} 2 * \mathrm{pco} 2\right)\right)+(\mathrm{k} 1 * \mathrm{Kco} *(\mathrm{pco}$ $\left.\left.{ }^{*} \mathrm{ph} 2^{\wedge} 1.5-\mathrm{pm} /\left(\mathrm{ph} 2^{\wedge} 0.5^{*} 0.000388\right)\right)\right) /\left(\left(1+\mathrm{Kco}{ }^{*} \mathrm{pco}+\mathrm{KCO} 2^{*} \mathrm{pco} 2\right)^{*}\left(\mathrm{ph} 2^{\wedge} 0.5+(\mathrm{Kwh}) * \mathrm{ph} 20\right)\right)$

\begin{tabular}{|l|l|l|l|}
\hline Variable & Initial guess & Value & 95\% confidence \\
\hline k & 0.001 & 0.0009681 & $2.729 \mathrm{E}-06$ \\
\hline Kh2o & 0.01 & 0.0032128 & $6.479 \mathrm{E}-05$ \\
\hline KcO2 & 0.01 & 0.0226146 & 0.0004574 \\
\hline k1 & 0.01 & 0.0231806 & $4.222 \mathrm{E}-05$ \\
\hline Kco & 0.001 & 0.0024066 & $4.973 \mathrm{E}-06$ \\
\hline KCO2 & 0.01 & 0.0624938 & 0.0015774 \\
\hline Kwh & 0.1 & 11.09971 & 0.4651571 \\
\hline
\end{tabular}

Nonlinear regression settings

Max \# iterations $=64$

Precision

\begin{tabular}{|l|l|}
\hline$R^{\wedge} 2$ & 0.8501624 \\
\hline$R^{\wedge}$ 2adj & 0.7859462 \\
\hline Rmsd & 0.0022748 \\
\hline Variance & 0.000163 \\
\hline
\end{tabular}

General

\begin{tabular}{|l|l|}
\hline Sample size & 21 \\
\hline Model vars & 7 \\
\hline Indep vars & 5 \\
\hline Iterations & 17 \\
\hline
\end{tabular}

The statistical information displayed in Table B.3 also indicated that the combined model was a statistically sound model. 